\title{
Approaching Complexity: Hyperthermia Dose and Its Possible Measurement in Oncology
}

\author{
Oliver Szasz, Andras Szasz \\ Biotechnics Department, St. Istvan University, Budaörs, Hungary \\ Email: biotech@gek.szie.hu
}

How to cite this paper: Szasz, O. and Szasz, A. (2021) Approaching Complexity: Hyperthermia Dose and Its Possible Measurement in Oncology. Open Journal of Biophysics, 11, 68-132. https://doi.org/10.4236/ojbiphy.2021.111002

Received: November 13, 2020

Accepted: January 24, 2021

Published: January 27, 2021

Copyright $\odot 2021$ by author(s) and Scientific Research Publishing Inc. This work is licensed under the Creative Commons Attribution International License (CC BY 4.0).

http://creativecommons.org/licenses/by/4.0/

(c) (i) Open Access

\begin{abstract}
A heuristic stochastic solution of the Pennes equation is developed in this paper by applying the self-organizing, self-similar behaviour of living structures. The stochastic solution has a probability distribution that fits well with the dynamic changes in the living objects concerned and eliminates the problem of the deterministic behaviour of the Pennes approach. The solution employs the Weibull two-parametric distribution which offers satisfactory delivery of the rate of temperature change by time. Applying the method to malignant tumours obtains certain benefits, increasing the efficacy of the distortion of the cancerous cells and avoiding doing harm to the healthy cells. Due to the robust heterogeneity of these living systems, we used thermal and bioelectromagnetic effects to distinguish the malignant defects, selecting them from the healthy cells. On a selective basis, we propose an optimal protocol using the provided energy optimally such that molecular changes destroy the malignant cells without a noticeable effect on their healthy counterparts.
\end{abstract}

\section{Keywords}

Self-Organizing, Self-Similarity, Avrami-Function, Weibull-Distribution, Temperature, Specific Absorption Rate (SAR)

\section{Introduction}

Hyperthermia has had a long and bumpy history from the dawn of human medicine. The overall body temperature has long served as the basic reference by which to measure the systemic hyperthermic effect of various conditions, including natural and artificial impacts. Localized heating, however, was not so easy to understand. The body's thermal homeostatic control regulates the blood-perfusion to prevent a sustained increase allowing for a rapid reduction in temperature, provided no further energy was provided from a local ener- 
gy-source. The blood which has a cooling action on the local tissue, also has a heating effect on the whole system as the heat is transferred through the circulation to the rest of the body tissues

However, the process of heat distribution in the body is not a simple thermodynamic process. Living organisms are highly heterogenic and have complex interconnections and feedback regulations within. The non-linearly increasing blood-flow $(B F)$ [1] for the regulation of rising temperature does not only act as a thermodynamical heat-exchanger. The blood delivers life-supporting molecules, such as oxygen and nutrients, as well as various regulating species such as circulation cells (like immune cells), proteins (like cytokines, chemokines, erythrocytes, etc.) and molecules (like carbon dioxide, various ions, etc.), for the chemical actions required for the processes of living. The thus intensified oxygen delivery supports the radiosensitivity of tissues. This effect is well established in radiotherapeutics. Moreover, the vasodilation and better perfusion through the vessel walls and the cell-membranes as a result of increased heat, together with the increased reaction rate of the chemicals, supports the action of chemotherapies. On the other hand, in massive tumours, the neo-angiogenic arteries do not vasodilate, as they lack musculature in their vessel walls [2].

The malignant tissues are different in their structure, cellular network, metabolic processes, and energy- and alkaline balances from their healthy counterparts. These particular biophysical differences determine the reaction to heating [3]. The bloodstream counteracts the overheating, regulating the flow capacity of the vessels as a result of physiological feedback cycles. The elevation of the temperature can cause vasoconstriction in certain tumours, reversing the development of blood perfusion and modifying the heat conduction [4]. The same increase in temperature in the neighbouring healthy tissue causes vasodilatation, with a corresponding rapid growth in its relative blood perfusion and heat conduction [5]. The change of blood-perfusion can result in a heat trap [6], helping us to selectively increase the temperature in the area of already-limited perfusion [7] caused by the higher internal pressure of the tumour [8]. The blood-flow $(B F)$ of tumour tissue behaves in a different way with respect to temperature than its healthy counterpart [9]. Due to the missing musculature of the neo-angiogenic arteries, tumours are not able to react in the same way as the normal vessels in an adult body, and so the $B F$ can decrease as a result of heating [10]. The relative $B F$ can even drop below that of healthy vessels [11] and the dynamism of the various tissues changes [12]. The increasing temperature can change local immune-reactions and the immune-status of the heated volume. A temperature of over $40^{\circ} \mathrm{C}$ downregulates the natural killer cell cytotoxicity [13], and other immune actions can be weakened too [14].

A mandatory parameter of all medical interventions is dosage, by which the desired effects and active changes are measured and controlled. Hyperthermia, by definition, involves a temperature increase, so the use of the temperature as a dosing parameter appears to be evident. However, for the regulative control of 
dose, we expect a volume/mass dependence of the applied unit, such that a half-dose could be applied for half the mass, with the size of the target determining the applied dose. The challenge is that the temperature does not satisfy this elementary supposition; it does not depend on the size of the target. If we apply temperature as a dose and have a certain temperature in a volume, then half of that volume will have the same temperature and, indeed, any portion of the volume will also have the same value of temperature because the temperature is the measure of an energy average. The challenge of dosage is a barrier to the acceptance of hyperthermia in oncology [15]. The solution could lie in defining a reference point [16] chosen for necrotic tissue damage. It is observed that a temperature of $43^{\circ} \mathrm{C}$ causes satisfactory necrosis in vitro in cell-culture of Chinese Hamster ovary tumour-cells [17].

The living object is a complex, mostly chemical piece of "machinery", where the temperature is one of the overall regulating factors. We can use the temperature dependence of the general chemical reaction rate (Arrhenius law [18]), which is also applicable in biology [19], where the Boltzmann distribution exists [20]. The dose was chosen according to this concept [21], and was later defined as "cumulative equivalent minutes at $43^{\circ} \mathrm{C}$ " $\left(C E M 43^{\circ} \mathrm{C}\right)$. The location of a phase transition within the cells is expected to be in the lipid membranes [22] [23] [24]. This cellular phase transition supports the choice of $43^{\circ} \mathrm{C}$, as the base temperature is at approximately $42.5^{\circ} \mathrm{C}$ [25]. The break characterizing this phase transition is observed clinically, too [26] [27].

While the challenge associated with the dose was overcome by fixing the dose of hyperthermia, another barrier in the acceptance of hyperthermia was highlighted. The $B F$ causes an unstable situation in the locally heated tumour due to its active cooling as it travels from the unheated body through the tumour. Additional to their extreme heterogeneity, most tumours create inhomogeneities in temperature in the tumour which is increased by the competitive thermal actions between the external heating and the blood-cooling in the capillary levels too. Isothermal equality, which is mandatory for the dosing, is therefore not guaranteed. The solution was to add an additional measure to the $C E M 43^{\circ} \mathrm{C}$ unit in which the character of the inhomogeneity is conveyed by a special notation, $T X$, denoting the percentage $x$ in the target volume having temperature $T$ : $C E M 43^{\circ} \mathrm{C} T X$. Presently this is the widely applied "official" dosage unit of hyperthermia applications in oncology. A new, temperature related dose is emerging, the TRISE, which correlates with the complete remission of the patients [28].

\section{Method}

The temperature development (measured in ${ }^{\circ} \mathrm{C}$ ) is interconnected with the specific absorption rate $(S A R)$ :

$$
S A R=\frac{\text { absorbed power }}{\text { mass which absorbsit }}\left[\frac{\mathrm{Watt}}{\mathrm{kg}}=\frac{\mathrm{W}}{\mathrm{kg}}\right]
$$

(The expressions in the [ ] brackets denote the SI units of the value). The energy 
absorption creates the increase in temperature, and the $S A R$ characterizes the dynamism of the absorbed energy

$$
\text { Power }=\frac{\text { absorbed energy }}{\text { time period of absorption }}\left[\frac{\text { Joule }}{\text { second }}=\frac{\mathrm{J}}{\mathrm{S}}=\mathrm{W}\right]
$$

The temperature change $(\Delta T)$ depends on the absorbed energy in the heated mass. The absorbed energy is determined by the absorbed power, the $S A R$ multiplied by the duration of its action providing the energy absorption in the target, so the absorbed energy is the sum of the products of the $S A R$ and its actual duration:

$$
\frac{\text { energy }}{\text { mass }}=E(t)=\sum_{0}^{t} S A R \cdot \tau=S A R \cdot t\left[\frac{\mathrm{J}}{\mathrm{kg}}\right]
$$

where $t$ is the duration of constant $S A R$ value. The $S A R=\operatorname{SAR}(\tau)$ usually depends on the time; consequently the energy is the integral of the $\operatorname{SAR}(\tau)$ by $\tau$ time until $t$ application time:

$$
E(t)=\int_{0}^{t} \operatorname{SAR}(\tau) \mathrm{d} \tau\left[\frac{\mathrm{J}}{\mathrm{kg}}\right]
$$

The energy absorption naturally depends on the specifics of the character of the matter ( $c$, specific heat), showing how much energy is necessary to heat up 1 $\mathrm{kg}$ of given material by $1^{\circ} \mathrm{C}$ :

$$
c=\frac{\text { energy }}{\text { mass } \cdot{ }^{\circ} \mathrm{C}},\left[\frac{\mathrm{J}}{\mathrm{kg} \cdot{ }^{\circ} \mathrm{C}}\right]
$$

Hence the temperature rise of the tissue with specific heat $c$ during the time period $\Delta t$ is:

$$
c \Delta T \sim \frac{\text { power }}{\text { mass }} \Delta t,\left[\frac{\mathrm{W} \cdot \mathrm{s}}{\mathrm{kg}}=\frac{\mathrm{J}}{\mathrm{kg}}\right]
$$

and consequently

$$
c \frac{\Delta T}{\Delta t}=\frac{\text { power }}{\text { mass }}=S A R\left[\frac{\mathrm{W}}{\mathrm{kg}}\right]
$$

However, the heating situation is more complicated because the local heat is conducted away by the $B F$, which acts as a heat-sink of the absorbed $S A R$. The specific heat of the blood is $c_{b}$ and the effective blood perfusion rate is $w_{b}\left[\frac{\mathrm{ml}}{100 \mathrm{~g} \cdot \min }\right.$ or $\left.\frac{1}{6} \times 10^{-6} \frac{\mathrm{m}^{3}}{\mathrm{~kg} \cdot \mathrm{s}}\right]$, which is the blood flow through the vasculature of the given volume per unit tissue-mass per unit time. In most cases, the tissue is considered to be equal in size to the complete volume of the micro-circulatory system. According to this approximation, the unit of the blood-perfusion transferred is approximately described by $\left[\frac{\mathrm{ml}}{100 \mathrm{~g} \cdot \min } \cong \frac{1}{100 \times 60} \frac{1}{\mathrm{~s}}=\frac{1}{6} \times 10^{-3} \frac{1}{\mathrm{~s}}\right]$. When we apply the above consideration for SI units, we get: $\left[\frac{\mathrm{m}^{3}}{\mathrm{~kg} \cdot \mathrm{s}} \cong 10^{-3} \frac{1}{\mathrm{~s}}\right]$. The error in 
this is $\frac{\rho_{b}}{\rho}<1 \%$, where $\rho_{b}$ and $\rho$ are the density of the blood and the surrounding tissue, respectively.) The blood density $\rho_{b},\left[\frac{\mathrm{kg}}{\mathrm{m}^{3}}\right]$ sinks energy thus:

$$
\text { cooling }=-c_{b} \rho_{b} w_{b} \Delta T,\left[\frac{\mathrm{J}}{\mathrm{kg} \cdot{ }^{\circ} \mathrm{C}} \cdot \frac{\mathrm{kg}}{\mathrm{m}^{3}} \cdot \frac{1}{\mathrm{~s}} \cdot{ }^{\circ} \mathrm{C}=\frac{\mathrm{W}}{\mathrm{m}^{3}}\right]
$$

Due to the regulatory role of the blood in thermal homeostasis, the $W_{b}$ depends on the temperature: $W_{b}=W_{b}(T)$. The thermal role of the $B F$ requires a massive thermal pool which keeps the base temperature constant (body temperature, $T_{\text {body }}=36.5\left[{ }^{\circ} \mathrm{C}\right]$ ). Various heat exchanges with the environment ensure the stability of the base temperature. We can therefore introduce a parameter $f$ [29] such that:

$$
f=\left[\begin{array}{ll}
1 & \text { when no heat loss } \\
0 & \text { when only heat loss }
\end{array}\right.
$$

The $f=1$ condition means all metabolic energy is used for the reactions associated with life, while $f=0$ means the metabolic energy does not support life; it is radiated to the environment as heat. Naturally, both are extremes, $f=1$ being impossible because the living state is an open system, and $f=0$ because life needs energy for itself. For human adults at rest $f \cong 0.15$ [30], so the heat exchange is intensive enough even though there is intense local heating. This is an important factor when the blood-cooling by $B F$ is considered, the heat being effectively radiated out, showing that the blood is able to maintain its cooling efficacy.

A further complication is the heat-diffusion in the tissues, by which the temperature spreads by time even without blood-circulation. This naturally depends on the gradient of the temperature in the space, given by $\operatorname{grad}(T)=\frac{\mathrm{d} T}{\mathrm{~d} \boldsymbol{x}}$, where $\frac{\mathrm{d} T}{\mathrm{~d} \boldsymbol{x}},\left[\frac{{ }^{\circ} \mathrm{C}}{\mathrm{m}}\right]$ is the temperature change $\mathrm{d} T$ in the space interval $\mathrm{d} \boldsymbol{x}$ calculated in all directions (all directions being designated by the bold lettering). This gradient will be the driving force of the smearing of the temperature in the space, so its change in the space characterizes the thermal diffusion:

$$
k \frac{\mathrm{d}[\operatorname{grad}(T)]}{\mathrm{d} \boldsymbol{x}}=k\left[\frac{\mathrm{d}^{2} T}{\mathrm{~d} x^{2}}+\frac{\mathrm{d}^{2} T}{\mathrm{~d} y^{2}}+\frac{\mathrm{d}^{2} T}{\mathrm{dz} z^{2}}\right]=k \nabla T,\left[\frac{\mathrm{J}}{\mathrm{m} \cdot{ }^{\circ} \mathrm{C}} \cdot \frac{{ }^{\circ} \mathrm{C}}{\mathrm{m}^{2}}=\frac{\mathrm{J}}{\mathrm{m}^{3}}\right]
$$

where the sign " $\nabla$ " symbolizes the thermal diffusion process in all three $(x, y, z)$ dimensions of the space, centred around the actually chosen $\boldsymbol{x}$ point, and where $k,\left[\frac{\mathrm{W}}{\mathrm{m} \cdot{ }^{\circ} \mathrm{C}}\right]$ is the coefficient of the heat-diffusion. (" $\nabla T$ " therefore, demonstrates the temperature spreading in all three dimensions). One more factor modifies the energy balance: the increased metabolic rate by temperature $\sim q_{0} \rho 11^{(\Delta T)}\left[\frac{\mathrm{W}}{\mathrm{m}^{3}}\right]$ [31], where $q_{0}$ is the basal metabolic rate $q_{0}=B M R,\left[\frac{\mathrm{W}}{\mathrm{kg}}\right]$. 
The $B M R$ has allometric scaling [32], which allows the determination of the $B M R$ depending on the body-mass [33].

Considering the above terms, the equation which describes the heating process is: (Pennes equation [34])

$$
\rho_{h} c \frac{\partial T}{\partial t}=\rho_{h} S A R-c_{b} \rho_{b} w_{b}(T)(\Delta T)-k_{h} \nabla^{2} T+q_{0} \rho 1.1^{(\Delta T)}
$$

The analytical solution of this partial differential equation is a difficult task. The first approach uses the Green-function [35] [36] and the Green heat kernel function [37], and approaches an analytical solution [38]. The point source Green function solution [39] can simulate the highly localised heating using a nanoparticle or thin needle. Heating by $915 \mathrm{MHz}$ from the skin's surface was calculated. Interestingly, when the $B F$ has spatial inhomogeneity due to the cooling bolus on the surface, it produces a bump in the temperature development by depth [40].

Despite the possibility of the analytical solution of the Pennes equation, it is not widely applied in practical use. Its complicated mathematics deters many physicians from using it, but in fact, the complicated mathematical calculation is not necessary. Numerical methods are precise enough for efficient use [41]. Using small differences (small steps of developing processes, denoted with $\Delta$ ), instead of the differential approach, is entirely compatible with the homeostatic control, which does not allow sudden, very rapid changes, even when the controlling signals are rapid. Clinical standards average the $S A R$ in the $\mathrm{MHz}$ range of frequencies over a six-minute period [42]. As a consequence, the differences can be used instead of derivatives in practical approaches. Hence the complete balance of treated healthy tissue is:

$$
\begin{aligned}
\rho_{h} c \frac{\Delta T}{\Delta t}= & \rho_{h} S A R-c_{b} \rho_{b} w_{b}(T)(\Delta T) \\
& -k_{h}\left(\frac{\Delta\left(\frac{\Delta T}{\Delta x} \boldsymbol{i}+\frac{\Delta T}{\Delta y} \boldsymbol{j}+\frac{\Delta T}{\Delta z} \boldsymbol{k}\right)}{\Delta x}\right)+q_{0} \rho 1.1^{(\Delta T)}
\end{aligned}
$$

where $\boldsymbol{i}, \boldsymbol{j}$ and $\boldsymbol{k}$ are the unit vectors in the 3D dimensions $x, y$ and $z$, and the equation is written using the SI units $\left[\frac{\mathrm{W}}{\mathrm{m}^{3}}\right]$.

The characteristic constants used, collected from various pieces of literature, are: $\rho_{\text {tumoqur }}=\rho_{t}=1050\left[\frac{\mathrm{kg}}{\mathrm{m}^{3}}\right], \quad \rho_{\text {blood }}=\rho_{b}=1060\left[\frac{\mathrm{kg}}{\mathrm{m}^{3}}\right]$, $\rho_{\text {healthy }}=\rho_{h}=1190\left[\frac{\mathrm{kg}}{\mathrm{m}^{3}}\right], \quad q_{0}=368\left[\frac{\mathrm{W}}{\mathrm{m}^{3}}\right] \approx 0.37\left[\frac{\mathrm{W}}{\mathrm{kg}}\right],[43] ;$ or $q_{0} \approx 1\left[\frac{\mathrm{W}}{\mathrm{kg}}\right] \cong 1000\left[\frac{\mathrm{W}}{\mathrm{m}^{3}}\right],[44] ; \quad c_{t}=3639\left[\frac{\mathrm{J}}{\mathrm{kg} \cdot{ }^{\circ} \mathrm{C}}\right] ; \quad c_{b}=3840\left[\frac{\mathrm{J}}{\mathrm{kg} \cdot{ }^{\circ} \mathrm{C}}\right],[45] ;$ $c_{h}=3800\left[\frac{\mathrm{J}}{\mathrm{kg} \cdot{ }^{\circ} \mathrm{C}}\right],[46] ; \quad k_{t}=0.56\left[\frac{\mathrm{W}}{\mathrm{m} \cdot{ }^{\circ} \mathrm{C}}\right] ; \quad k_{h}=0.56\left[\frac{\mathrm{W}}{\mathrm{m} \cdot{ }^{\circ} \mathrm{C}}\right] ;$ 
$W_{b \text {-tumour }}=\rho_{b} w_{b t}=1.8\left[\frac{\mathrm{kg}}{\mathrm{m}^{3} \cdot \mathrm{s}}\right] ; W_{b \text {-healthy }}=\rho_{b} w_{b h}=3.6\left[\frac{\mathrm{kg}}{\mathrm{m}^{3} \cdot \mathrm{s}}\right] ;$ [47] [48]. Data may vary by organs [49].

It is evident that the $B F$ can fundamentally modify the calculations. The measurements of the $B F$ in clinical practice give inconsistent results measured even in the same patient. The person's actual state, comfort level, stresses, and environmental and social factors cause deviations in the skin condition, modifying the results of the measurements, so the uncertainty is clinically inherent [50].

The $S A R\left[\frac{\mathrm{W}}{\mathrm{kg}}\right]$ identifies the power intake per unit mass from outside energy sources. The critical fact is that the electromagnetic non-ionizing heating processes dominantly use electric fields, pumping considerable energy into the larger target. The $S A R$ depends on the conductivity $\left(\sigma\left[\frac{1}{\Omega \cdot \mathrm{m}}\right]\right)$ and the allied electric field ( $\left.\Xi\left[\frac{\mathrm{V}}{\mathrm{m}}\right]\right)$ :

$$
\rho S A R=\sigma \Xi^{2}\left[\frac{\mathrm{W}}{\mathrm{m}^{3}}\right]
$$

when the electric field is sinusoidal then its peak value has to be divided by $\sqrt{2}$ to obtain the average. Consequently, in practical use, [51]:

$$
S A R=\frac{\sigma}{2 \rho} \Xi^{2}\left[\frac{\mathrm{W}}{\mathrm{kg}}\right]
$$

The most substantial challenge in the calculation of the absorbed energy is the high heterogeneity of the absorption process. The human target is heterogenic in the thermal, electrical and structural aspects.

Additional to the static challenges, the heterogeneity appears in the dynamism of the transports non-linearly, as well as in the various chemical reactions that consume energy in the living target. Consequently, the parameters in (11) and (14) are time $(t)$ and space $(x)$ dependent so the correct equations, taking into consideration the heterogeneity in micro and macro ranges, are in reality very complicated. The Pennes equation with spatiotemporal $(x, t)$ dependences is:

$$
\begin{aligned}
& \rho_{h}(x, t) c(x, t) \frac{\partial T(x, t)}{\partial t} \\
& =\rho_{h}(x, t) \operatorname{SAR}(x, t)-c_{b} \rho_{b} w_{b}(T, x, t)(\Delta T(x, t)) \\
& -k_{h}(x) \nabla^{2} T(x, t)+q_{0}(x, t) \rho(x, t) 1.1^{(\Delta T(x, t))}
\end{aligned}
$$

and the external energy-pumped is:

$$
\operatorname{SAR}(x, t)=\frac{\sigma(x, t)}{2 \rho(x, t)} \Xi^{2}(x, t)\left[\frac{\mathrm{W}}{\mathrm{kg}}\right]
$$

Due to the complications, we usually simplify the situation with rational assumptions:

1) The metabolic addition in the heating phases will be negligible compared to 
the incoming $S A R$, so it is not considered in most of the calculations. The neglection can be explained according to the principal of the optimization of living processes in their adaption to environmental challenges. The consequence of the life-optimization of energy transfers via chemical reactions minimizes thermodynamic losses [52] [53]. However, hyperthermia increases biochemical reaction rates [54] and, therefore, the metabolic rate as well. The rapid growth and higher metabolism of tumours typically yield tumour temperatures higher than the surrounding healthy baseline temperature [55]. When the metabolic addition is more than $5 \%$ on top of the $S A R$, we include it in the calculation.

2) In a tumour situation, the main macroscopic heterogeneity is between the tumour and its healthy environment. The parameters at the surface of the tumour do not jump but have a slope, depending on the kind of the tumour and its stage. The gradient is mostly created by the homeostatic control of the $B F$.

3) The macroscopic spatiotemporal dependence of the densities $(\rho)$, specific absorption rates $(c)$ and conductivity $(\sigma)$ is weak, usually it is less than $5 \%$ in both the tumorous and healthy tissues. Consequently, in practical calculations, we consider these parameters as constants in the specific tissues, distinguishing only the tumorous and non-tumorous mass. Detailed reviews and discussions on tumour-blood-flow affecting the applied temperature are available [56] [57].

4) The largest heterogeneity, however, is microscopic. The tissue contains inherently different electrolytes separated by membranes and other structures (such as vessel-walls, node-walls, etc.). In tumours, the malignant cells and their microenvironment dominate the heterogenic behaviour. The microscopic heterogeneity can be specially targeted, choosing the proper frequency for selection [58] [59]. The frequency dispersion by the various components of the microscopic tissue environments will be discussed later.

The homeostasic functions characterize the local stability of the living system, having very complex feedback mechanisms which secure the stability against a relatively wide-range of perturbations. The homeostasis is not static. It is a self-organized dynamic process that has no static state at all. The system is energetically open. Its rigid, static state is death. The complexity of the dynamic behaviour guarantees robust stability, so the system is in a homeodynamic position rather than homeostatic.

The complexity of the dynamic interaction represents a feedback regulation of the system at every level of its structure. The complex system cannot be considered as a sum of its distinct parts. The whole is more than the sum of the parts; the interactions are largely non-linear; the system is energetically open and has adaptive exchanges with its environment. The approach to describing it must be analytic and not synthetic. Considerations regarding the complexity create huge challenges in the development of the calculations, the attempted solutions to which typically uses a synthesis of the parts, which could be calculated. However, this calculation strategy does not work. The analysis must consider the complexity. 
We could overcome the above difficulties by considering one of the robust behaviours of this complexity: the self-organization and its consequent self-similarity [60]. The complexities of the living structures have a universal behaviour: they are self-organized [61]. Recent decades have seen the development of various approaches describing the complexity of systems on the basis of self-organization [62] [63]. A great many studies deal with fractal physiology [64] [65], describing biological self-organization [66]. This peculiar structure is built up according to relatively simple rules based on self-similarity [67]. The dynamism of the structure is determined by the symmetries of the system [68], and constructs a self-managed spatiotemporal fractal network [69] [70], leading to a common bioscaling behaviour of living material [71]. As a result, the similarity of living species [72] allows allometric scaling in 24 orders of magnitude from the smallest to the largest bio objects [73].

Living systems are open dynamic structures, completing random stationary stochastic self-organizing activities [74]. The self-organizing technique generates a spatiotemporal fractal structure, which is self-similar both in space and time [75]. The emerging fields of bio-scaling [32] [76] [77], and network analysis [78] [79] extend detailed analyses. The characteristic stochastic (probability) behaviour of living matter is related to the intrinsic bifurcation in the entirety of the living organization. The basic bifurcation mechanism could be represented by a non-linear double-well potential of chemical reactions [80] [81], generating a chaotic arrangement.

The self-organized self-similarity describes and defines living objects [82] according to the universality of their complex feedback mechanisms to control the actual dynamic equilibrium, that is, their homeostasis. The progression of life involves non-linear and non-equilibrial thermodynamic and chemodynamic consequences including fractal structures and phase transitions like in non-living systems. We may use the robust self-similar actions in solving the heating process in a stochastic way.

To calculate the temperature development over time, let us introduce a stochastic variable $\theta$ defined by measurements on the cohort of individuals. $\theta$ is the time taken to reach thermal homeostasis, a saturation in the temperature development (the time to the stage when $\frac{\Delta T}{\Delta t} \cong 0$ ). The deterministic approach gives modelling facilities for the interpretation of data, but the reality is stochastic, determined by the probabilities of events, and no deterministic decisions can be made. Deterministic models could give information about the large-scale average nature of the dynamism, but the details will be hidden. The stochastic description describes the reality in a very general way and provides a good tool for the design and analysis of experiments. The introduced $\theta$ stochastically describes the personal and individual differences in obtaining $\frac{\Delta T}{\Delta t} \cong 0$ conditions during the time of treatment. It shows the variation in the control of thermal homeostasis $(T H)$ according to the subject of an individual treatment; see Figure 1. 


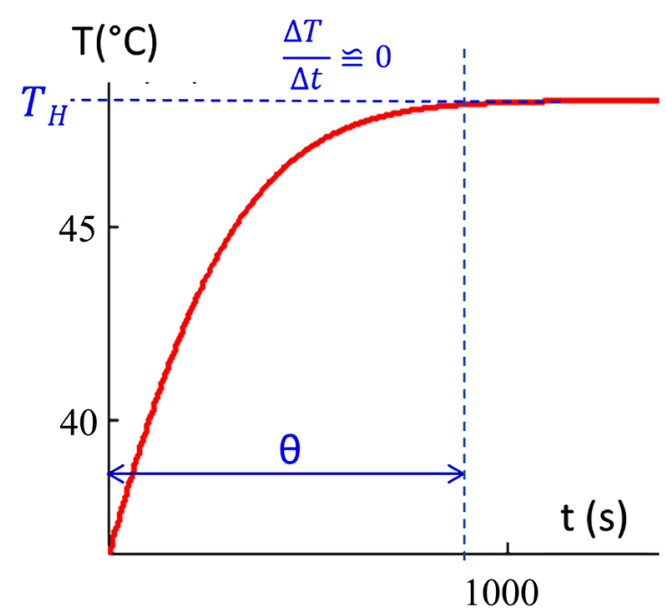

Figure 1. The $T H$ state fixes a temperature value $T_{H}$, where the curve saturates, and the thermal homeostasis keeps the temperature constant $\left(\frac{\Delta T}{\Delta t} \cong 0\right)$. The stochastic timeparameter $\theta$ of the individual heating characterizes the time when the TH happens.

The distribution function of $T H$ is the probability of the $\theta$ time being less than or equal to time $t$, namely

$$
p_{T H}(t)=P\{\theta \leq t\}
$$

Thus, the probability distribution of dynamic equilibrium (temperature development function, the time of control of the development $(C)$ ) can be defined by the probability of the equilibrium $\theta$ time being higher than $t$, which can be expressed in the form

$$
p_{C}(t)=1-p_{T H}(t)=P\{\theta>t\}
$$

The density function of the dynamic control distribution function is a derivative of $p_{C}(t)$ :

$$
f(t)=\frac{\mathrm{d} p_{C}(t)}{\mathrm{d} t}
$$

The $f(t)$ is the density of the probability of $\theta$, therefore, the average $\theta$ is:

$$
\langle\theta\rangle=\int_{0}^{\infty} t f(t) \mathrm{d} t=\int_{0}^{\infty} p_{C}(t) \mathrm{d} t
$$

Let us introduce a function of the rate at which a loss of control occurs at $(t+\Delta t): h(t)$. This failure-rate refers to when the thermal homeostasis cannot control the heating process. It is a "hazard" that $\theta$ does not describe the homeostatic process. The $h(t)$ is the "uncontrolled rate" or "out of control rate". The $h(t) \mathrm{d} t$ rate measures the probability of the failures during the $t$ length of control-time of the evolving process to $T H$. Therefore, the probability that in the case of a $t$ length of time to $T H$, loss of control occurs at $(t+\Delta t)$ is:

$$
h(t) \Delta t=1-\frac{p_{C}(t+\Delta t)}{p_{C}(t)}=-\frac{\mathrm{d} \frac{p_{C}(t)}{\mathrm{d} t}}{p_{C}(t)} \Delta t=-\frac{\frac{\mathrm{d}\left[1-p_{T H}(t)\right]}{\mathrm{d} t}}{p_{C}(t)} \Delta t=\frac{f(t)}{p_{C}(t)} \Delta t
$$


Hence:

$$
h(t)=-\frac{\mathrm{d} \frac{p_{C}(t)}{\mathrm{d} t}}{p_{C}(t)}=\frac{f(t)}{p_{C}(t)}
$$

It's cumulative form is:

$$
H(t)=\int_{0}^{t} h(\tau) \mathrm{d} \tau=-\ln \left(p_{C}(t)\right)
$$

and consequently:

$$
p_{C}(t)=\mathrm{e}^{-H(t)}
$$

As we discussed above, the inherent property of living objects is self-organization and the consequent self-similarity [60]. This could be the basis of the proper parameterization of homeostatic thermal control, and likewise of the control of the $T H$. Taking this self-similarity into consideration, the failure rate in (22) must be a self-similar time function [83], mirrored by a scaling, shown as follows:

$$
h(t)=\alpha t^{\beta}
$$

Its self-similarity is obvious because it gives the same function by a magnification of any number $m$ :

$$
h(m t)=\alpha(m t)^{\beta}=m^{\beta} \alpha t^{\beta}=m^{\beta} h(t)
$$

The survival probability distribution function from (23) and (24) is:

$$
p_{C}(t)=\mathrm{e}^{-\int_{0}^{t} h(\tau) \mathrm{d} \tau}
$$

The self-similar failure rate (hazard function) is:

$$
H(t)=\int_{0}^{t} \alpha \tau^{\beta} \mathrm{d} \tau=\frac{\alpha}{\beta+1} t^{\beta+1}
$$

Substituting (28) with survival (27), we get:

$$
p_{C}(t)=\mathrm{e}^{-\int_{0}^{t} \alpha \tau^{\beta} \mathrm{d} \tau}=\mathrm{e}^{-\frac{\alpha}{\beta+1} t^{\beta+1}}
$$

Introducing

$$
t_{0}=\left(\frac{n}{\alpha}\right)^{\frac{1}{n}} \text { and } n=\beta+1
$$

we hence arrive at:

$$
p_{C}(t)=\mathrm{e}^{-\left(\frac{t}{t_{0}}\right)^{n}}
$$

which has two parameters for one curve, $t_{0}$ being the scale parameter, which is the natural scale of the time-function variation, and $n$ being the shape parameter. Consequently, the thermal homeostatic distribution function $p_{T H}(t)$ by (17) and (18) is the well-known cumulative form of the two-parametric Weibull distribution $(W(t))[84]$ : 


$$
p_{T H}(t)=W(t)=1-\mathrm{e}^{-\left(\frac{t}{t_{0}}\right)^{n}}=1-p_{C}(t)
$$

with the additional conditions that $t \geq 0, W(t)=0$ when $t<0$. The inverse function, when the time $t$ is calculated from a given probability $\mathrm{p}$ is:

$$
t=W_{\text {inv }}(p)=t_{0}(-\ln (1-p))^{\frac{1}{n}}
$$

The full regulation and controlling processes are essentially, inherently dynamic, so it is better to use the term "homeodynamics" instead of "homeostasis" [85]. A broad-spectrum of self-organized structures could be described with the $W(t)$ function, among these structures gene expression data [86] and neural networks [87]. A consequence of the widely applicable universality of behaviour, general ontogenic growth [88] also allows the deduction of the Weibull distribution [89]. Importantly, the information traffic on networks also has self-similar fractal behaviour as described by the Weibull distribution [90], which also allows the self-organizing dynamic approach for the stabilizing regulation of the system. We may conclude that self-organizing and self-similarity are universal laws fingerprinted in the fractal description and can be described by a cumulative Weibull distribution $W(t)$.

Note, that we have preciously applied a mathematical transformation which unified the physical models of biological processes and self-similar processes with the help of an appropriate comparative function [83]. Choosing the Avrami-like comparative function, the mathematical model of the processes will be described by the Avrami-equation [91]. This unusual universality is a consequence of the self-organized behaviour of the homeodynamic conditions of life, and the general analogy of self-organized processes can be a fruitful heuristic method in biological model-calculations. The Avrami describes some living phenomena well [92] [93], and the equation is connected to the self-similarity and dynamism of the living structures [87]. The Avrami-equation has the following form, which is identical to the Weibull distribution using Weibull function $(W F)$ :

$$
1-W(t)=W F(t)=\mathrm{e}^{-\left(\frac{t}{t_{0}}\right)^{n}}
$$

The shape parameter is usually $n>1$, having the same shape as the psychometric function [94], a consequence of the Weber-Fechner law. In the case that $n=1, W F$ is a simple exponential function, and where $n<1$, the decrease is faster than an exponential decrease.

The case in which $n=1$ is a simple, very frequently occurring behaviour of stand-alone systems, satisfying the basic rule of self-regulation by negative feedback: the change of the property $\Theta$ over time is negatively proportional to the value of the property $\Theta$. In mathematical form:

$$
\frac{\mathrm{d} \Theta(t)}{\mathrm{d} t}=-c \cdot \Theta(t)
$$


The solution is exponential decay:

$$
\Theta(t)=\Theta(0) \mathrm{e}^{-c t}
$$

where $c$ is a constant and $\Theta(0)$ is the starting $\Theta(t)$ value $(t=0)$. When the starting $\Theta(0)=0$, then the solution is a decreasing function from $\Theta(0)$ :

$$
\Theta(t)=\Theta(0)\left(1-\mathrm{e}^{-c t}\right)=\Theta(0)\left(1-\mathrm{e}^{-\left(\frac{t}{t_{0}}\right)}\right)
$$

where $t_{0}=\frac{1}{c}$. This is the form of $W(t)$ at $n=1$. By the growth of $n>1$, the complexity of the interaction grows. The equation modifies, thus:

$$
\frac{\mathrm{d} \Theta(t)}{\mathrm{d} t}=-c \cdot t^{n-1}(\Theta(0)-\Theta(t))
$$

and the solution is:

$$
\Theta(t)=\Theta(0)\left(1-\mathrm{e}^{-\left(\frac{t}{t_{0}}\right)^{n}}\right)
$$

where $t_{0}=\left(\frac{n}{c}\right)^{\frac{1}{n}}$. The solution in (39) is identical to that in (37) at the limit of $n=1$.

It is clear that the shape factor $n$ characterizes the complexity of the function. The initial change is a power function and is not linear. The changes in the $W F(t)$ function are shown in Figure 2. The limit $\lim _{n \rightarrow \infty} W F(t)$ is a step function at $t=t_{0}$, while the $\lim _{n \rightarrow \infty} W F(t)=\frac{\Theta(0)}{\mathrm{e}} \cong 0.368 \cdot \Theta(0)$ is constant.

The mean, the median, and the inflection points are frequently used in the practical evaluation, as shown in Figure 3:

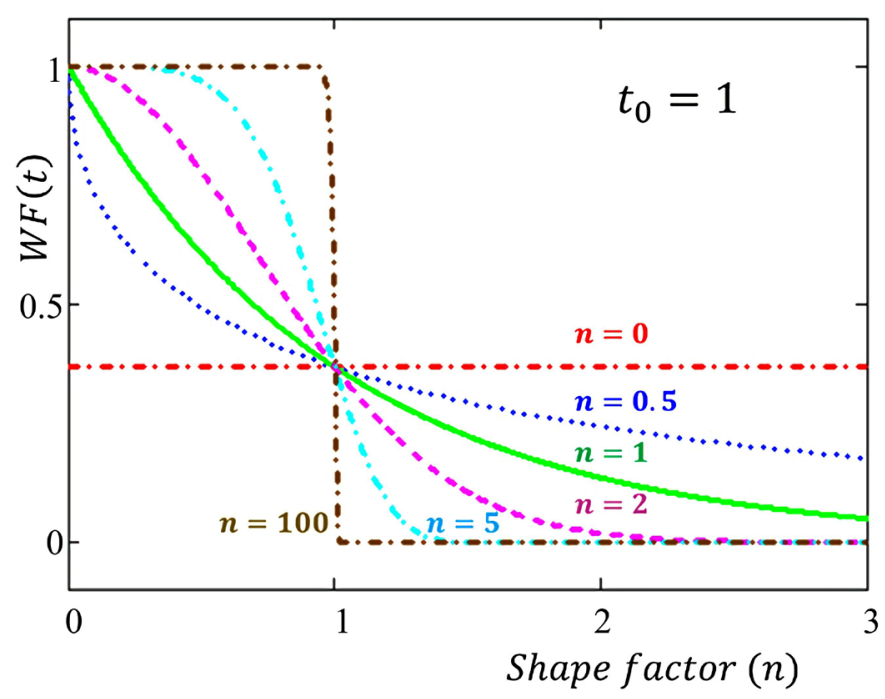

Figure 2 . The changes in $W F(t)$ by $n$, measured in self-time units $\left(t_{0}=1\right)$. 


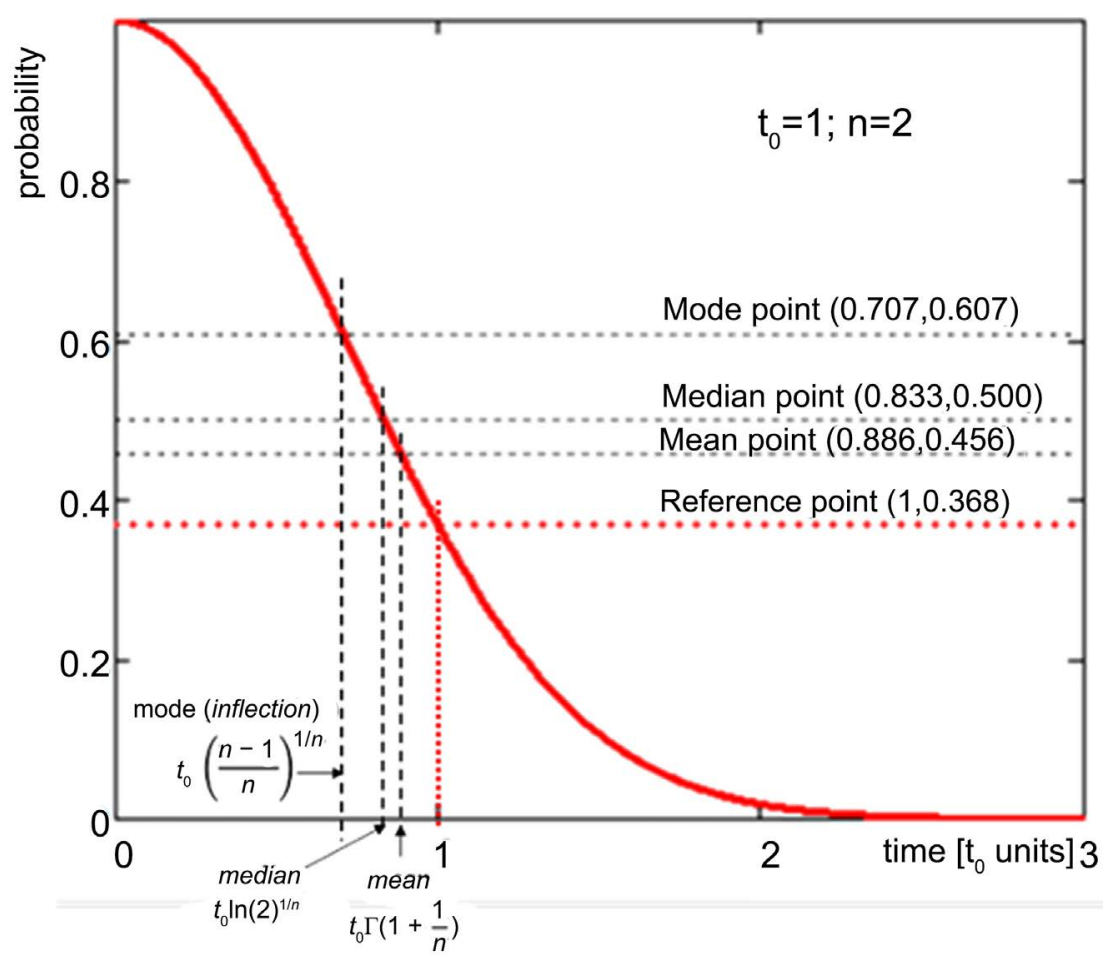

Figure 3. The noteworthy points of $W F$, when $t_{0}=1$ and $n=2$. The reference point is $\frac{1}{\mathrm{e}} \cong 0.37$, when $t=t_{0}$. The inflection point marks the mode, the change of the sign of the growth of the derivative of the function.

$$
\begin{aligned}
& \operatorname{median}\left[p_{S}(t)\right]=t_{0}[\ln (2)]^{\frac{1}{n}} \\
& \operatorname{mean}\left[p_{S}(t)\right]=t_{0} \int_{0}^{\infty} \mathrm{e}^{-x} x^{\frac{1}{n}} \mathrm{~d} x=t_{0} \Gamma\left(1+\frac{1}{n}\right) \\
& \operatorname{mode}\left[p_{S}(t)\right]=t_{0}\left[\frac{n-1}{n}\right]^{\frac{1}{n}}
\end{aligned}
$$

The values of the median, mode and mean when $t_{0}=1$ and $n=2$ are 0.5 , 0.607 and 0.456 , respectively. The quantile of the $W F$ function is $\approx 0.632$, and it is independent from the value of $n$. All the notable points are proportional to $t_{0}$, and consequently, $t_{0}=1$ is chosen for the natural unit of the elapsed time. The value of $t_{0}$ characterizes the self-time of the living system, which is responsible for the individual complexity (personal variation) of the living unit [95]. Thermodynamic optimizing introduces variation in self-time, on the basis of constant entropy production over time [96]. Self-time is connected to allometry [97], and it scales with the allometric factor, which is usually $\alpha \approx \frac{3}{4}$, the power rule of which is strongly supported by various physiological times [98]. The real observed coordination time and the self-time are strictly connected, and their values are transformed into each other [95]. The changes of self-time in the various parameter-pairs of $W F$ are shown in Figure 4. 


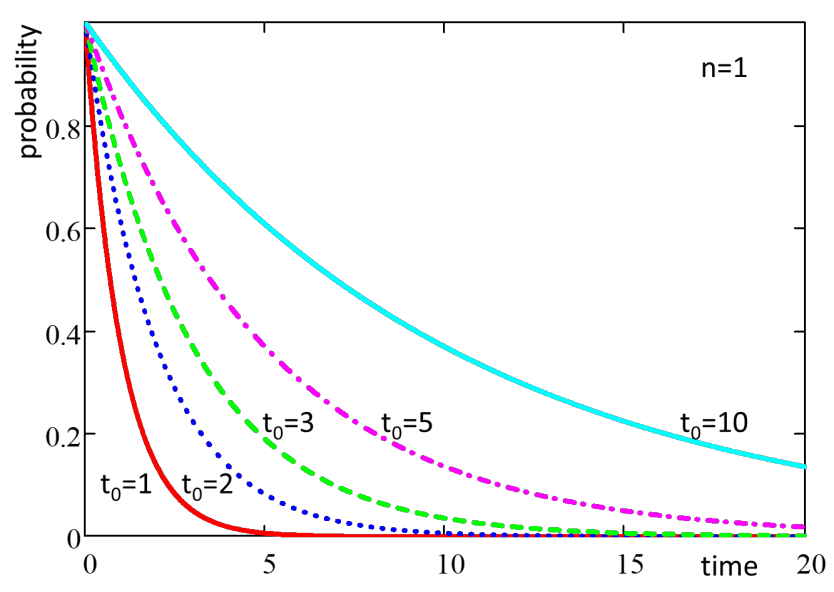

(a)

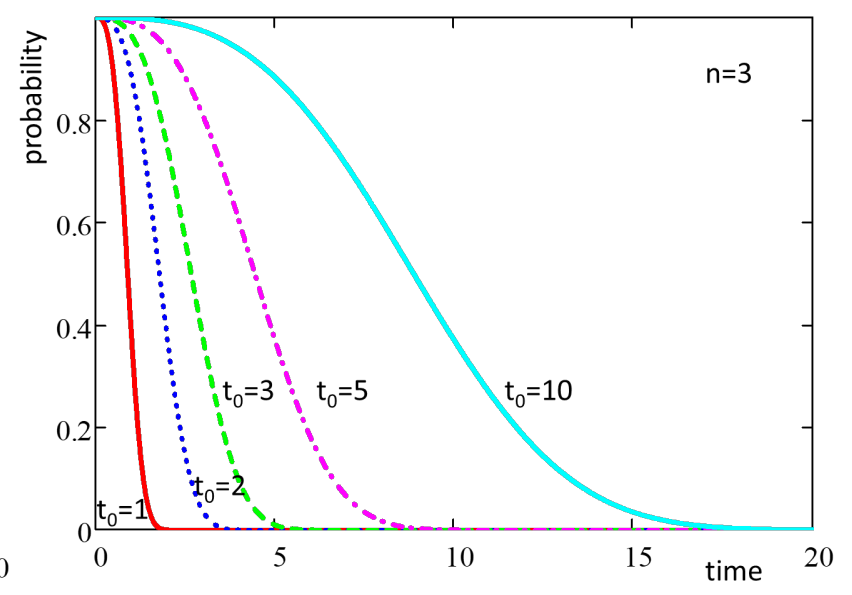

(b)

Figure 4. WF with various parameters: (a) changing $t_{0}$ (scale parameter) in simple exponential conditions, (the shape parameter is $n=1)$; (b) the shape parameter differs from the exponential, containing extended complexity $(n=3)$.

The energy absorption of living objects follows the rule of complexity, and the temperature development depends on it. The complex structure determines the heat-conduction, the dynamic feedback properties, and the steady-state saturation and stabilization of the temperature, providing a constant $S A R$ value. We assume that the complex behaviour of the $W F$ describes the absorption and wash-out processes well, and without a complicated solution of the Pennes Equation (15) we may describe the hyperthermia process by temperature development in a complex system.

\section{Results}

The $W F$ function is assumed to describe the complex heating process over time in conditions of thermal homeostasis. Consequently, the entire velocity $V_{T}$ of the change of the temperature could be described with the $W F$ :

$$
W F(t) \propto \frac{\Delta T}{\Delta t}=v_{T}
$$

The letter $\propto$ means that $v_{T}$ behaves in the same way as $W F(t)$ does. It denotes only a character of heating and not equality, because the values of $W F(t)$ are limited $(0 \leq W F(t) \leq 1)$. The character $v_{T}$ is a multiplicative factor of the real reaction when the system reaches its heating maximum at the $T H$ in time $t_{T H}$ then $W F\left(t_{T H}\right)=1$. In this approach, the development of the temperature behaves like the sum of $W F(t) \Delta t$ terms:

$$
\sum W F(t) \Delta t \propto \Delta T
$$

In analytical form, using (34) and referring to the body temperature $\left(T_{b o d y}\right)$ as the base-line:

$$
T(t)-T_{b o d y} \propto \int_{0}^{t} \exp \left(-\left(\frac{\tau}{t_{0}}\right)^{n}\right) \mathrm{d} \tau
$$

Hence Figure 5 shows the graphical measure of the temperature. 


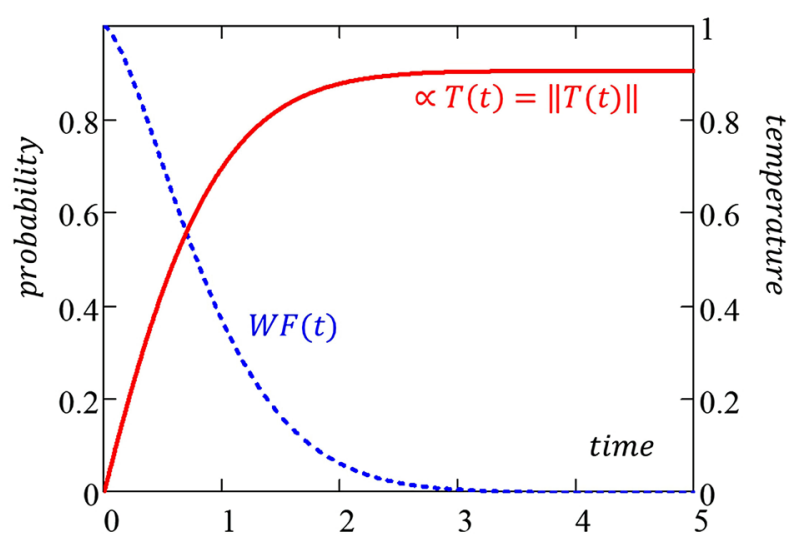

Figure 5. The approximation of temperature development (solid line) by the $W F$ (dashed line). The parameters are $n=1.48$ and $t_{0}=1$. The unit of time is $t_{0}$. The temperature development is a relative form (it is normalized) of the real temperature, so it is denoted by $\|T(t)\|$ in the curve.

The normalization of $\|T(t)\|$ can be determined from the saturation value (the $T_{H}$ value) of the actual homeodynamic case. The $T H$ condition reduces the Pennes Equation (11) thus:

$$
c_{b} \rho_{b} w_{b}(T)(\Delta T)+k_{h} \nabla^{2} T=\rho S A R+q_{0} \rho 1.1^{(\Delta T)}
$$

because in this state $\frac{\partial T}{\partial t} \cong \frac{\Delta T}{\Delta t}=0$. As we discussed, the metabolic term $q_{0} \rho 1.1^{(\Delta T)}$ is negligible compared to $\rho S A R$. The diffusion term is also small compared to the $B F$, which is an effective heat exchanger. Hence these approximative steps reduce (44) to:

$$
c_{b} \rho_{b} w_{b}(T)(\Delta T)=\rho S A R \Rightarrow T-T_{b o d y}=\frac{\rho S A R}{c_{b} \rho_{b} w_{b}(T)}
$$

The density $\rho$ characterizes the healthy $\left(\rho_{h}\right)$ or tumorous $\left(\rho_{t}\right)$ tissue, depending on the absorption volume under investigation. Also, the $B F$ changes as well, depending on whether we consider a healthy $\left(w_{b h}\right)$ or tumorous $\left(w_{b t}\right)$ target. An early study has shown that an internal temperature change (mild fever) causes a sudden increase in the heat conductance of healthy tissues [99] due to, after passing a threshold, the $B F$ delivering seven times more power (up from $21 \mathrm{~W} / \mathrm{K}$ to $150 \mathrm{~W} / \mathrm{K}$ with an increase in body temperature of $<1^{\circ} \mathrm{C}$ ). Later it was shown that the development is not a step-function but a power function. For the temperature-dependent $B F$ we use the results obtained by a nonlinear three-dimensional heat-transfer model [100]. The obtained functions for prostate and surrounding tissues are:

For healthy muscle

$$
\rho_{b m} w_{b m}(T)= \begin{cases}0.45+3.55 \exp \left(-\frac{(T-45)^{2}}{12}\right) & \text { if } T \leq 45 \\ 4 & \text { if } T>45\end{cases}
$$


for healthy adipose tissue

$$
\rho_{b a} w_{b a}(T)= \begin{cases}0.36+0.36 \exp \left(-\frac{(T-45)^{2}}{12}\right) & \text { if } T \leq 45 \\ 0.72 & \text { if } T>45\end{cases}
$$

for tumour tissue

$$
\rho_{b t} w_{b t}(T)= \begin{cases}0.833 & \text { if } T<37 \\ 0.833-\frac{(T-37)^{4.8}}{5438} & \text { if } 37 \leq T \leq 42 \\ 0.416 & \text { if } T>42\end{cases}
$$

The graphs of these solutions are shown in Figure 6. The vasoconstriction of tumour-tissue is expected from finite elements calculations too, modelling the human prostate [101].

With increasing temperature, the tumour serves as an effective heat-trap due to the $B F$ within barely increasing [102], so the heat-sinking effect seen in healthy tissue is absent. The characteristic difference between the absolute $B F$ of a tumour and healthy tissue has been observed by others, too [103] [104]. Due to the angiogenetic effect, the size of the tumour also affects the $B F$. This depends on the tumour-weight by negative logarithmic function [105].

Equations (46)-(48) allow the determination of the $T_{H}$ from (45). When there is forwarded power applied $\left(P_{f w r}\right)$, and the complete heated mass is $M$ containing $m_{t}$ and $m_{h}$ tumour and healthy masses, then $M=m_{t}+m_{h}$. Assuming an equal $S A R$ throughout the volume of $M$, we may calculate the SAR taking into account the reflected power $\left(P_{\text {reff }}\right)$ and the efficacy $(\eta)$, which is calculated from the various losses by the technical realization; we get:

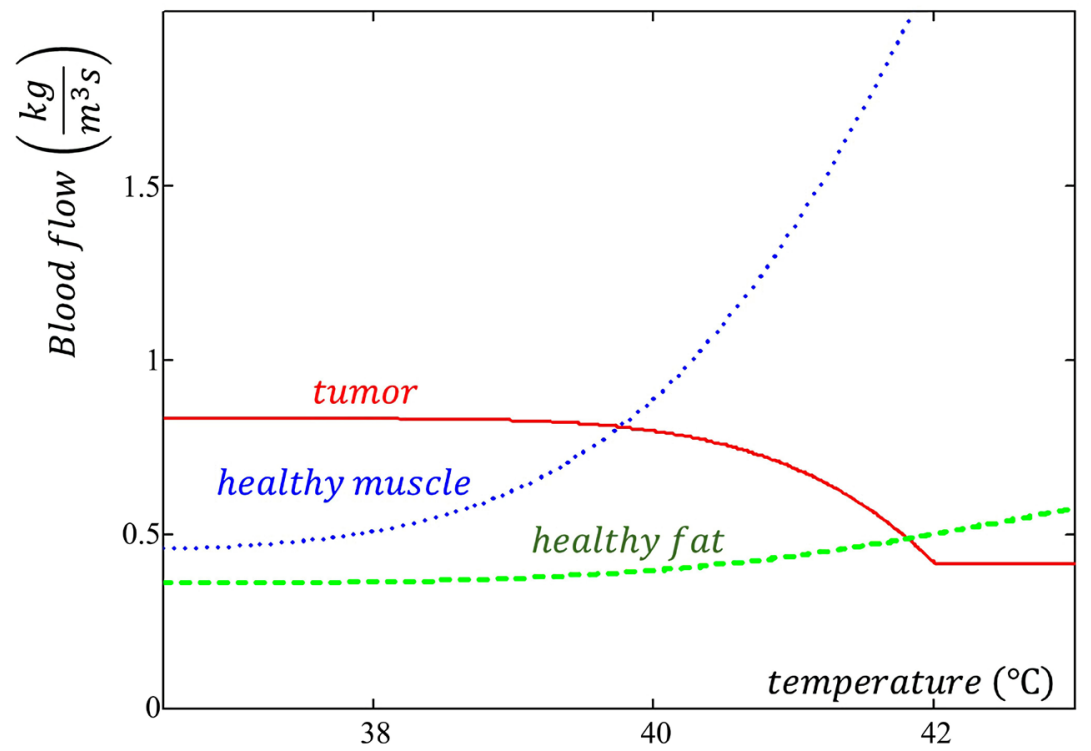

Figure 6. The modelled blood flow by temperature variation [104]. Tumorous tissue (solid line), healthy muscle (dotted line), healthy fatty tissue (dashed line). 


$$
S A R=\frac{\left(P_{f w r}-P_{r e f l}\right) \eta}{m_{t}+m_{h}}
$$

Using (46) and (48) for muscle and tumour, respectively, we may calculate the $T_{H}$, solving Equation (45). Denoting the roots of tumour and muscle $T_{H}$ by $T_{t}$ and $T_{m}$, we can construct the final $T_{H}$ by supposing a complete isothermal $T H$ condition:

$$
T_{H}=\frac{m_{t} T_{t}+m_{h} T_{m}}{m_{t}+m_{h}}
$$

Knowing this $T_{H}$ value, the temperature gain is $T_{\text {gain }}=T_{H}-T_{\text {body }}$, and so, using the normalized $\|T(t)\|$, the curve of temperature growth can be obtained:

$$
T(t)=T_{\text {body }}+\frac{\|T(t)\|}{T_{H}} T_{\text {gain }}
$$

This curve captures all the complex interactions arising from the structure of the heated volume. The two parameters $n$ and $t_{0}$ contain the stochastic complexity characterizing the $W F$ of the system, so the diffusivity is also included in the pool of the complexity.

Let us make the calculation for the capacitive coupling of modulated electro-hyperthermia (mEHT, trade name oncothermia [106]), with actual values of $W F$ parameters $n=1.48$ and $t_{0}=1$. We will assume the following parameters:

The diameter of the applicator $D_{\text {app }}=0.2 \mathrm{~m}, P_{f w r}=150 \mathrm{~W}$, $P_{\text {refl }}=3 \mathrm{~W}(2 \%), \eta=0.85$, depth of the tumour $h_{t}=0.1 \mathrm{~m}$, the size of the tumor $s_{t}=0.1 \times 0.05 \times 0.1=0.5 \times 10^{-3} \mathrm{~m}^{3}=0.5 \ell$, the body thickness in the supine position at the belly $d_{\text {body }}=0.2 \mathrm{~m}$, and size of the entire affected volume $s_{V}=9.05 \times 10^{-3} \mathrm{~m}^{3}=9.05 \ell$.

The calculated values are: $m_{t}=0.595 \mathrm{~kg} ; m_{h}=9.5 \mathrm{~kg} ; \quad S A R=12.377 \frac{\mathrm{W}}{\mathrm{m}^{3}}$. The obtained $T_{H}$ temperatures $T_{t}=45.89^{\circ} \mathrm{C} ; T_{h}=40.32^{\circ} \mathrm{C}$, and consequently $T_{H}=40.65^{\circ} \mathrm{C}$; hence $T_{\text {gain }}=4.15^{\circ} \mathrm{C}$. The metabolic addition has no role in this approximation. The temperature grows as shown in Figure 7.

The metabolic addition is $381 \frac{\mathrm{W}}{\mathrm{m}^{3}}=0.38 \frac{\mathrm{W}}{\mathrm{kg}}$, [43]. For simplicity, we count the metabolic rate as equal in the tumour and healthy tissue, because the same volume, where the tumour has less malignant cells due to the increased volume of extracellular electrolyte [107], as well as its volume having certain necrotic parts. Consequently, with the already higher than healthy metabolic rate of the tumour-cells, their metabolic activity in the unit-volume is equal to that in the healthy volume. The overall metabolic activity is $3 \%$ of the applied $S A R$, so it could be counted in the calculation. In this case, the determined $T_{H}$ values are: $T_{t}=47.10^{\circ} \mathrm{C} ; T_{h}=40.44^{\circ} \mathrm{C}$, and consequently $T_{H}=40.85^{\circ} \mathrm{C}$; hence

$T_{\text {gain }}=4.35^{\circ} \mathrm{C}$, which is $0.2^{\circ} \mathrm{C}$ higher with metabolic addition than without it. In a more general estimation, we use the metabolic part of the $\frac{\Delta T(t)}{\Delta t}$ change: 


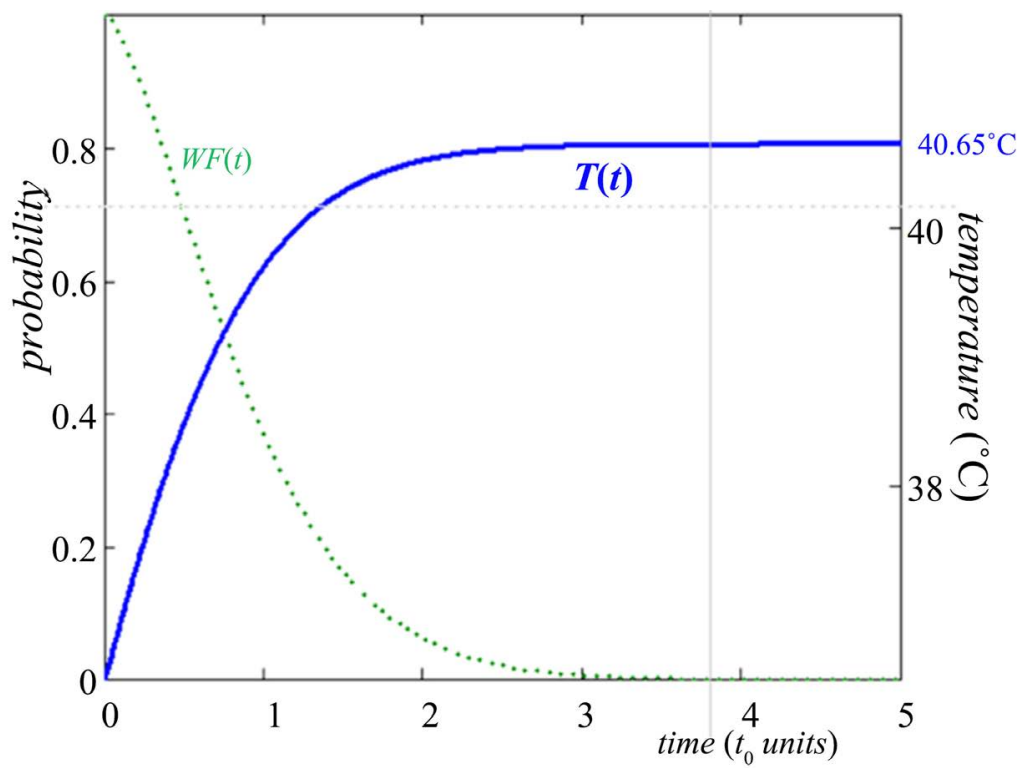

Figure 7. The temperature development of the tumour (right-hand axis) $m_{t}=0.595 \mathrm{~kg}$ and $m_{h}=9.5 \mathrm{~kg}$ by the WF approximation $\left(n=1.48, t_{0}=1\right)$ calculated for mEHT. ( $\left.P_{f w r}=150 \mathrm{~W}, P_{\text {refl }}=3 \mathrm{~W}(2 \%), \eta=0.85\right)$. Other parameters in the calculation are in the text.

$$
\rho_{h} c \frac{\Delta T(t)}{\Delta t}=q_{0} \rho_{t} \cdot 1.1^{(\Delta T(t))} \Rightarrow \Delta T(t) \cong \frac{q_{0} \rho_{t}}{\rho_{h} c} 1.1^{(\Delta T(t))} \Delta t
$$

In the case of a $6^{\circ} \mathrm{C}$ temperature increase during the entire $t=1 \mathrm{~h}$ period of treatment, the metabolic addition is $\Delta T \leq 0.5^{\circ} \mathrm{C}$. Consequently, ignoring it is correct.

The beginning of the heating process is quasi-adiabatic, due to the relatively slow processes of the homeostatic feedback [108] [109]. This situation means that at the beginning of the heating, the energy entirely heats the target without other components of the energy balance.

$$
q_{0} \rho 1.1^{(\Delta T)}-c_{b} \rho_{b} w_{b}(T)(\Delta T)-k_{h} \nabla^{2} T \cong 0
$$

Hence the task at the start of the heating is to determine the slope of the starting curve from (15):

$$
\rho_{h} c \frac{\partial T}{\partial t} \approx \rho_{h} S A R \Rightarrow \frac{\Delta T}{\Delta t}=\frac{S A R}{c}
$$

This approximation is allowed up until it reaches the non-linearity shown in the curve, numerically calculated for the above data; see Figure 8.

The activation of the various feedback mechanisms, like the $B F$, the metabolic rate, and the heat-conduction, causes the curve to deviate from the linear slope. The variation of the forwarded power changes the curves, and the appropriate equilibrium temperature is shown in Figure 9.

The change of the $t_{0}$ self-time changes the shape of the heating curve, but the final temperature in equilibrium remains constant; see Figure 10. 


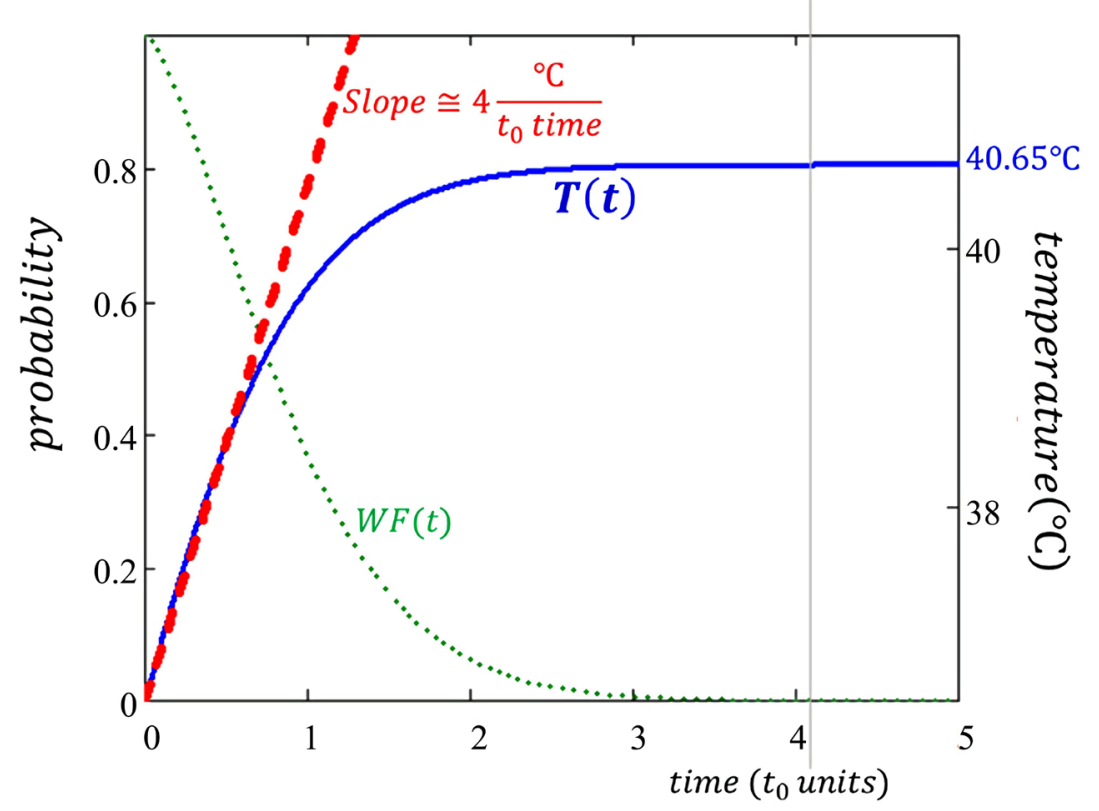

Figure 8. The linear slope of $T(t)$ at start (dashed line, right-hand axis). The temperature development of the tumour $m_{t}=0.595 \mathrm{~kg}$ calculated for $\operatorname{mEHT}$ ( $P_{\text {fwr }}=150 \mathrm{~W}$, $\left.P_{\text {refl }}=3 \mathrm{~W}(2 \%), \quad \eta=0.85\right)$. Other parameters in the calculation are in the text.

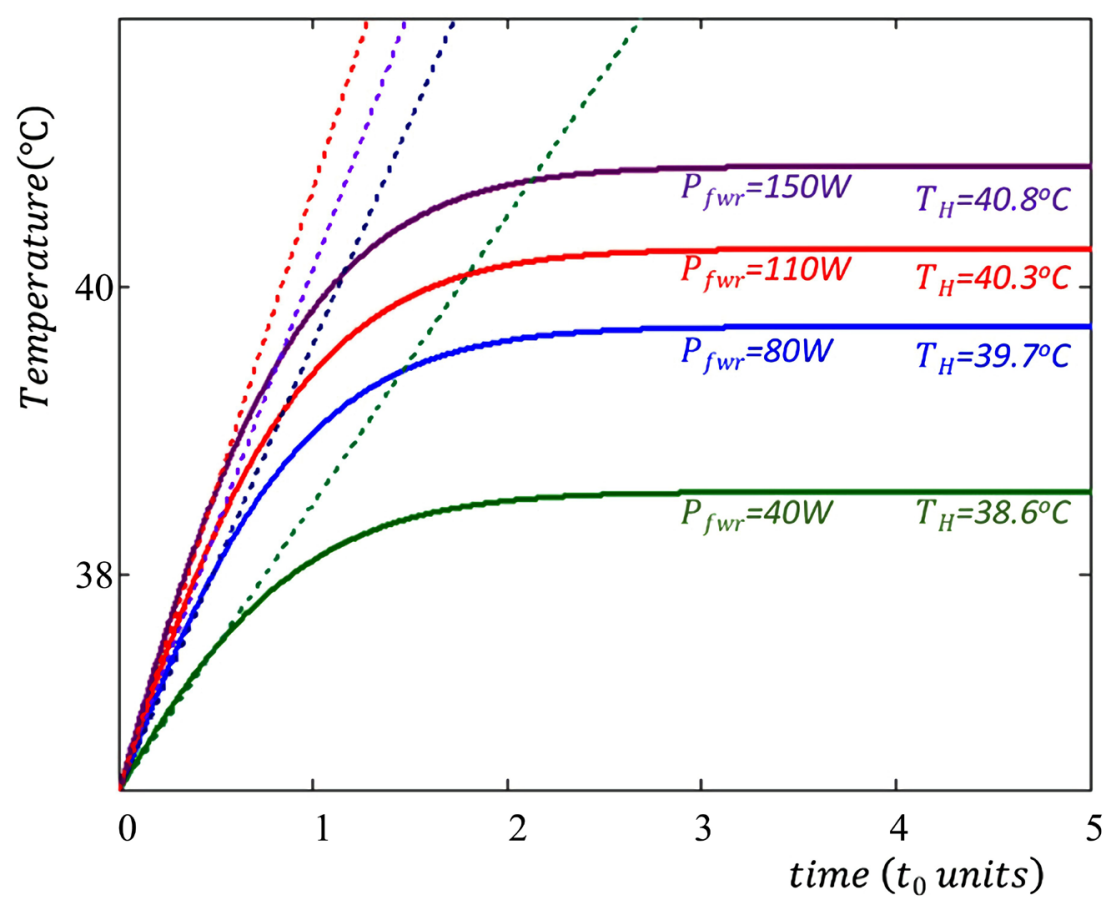

Figure 9. The temperature development (solid lines) of the tumour $m_{t}=0.595 \mathrm{~kg}$ by various forwarded powers, calculated for $\mathrm{mEHT}\left(P_{\text {refl }}=3 \mathrm{~W}(2 \%), \quad \eta=0.85\right.$ ). The slopes are shown (dashed line). Other parameters in the calculation are in the text.

The change of the $n$ shape-factor does not effect as robustly as the scale factor did; see Figure 11. 


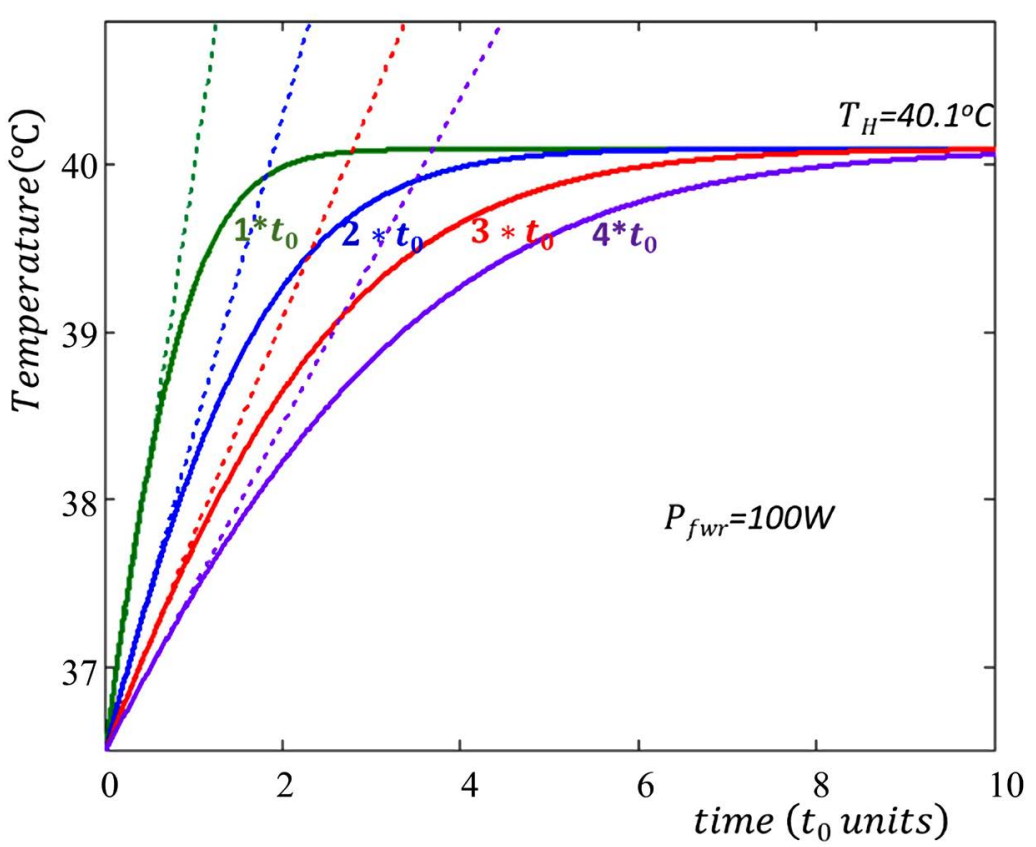

Figure 10. The temperature development (solid lines) of the tumour $m_{t}=0.595 \mathrm{~kg}$ by various time-constants, calculated for mEHT. ( $\left.P_{f w r}=100 \mathrm{~W}, P_{r e f l}=3 \mathrm{~W}(2 \%), \quad \eta=0.85\right)$. Other parameters in the calculation are in the text.

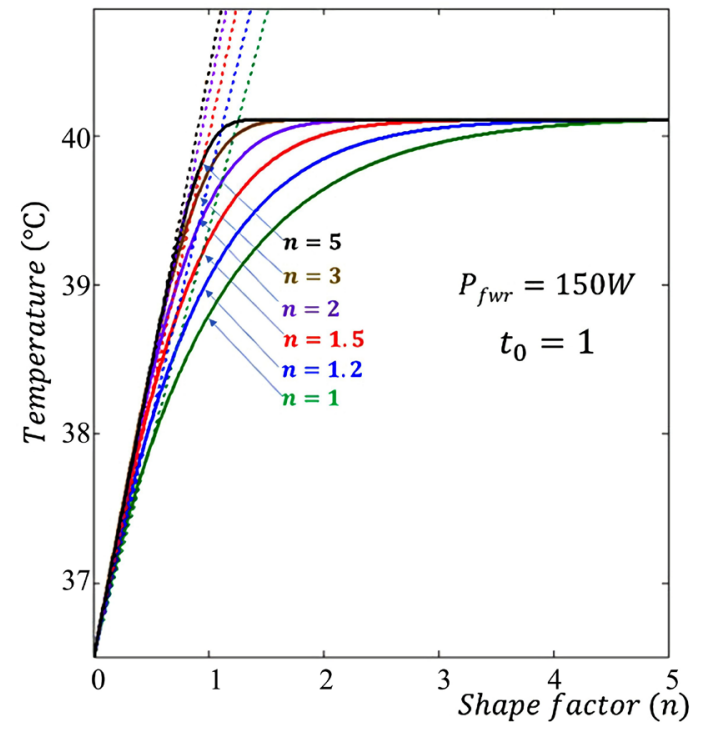

(a)

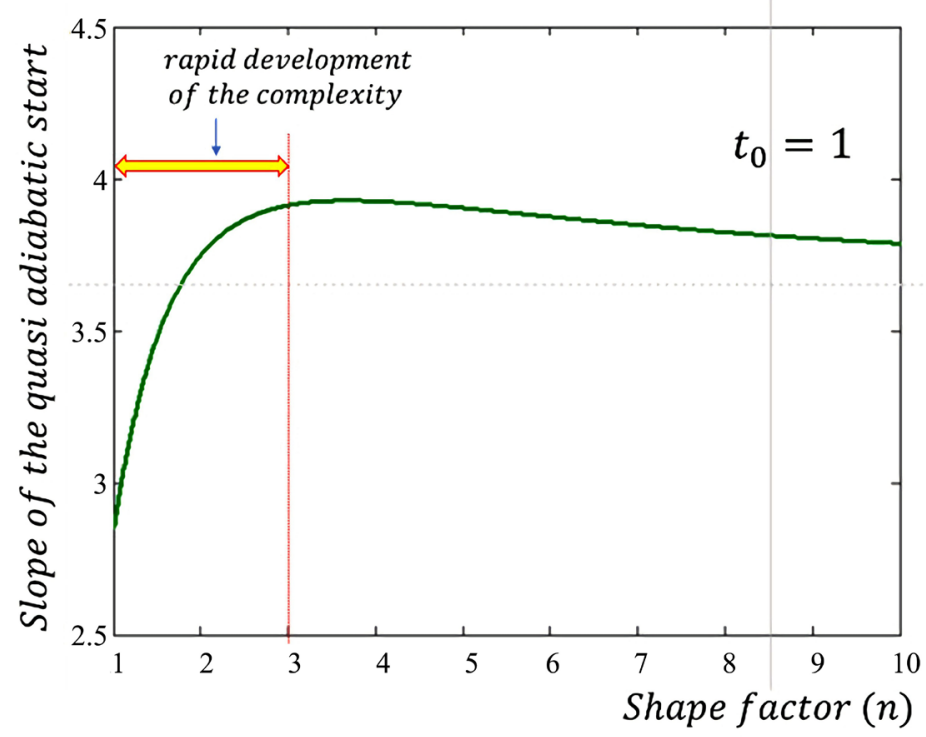

(b)

Figure 11. The effect of developing complexity by growing shape factor $n$ : (a) temperature development; (b) change to the starting, quasi adiabatic slope value by $n\left(P_{f w r}=150 \mathrm{~W}, P_{r e f l}=3 \mathrm{~W}(2 \%), \quad \eta=0.85\right)$.

The shape-factor $n$, which characterizes the complexity by (39), is distinguishable from the simple, single feedback mechanism $(n=1)$. While complexity develops ( $n$ increases) the adiabatic slope starts changing considerably in the $1 \leq n \leq 3$ interval, but afterwards the change is not considerable.

When the power is switched off, $S A R=0$, the system cools down as a result 
of its complex interactions, and Equation (11) reduces to the form where the complex interactions in (54) derive the change of the temperature:

$$
\rho_{h} c \frac{\partial T}{\partial t}=-c_{b} \rho_{b} w_{b}(T)(\Delta T)-k_{h} \nabla^{2} T+q_{0} \rho 1.1^{(\Delta T)}
$$

The washout time, driven by the $B F$, is different for thermal processes and the clearance of molecules (like radiofarmacons, tracers or blood-delivered molecules or particles). The main difference is in the mechanisms of diffusion, which are different for various blood-delivered particles or molecules and for heat. The thermal washout is also a complex process mainly driven by the $B F$, but not determined by it alone. In investigations of the clearance of tracers, it is clearly shown that in reality the clearance (wash-out) tightly depends on $B F$, but these parameters are not equal, instantaneous mixing with metabolic changes and diffusion breaking the unity. Also, the metabolic heat does not have a direct action on the clearance, while the thermal washout is directly modified by it.

A "similarity" can be observed in the washout of tracers [110], which is a rescaling of the time, showing similar scaling behaviour as we have seen in the heat-up process. The scaling of washout "similarity" is present in the wash-in of tracers as well [111]. An important observation in contrast material studies is that the enhancement of the contrast material decreases with temperature growth, while it increases with the thermal cooling coefficient; see Figure 12 [112]. The main message of this is that the high variability of the $B F$ by tumour entities, as well as the tumours having massively heterogenic $B F$, form a gradient from the centre to the periphery.

In most of the examinations, the diffusion and metabolic parts are neglected for simplicity, and the temperature dependence of the $B F$ not being considered, so the following equation remains to be investigated:

$$
\rho_{h} c \frac{\mathrm{d} T}{\mathrm{~d} t}=-c_{b} \rho_{b} w_{b}\left(T-T_{b o d y}\right)
$$

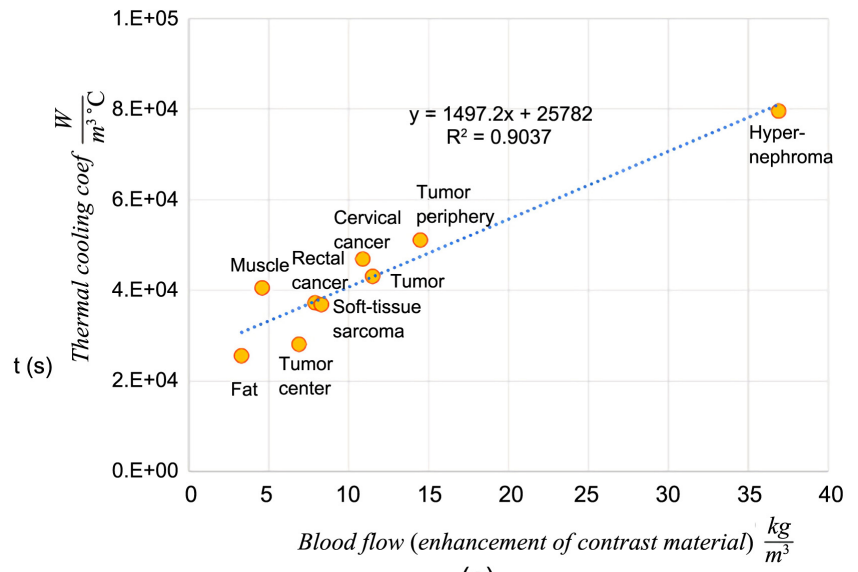

(a)

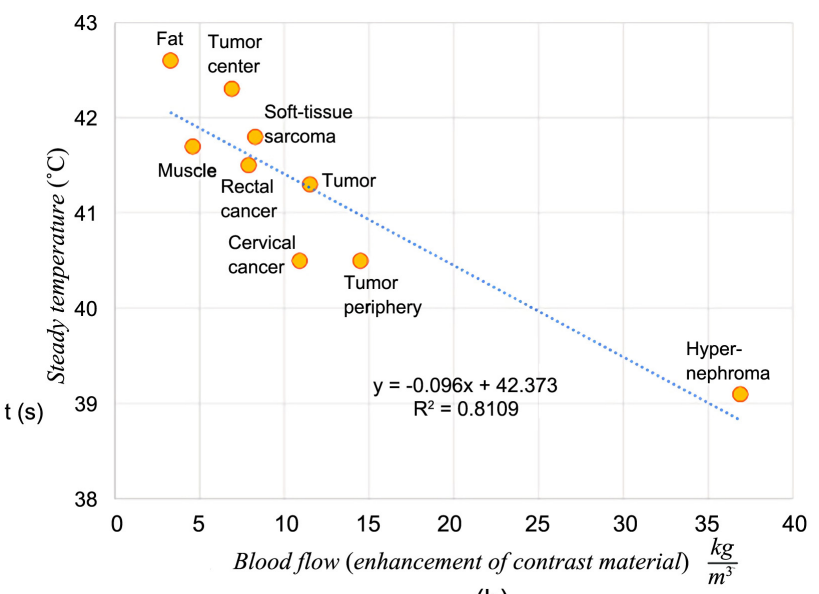

(b)

Figure 12. The effect of $B F$ on the thermal coefficient and the steady temperature measured in different tumours. It is important to note that the tumour-periphery has the highest $B F$. The $B F$ was measured with the concentration of the contrast material. 
The starting temperature is $T_{H}$ and so the analytical solution is exponential:

$$
T(t)=\left(T_{H}-T_{b o d y}\right) \mathrm{e}^{-\frac{t}{t_{0}}}+T_{b o d y} \text { where } t_{0}=\frac{c \rho_{h}}{c_{b} \rho_{b} w_{b}}
$$

It is a simple exponential equation, which is a special case of $W F$, when $n=1$. In general, neglecting the time-dependent metabolic addition, the thermal cooling is exponential; see Figure 13. The initial slope of the curve characterizes the quasi-adiabatic energy-take-off again, so it describes the given conditions determined by the blood flow.

The thermal washout (cooling rate) measurement validated Equation (57) in the given circumstances, and the guessed washout time, (when the $t=t_{0}$ ) is about $6.5 \mathrm{~min}$, cooling down from $42^{\circ} \mathrm{C}$ after $30-60 \mathrm{~min}$ microwave heating [113]. This approximation was made based on the measurement of the first 3 min, while the cooling to the $T_{b o d y}$ required a longer time. The washout depends on the measured tissue and other conditions; see Figure 14.

The time of thermal washout can be modified by changing the metabolic rate by lowering the temperature, causing a longer tail to the washout function in time. Consequently, with a longer $t_{0}^{\prime}>t_{0}$ the value will be added to the simple exponential, which depends on the decreased metabolism resulting from the cooling process. This additional effect will have a time-lag because of the actual physiological time of metabolic reaction. Due to the physiological self-time, which is approximated as the thermal washout physiological time, this time-lag will be nearly 6 min.

The thermal self-cooling mechanism also has complex behaviour, because it too depends only on the simple unchanged $B F$. The $B F$ depends on the temperature, as well as the heat-conduction, the surface cooling with the environment, and other physiological factors (like sweating, control by the hair, stress-status).

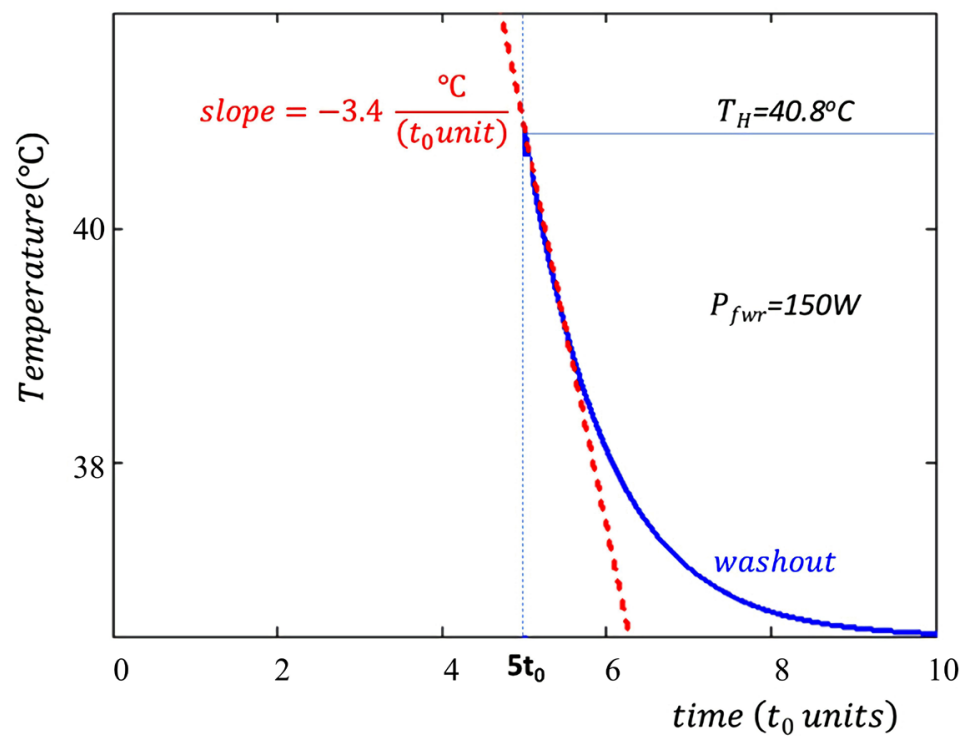

Figure 13. The exponential thermal cooling (washout) of the heated target (solid line). The quasi-adiabatic fit is shown (dashed line). 


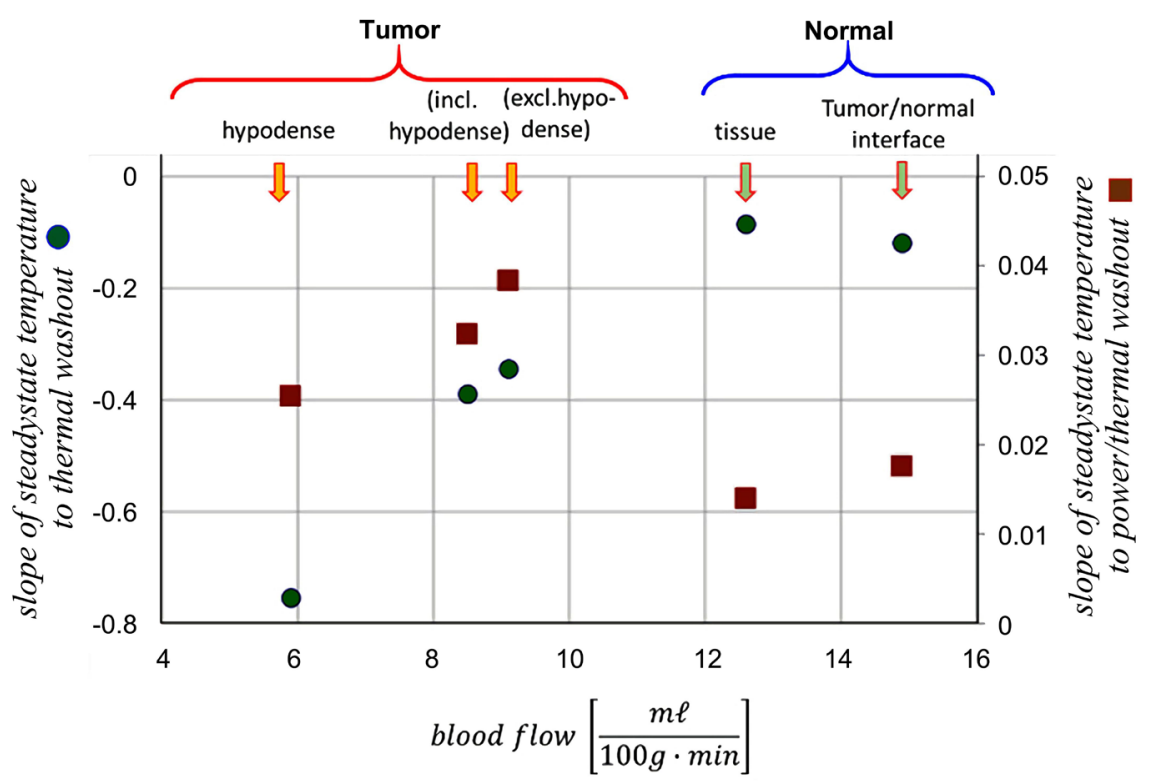

Figure 14. The slopes of the linear fit of the blood-flow vs the washout time of various tissues [117]. ( $\bullet$ slope of steady-state temperature vs thermal washout; - the slope of the steady-state temperature vs $\frac{\text { power }}{\text { theraml washout }}$.)

The decreasing temperature causes slower $B F$ and lessens the other regulatory actions off the cooling rate, so the cooling will have a longer tail than the exponential ( $W F n=1)$ alone. This complexity again induces the application of the integrative $W F$ instead of the simple exponential. The integral of $W F$ with the parameter $n>1$ is shown in Figure 15.

The complete heat-up and cool-down temperature development are shown in Figure 16. Both the heating and cooling have a quasi-adiabatic fit to the linear slope covering the curve for pretty long sections. Still, the slopes differ, due to the separate mechanisms and conditions. The heating starts from body temperature, while the cooling starts higher, from the homeostatic one. The conditions of the $B F$ and other factors change, which cause the deviations from linearity during the thermal processes. The heating linearity deviates by $S A R$-promoted intensified activities of $B F$, heat-diffusion, and metabolic rate, so the thermal conditions are forced by energy-absorption. In the cooling period, the system is alone, and with no constraints, the $B F$, the metabolic rate, and the temperature decrease. The heating has an $n>1$ condition, depending on the structure of the target, and the self-organized network, which absorbs the energy, while during cooling $n \approx 1$.

The curve changes characteristics with the applied $S A R$ values. Calculating the $S A R$ from the power situation, we have temperature curves for different applied power; see Figure 17.

\section{Discussion}

The original Pennes Equation (11) describes a non-equilibrial heat-flow when 


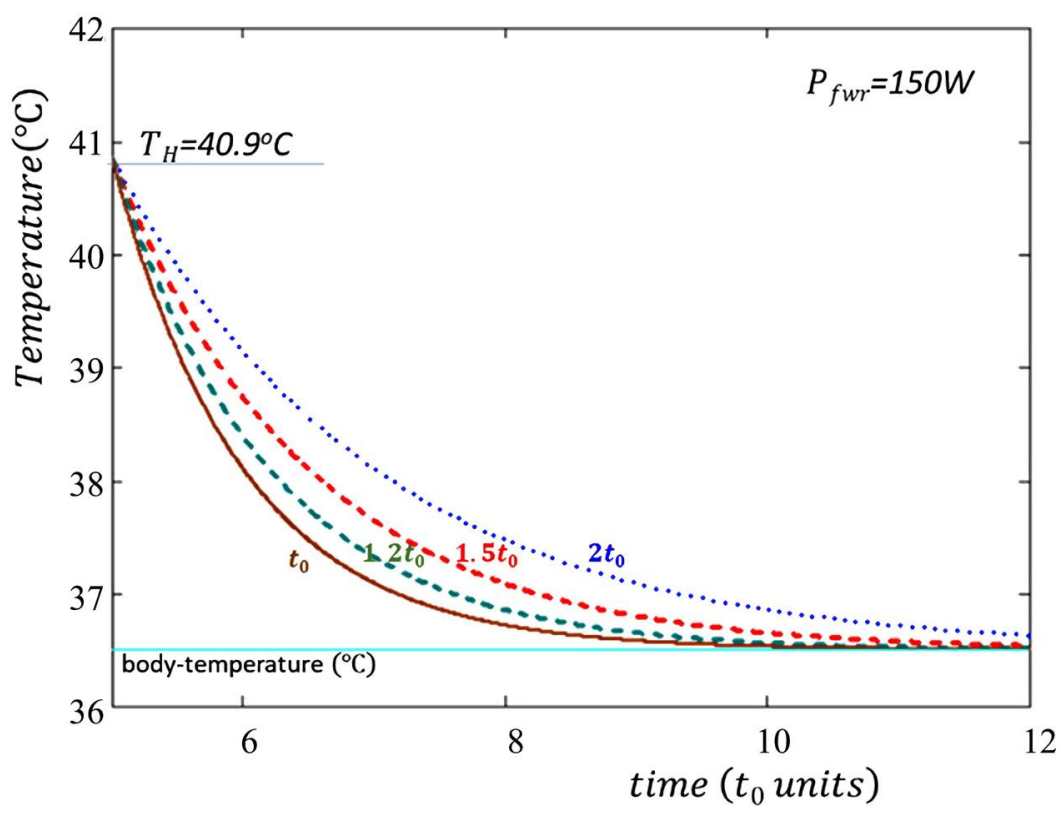

Figure 15. The long-tail washout function due to the complexity of cooling.

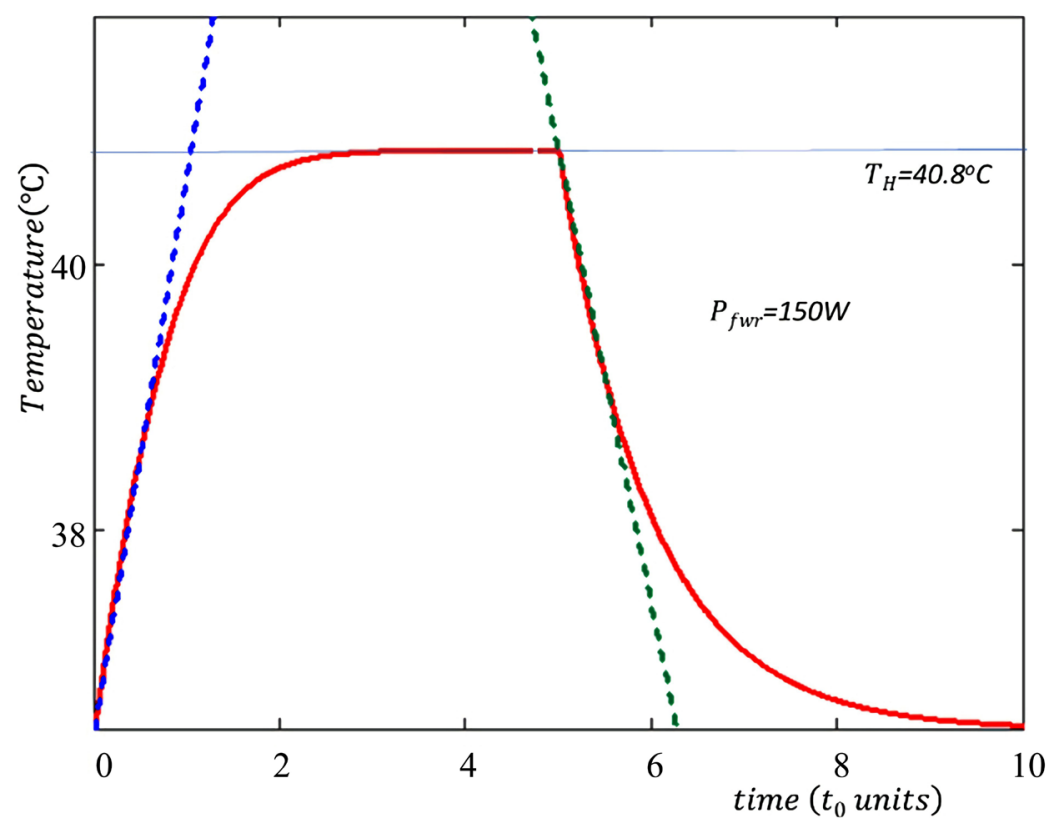

Figure 16. The complete temperature history of heating and the self-cooling by thermal homeostasis after the switching off of power-absorption.

the temperature is the only driving force, and the parameters are constants, independent of the temperature. The temperature definition supposes a system in which the participating units are independent, and only their mechanical energy changes by growing energy-intake. This has a temperature distribution [114], and supposes no interactions between the participating units (called an ideal gas). The Pennes equation is correct and usable, since the internal energy depends exclusively on the temperature, for which numerous model-calculations have been 


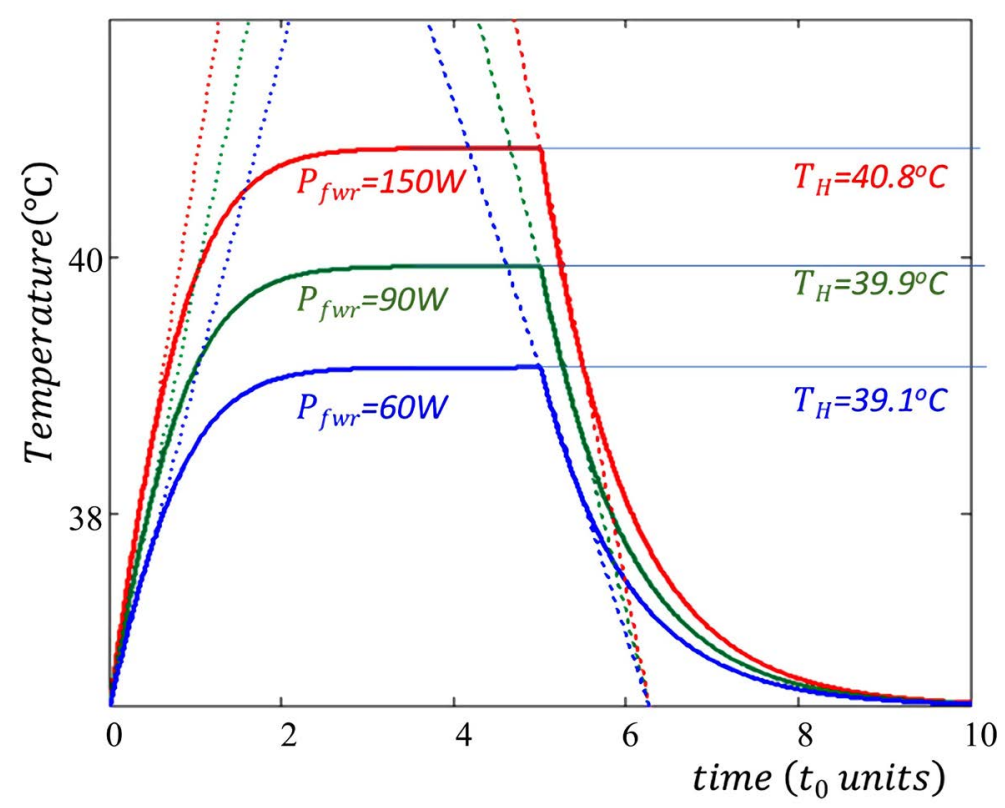

Figure 17. The temperature development by the applied power.

provided [115] [116] [117] [118]. To tackle time-dependent transient problems, some solutions have been published [39] [119].

Nevertheless, in reality, these are temperature-dependent values, and furthermore, their temperature functions are non-linear due to their complexly interconnected functions. The non-linear complexity of homeostasis is a game-changer for the discussion of (11).

Naturally, living objects are not such systems. Interactions with homeostatic functions must be considered, modifying the energy distribution in the heated matter. This type of energy utilization is missing from the Pennes bioheat-equation, leading to the above application of $W F$ to represent the homeostatic complexity. The main basic constants, the $B F$, the densities, the specific heat values, the coefficient of the heat-diffusion and the metabolic rate represent the main constants in (11), but as a consequence of the homeostatic interactions, these parameters are also altered, which we denoted by the spatio-temporal functions in (15).

The complexity of the task is extended with the inhomogeneous breaks on the curves when phase transition happens. As a consequence of energy-induced structural changes, enzyme-assisted phase transitions are frequent in the homeostatic system. The massive number of these structural transitions (entropy changes in micro-environment of the molecules) gives us the possibility to handle them as a distribution, and we are again in the realm of the self-similarity self-ordering idea described by $W F$.

Hyperthermia in oncology is devoted to destroying the malignant cells as selectively as possible. The Weibull distribution is used with success for the self-organized malignancy in space and time [120]. Cancer breaks the network of normal cells. The cooperative harmony of the tissue changes to non-cooperative competitiveness. It forms a new complex structure non-linearly, far from ther- 
modynamic equilibrium, but also self-organized. It could be described as a dynamic phase transition from healthy to cancerous [121], described with a clear analogy to phase transitions in a lifeless phenomenon. The self-organized biological development of tumours intrinsically developing in a healthy environment, the tumour-development deriving from that environment and showing the universal law of growth [122] [123], $W(t)$ is preferred to describe malignant diseases too.

The heating not only effects the temperature growth but also naturally causes physical changes. The structure of the tissue will not remain the same as it was before. The structural rearrangements will be temperature-dependent, and also energy-consuming. When the energy causes the phase to change, the temperature does not change; only the structure changes. This is like when water is being heated and it reaches $100^{\circ} \mathrm{C}$, and for a period the system expends all its energy to turn the liquid to gas (structural transition), while the temperature does not change during this process. The process is naturally thermal, but the temperature does not change. When the structural rearrangement is complete, the temperature starts to rise again as the energy intake continues. A similar effect occurs with ionizing radiation therapy when we expect the breaking of the DNA strands, which absorbs energy. The energy which is not used for this bonding break causes an increase in temperature, which would be an adverse effect in radiation therapy.

Some special papers have been devoted to modifying the Pennes-like equations [124] [125] [126] [127], but none have yet to consider the energy used in the distortion of the actual arrangements. The energy could be used solely to bring about chemical changes (distortion of the molecules and restructuring of the arrangements) in oncological hyperthermia. The temperature will not be changed locally when the energy is consumed for structural change. The temperature is only a condition (when the change happens) but not a measure of the change itself. The Pennes equation could be generalized [128] considering the cellular destruction and the structural rearrangements [129].

The introduction of a $W F$ assisted solution offers the possibility to measure this structural change from the temperature development curve. The $W F$ as the velocity of temperature change (41) has a development which is described by the probability distribution function (PDF) as the derivative of the $W F$ which we used:

$$
\frac{\mathrm{d} v(t)}{\mathrm{d} t}=\frac{\mathrm{d} W(t)}{\mathrm{d} t}=W F_{P D F}(t)=\left[\begin{array}{ll}
\frac{n}{t_{0}}\left(\frac{t}{t_{0}}\right)^{n-1} \mathrm{e}^{-\left(\frac{t}{t_{0}}\right)^{n}} & \text { if } t \geq 0 \\
0 & \text { if } t<0
\end{array}\right.
$$

First, the velocity changes very rapidly and then, after a peak, it decreases; with homeostatic control, the reaction of the body activates (Figure 18). This distribution determines the change of temperature (the WF function), which determines the temperature curve (the $T(t)$ function), as shown in Figure 7. 


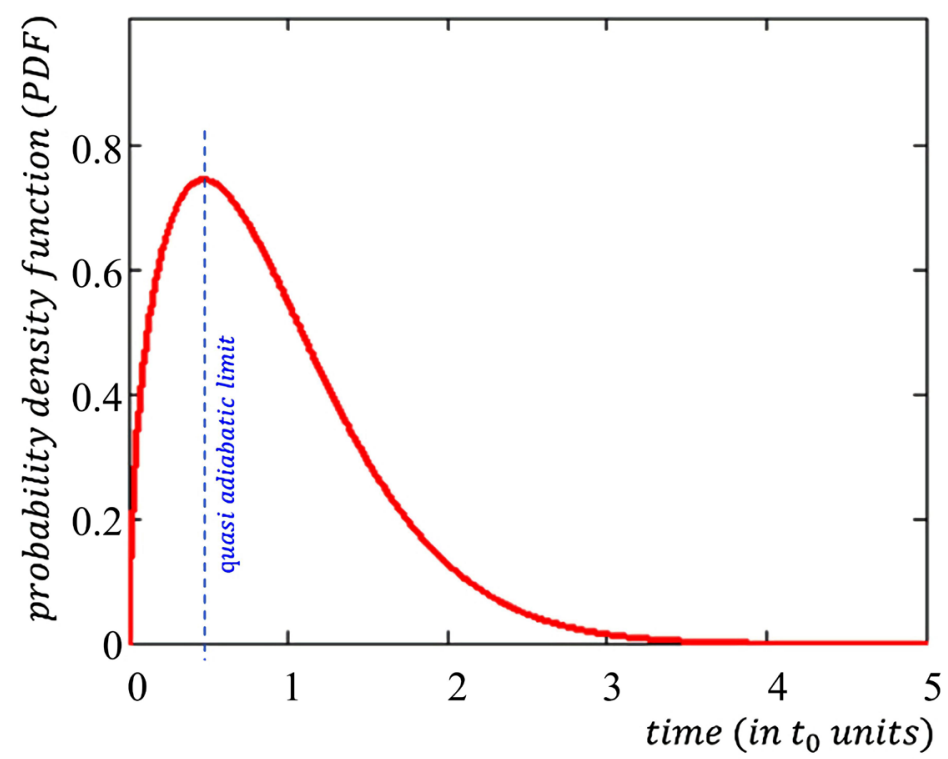

Figure 18. The power-density function of $W F$. The maximum of the PDF curve is the approximate limit of the quasi adiabatic heating (see text).

The PDF curve shows the change in velocity of the temperature growth. The curve starts with the rapid increase in temperature until reaching its peak. The comparatively very rapid growth could be considered the quasi-adiabatic process, which determines the starting slope in Figure 8, and so determines the certainty of the slope.

A simple approach of $W F$ parameters could be obtained from the measured temperature plot by time [130]. Two helpful points have to be noted, as shown in Figure 19. The point $x_{m}$ marks the highest point where the linear fit of the quasi-adiabatic slope $\left(\frac{\Delta T}{\Delta t}\right)$ follows the measured curve, and $x_{H}$ is determined by the point at which the temperature reaches a steady state (homeostatic equilibrium). These are measured in real-time (in seconds), and are different of course for tumorous and for healthy plots, which are denoted by the additional subscripts $t$ and $h$, respectively. We show these values in Figure 19.

The $x_{m}$ point fits the mode of the distribution function because it corresponds to the peak of the change of velocity (Figure 18), while the $x_{H}$ point denotes when the $W F$ decreased to below an error value, which we decide on as $1 \%$. Recognizing these values, we get:

$$
x_{m}=t_{0}\left(\frac{n-1}{n}\right)^{1 / n} \text { and } x_{H}=t_{0} \exp \left(\frac{\ln (-\ln (0.01))}{n}\right)
$$

Both parameters of the original $W F$ could be determined from the two equations of (59). In doing this, we are able to use the original $t_{0}$ units for exact evaluations. Note, $x_{H}$ marks a point from the stochastic approach, which was denoted by $\theta$ at the introduction of the $W F$; see Figure 1. The difference seen in Figure 19 between the tumorous and healthy temperature plots follows the selectivity of 


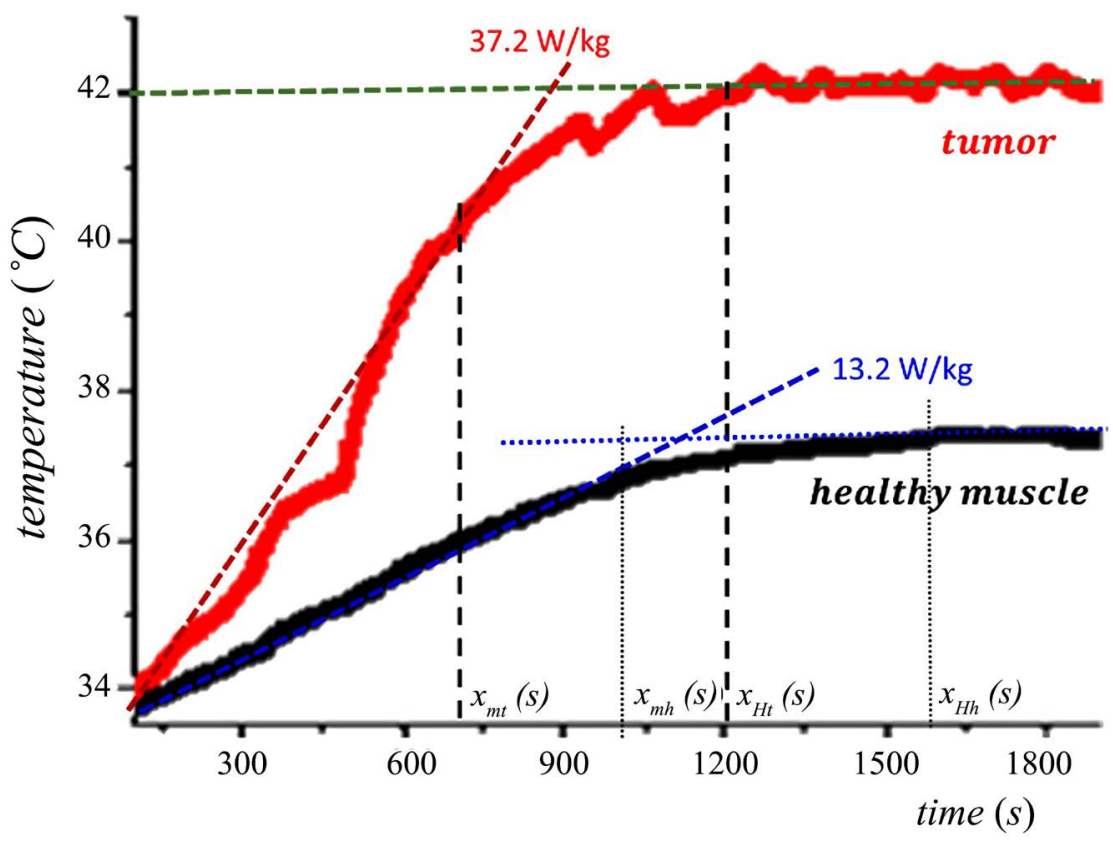

Figure 19. The measured temperature plot is a preclinical measurement [130].

the treatment, which can be quantified by the starting slopes as well as by the specific differences of the parameters $\left(x_{m t}-x_{m h}\right)$ and $\left(x_{H t}-x_{H h}\right)$.

The $t_{0}$ point can be determined by simple geometric fitting. We know that the value of $t_{0}$ is always at the point where $1 / \mathrm{e} \cong 0.368$, so having a slope with this value on the temperature plot determines the position of $t_{0}$, as shown in Figure 20. The angle of the specific slope which we use is 0.353 [rad] or $20.2^{\circ}$. This simple approximation directly determines the conversion of time to $t_{0}$. Note, the derivative of $W F$ at the $t_{0}$ point $\frac{\mathrm{d} W\left(t_{0}\right)}{\mathrm{d} t}=-\left(\frac{1}{\mathrm{e}}\right) \frac{n}{t_{0}} \cong-0.368 \frac{n}{t_{0}}$ differs by multiplication with $\frac{n}{t_{0}}$ from the same-point derivative of the temperature plot, $\frac{\mathrm{d} W\left(t_{0}\right)}{\mathrm{d} t}=-\left(\frac{1}{\mathrm{e}}\right) \frac{n}{t_{0}} \cong-0.368 \frac{n}{t_{0}}$.

The comparison of the results of Figure 10 and Figure 11 shows that the scale factor $t_{0}$ causes a massive change in the quasi-adiabatic starting slope, while the shape factor $n$ causes only a minor change. The difference mirrors their roles in homeostatic (homeodynamic) control: the $t_{0}$ scale factor depends on the dynamic processes in the regulation, principally on $B F$, while the $n$ shape factor primarily reflects the structural differences. In this way, the shape parameter follows one of the major factors of the complexity in the temperature development, the $B F$, which changes non-linearly with the temperature [131]. The non-Newtonian behaviour [132], and the flow-state, which can cause the negative impedance of $B F$ [133], alters the non-linearity by temperature. The difference in angiogenesis between the tumour and healthy vessel network [134] could also affect the temperature dependence of the $B F$. The attractive idea of our present approach is the 


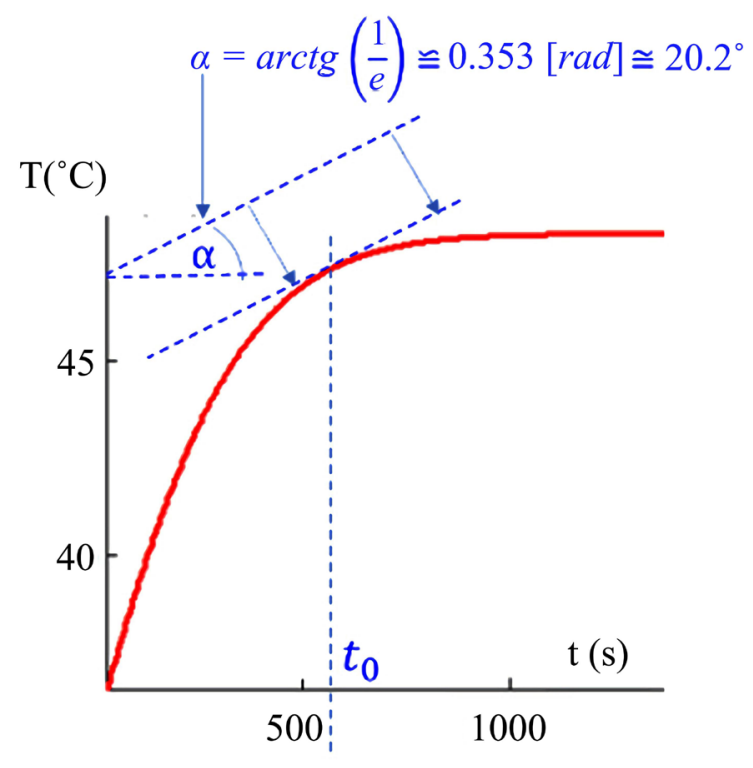

Figure 20. A simple geometric fitting to determine the $t_{0}$ unit (see text). Calculating with (59) could perfectly control this approximate fit.

stochastic considerations, so these effects are well presented in the personal differences in the heating reactions, which are considered in the personalized fit of $W F$ approach; the complex package in $W F$ considers all, even small, modifications.

The assumption is ordinarily that the temperature reaches the homeostatic state by a rigorously monotonic function. This could be incorrect, however, when the homeostatic control is achieved too late, or when it does not have enough cooling capacity to compensate for the heating energy [135]. When saturation occurs earlier than the negative physiological feedback to regulate it, an overshoot can happen, or an equilibrium may not be formed due to the massive energy input (Figure 21). The uncontrolled absorption leads to ablation. Such overshooting and ablation (burning) situations are beyond the possibilities of these present considerations. The complexity described by $W F$ is valid only in near stationary developments.

When phase transition does not occur (like when heating water from $0^{\circ} \mathrm{C}$ to $100^{\circ} \mathrm{C}$ at normal pressure), the temperature plot is linear across its full range, but keeping a constant temperature at the phase transition $\left(100^{\circ} \mathrm{C}\right)$ and then continuing linearly with another slope, corresponding to the thermal parameters of the new phase (Figure 22).

Note the development of the temperature in the case of heating pure water. Here a fraction of the power applied to humans in local hyperthermia could heat up the same mass of the water from $36^{\circ} \mathrm{C}$ to $45^{\circ} \mathrm{C}$ (Figure 23).

Living objects, of course, do not have the same behaviour as pure water. The water phantom is far from correct in comparison to a living reality. The water phantom is homogenous, having only non-homogenous heating due to the exponential decay of the electromagnetic energy-absorption by depth [136], which 


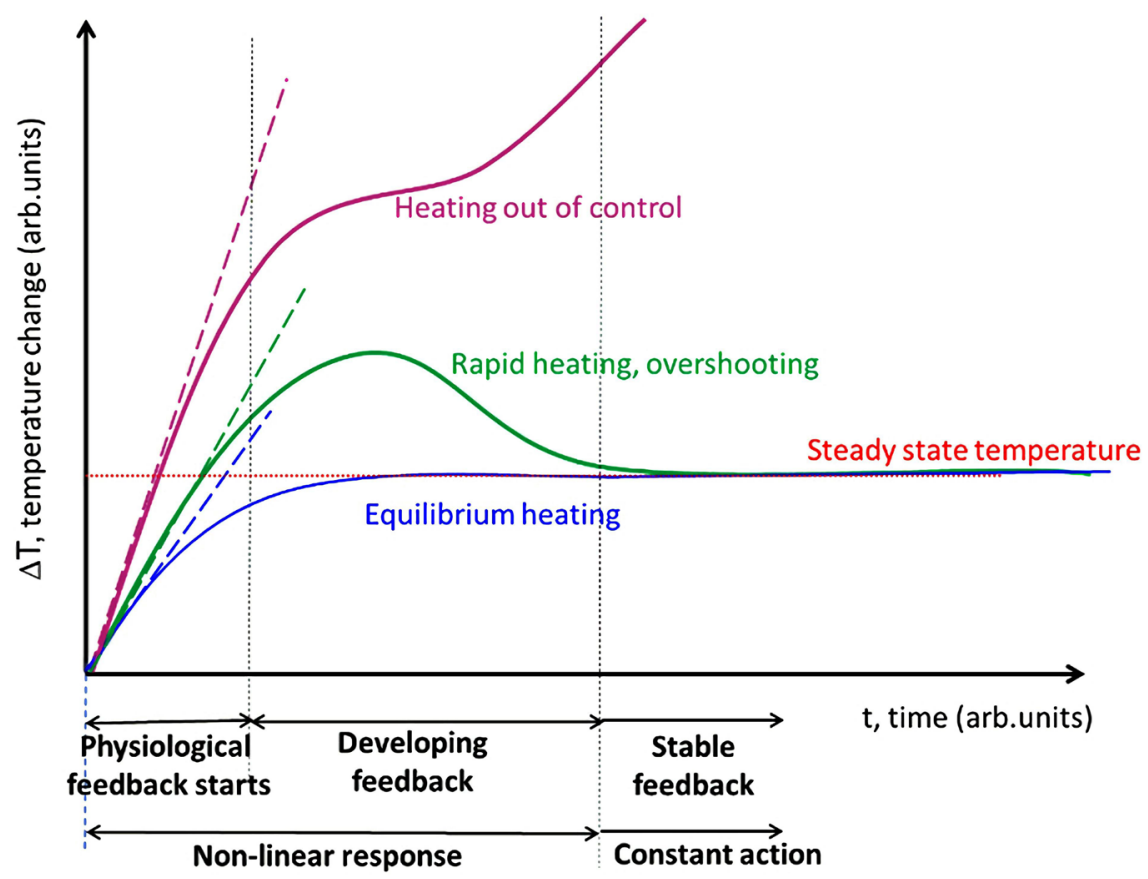

Figure 21. Relation of the absorbed energy to the homeostatic thermal regulation. The timing and the energy-compensation balance the actual shape of the temperature plot.

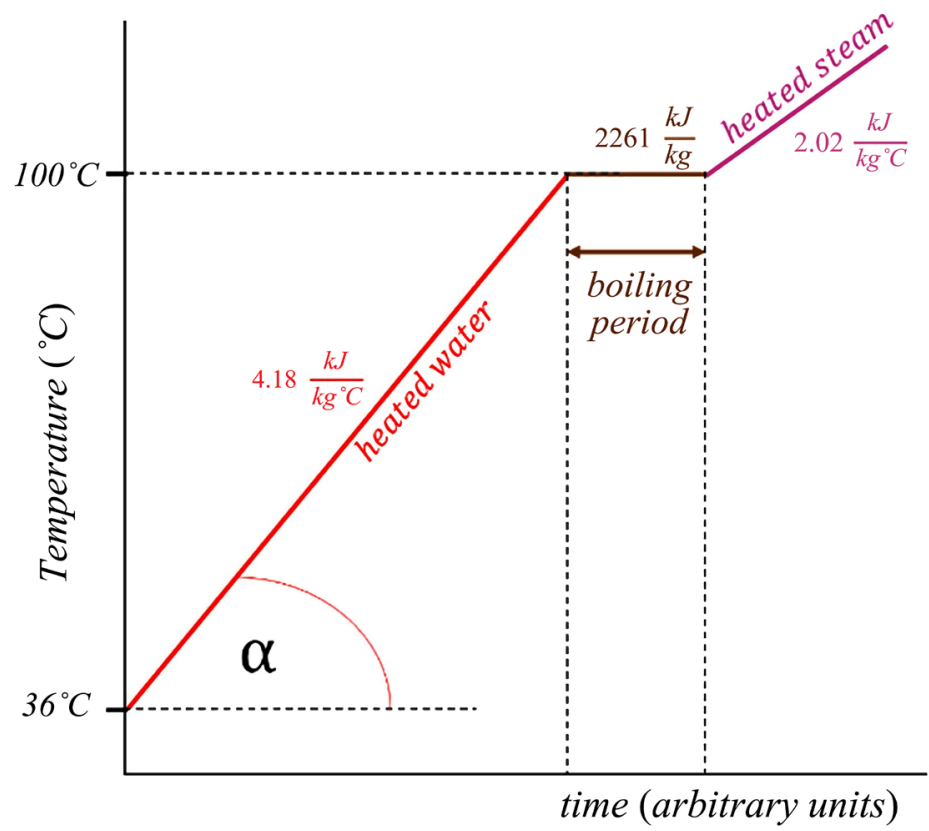

Figure 22. Heating of simple water phantom, temperature vs time. The phase transition at $100^{\circ} \mathrm{C}$ happens at a constant temperature, while the elapsed time develops.

may initialize mas-transports by temperature gradient in the volume. The exponential decay sharply, and inversely depends on the wavelength [137]. The attenuation of the power absorption of human tissues differs from water [138]; nevertheless, the penetration remains exponential with various rates of decrease in the variety of tissues. 


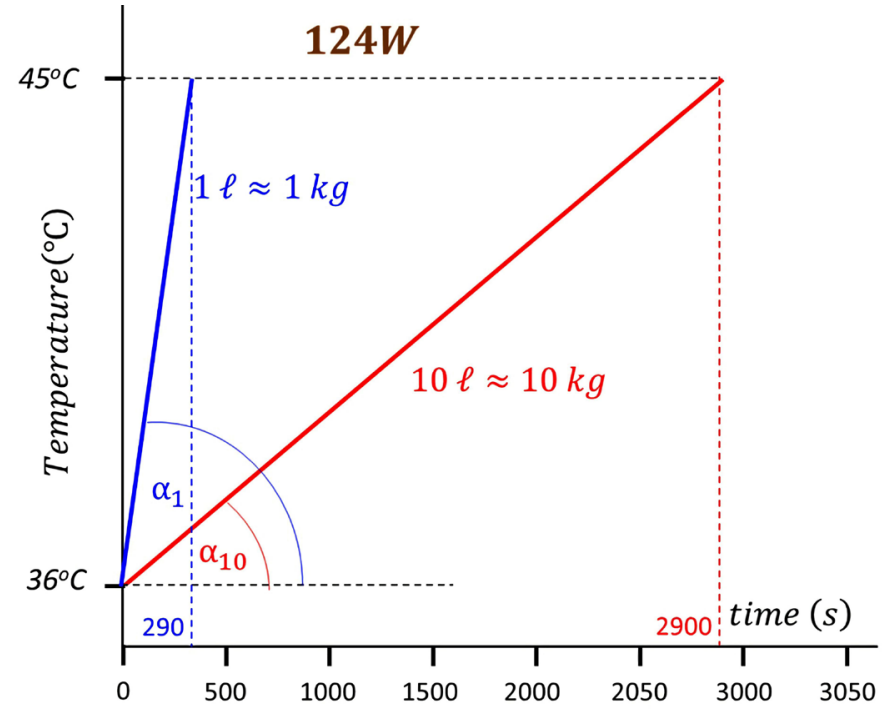

(a)

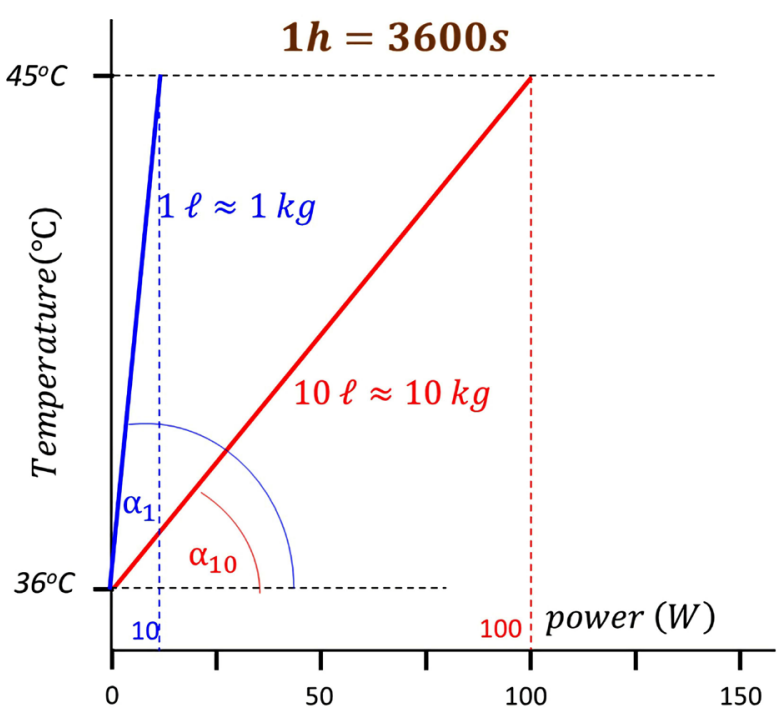

(b)

Figure 23. The heating of the water phantom only: (a) $124 \mathrm{~W}$ is applied (using $150 \mathrm{~W}$ forwarded but calculating $3 \%$ reflected power and $85 \%$ efficacy of heating) and heats up ten litres of water from $36^{\circ} \mathrm{C}$ to $45^{\circ} \mathrm{C}$ in a duration of less than an hour, while a volume of 1 litre needs only less than $5 \mathrm{~min}$; (b) ten litres of water reaches the desired $45^{\circ} \mathrm{C}$ within one hour with $100 \mathrm{~W}$ absorbed power, while one litre needs only $10 \mathrm{~W}$ to elevate the temperature from $36^{\circ} \mathrm{C}$ to $45^{\circ} \mathrm{C}$.

A living structure represents an inherent decisional heterogeneity, having a large number of electrolytes separated by various walls and membranes. Consequently, both the thermal and electromagnetic parameters vividly change in the macroscopic and microscopic ranges and the homogeneous $S A R$ is illusory. The self-organized structure drives the organization of the heterogeneity, forming fractal behaviour [139]. The self-organized self-similar structure present both in space and time [75], develops spatio-temporal behaviour of the tissues. The concentration of the electrolytes dynamically changes due to their energetically open structure, which initializes the dynamism of the system. The living dynamism performs random stationary stochastic self-organizing processes [74] [140] as a consequence of its self-similar stochastic behaviour. It fluctuates by a particular noise (called pink-noise, or temporal fractal noise) [141] [142], a fingerprint of the self-organizing [143], representing a general behaviour of living biomaterial [70].

Together with the macro heterogeneity, the tumour is also massively diverse on a microscopic level. The $B F$ in the tumour has a threshold between the vasodilation and vasoconstriction. The threshold depends on the temperature, and is usually at an interval between $39^{\circ} \mathrm{C}$ and $43^{\circ} \mathrm{C}$ [11]. The angio-change is independent of the general inhomogeneity of the tissue but depends on the type of the tumour and its stage. The angio-reaction will change the temperature development, due to the massive change of $B F$ from the vasodilated situation to the low- $B F$ vasoconstriction. The drop in $B F$ increases the temperature due to the lowered cooling capacity. The quasi-adiabatic slope jumps in the vasoconstrictive stage of the tumour, and the same $S A R$ generates a greater temperature development per unit time [135]. 
Further microscopic heterogeneity is observed on a molecular level. The structural disruption and rearrangements use a part of the energy without any considerable change of temperature. Where the energy concentrates on the structural order, the points on the temperature plot by time remain approximately at the same temperature values, despite the continuously absorbed $S A R$ accompanied by the approximately constant temperature as we expect during phase transitions. The $S A R$ at these points is dominantly consumed by the structural energy and not for the heating of the tumour's environment.

The heterogeneities influence temperature development, and such a linear temperature development, as we have in the case of water (Figure 23) is unrealistic in the human body. The macroscopic temperature is roughly like that seen in Figure 8, presenting a linear slope only at the beginning of the heating when the heat is not yet spreading intensively by diffusion, and the blood-flow regulation has a lag. However, the simple picture has a fine-structure depending on the dynamism of the heat-diffusion and the blood-flow and other regulating components like metabolism. The initial linear slope starts curving downwards, and after a maximum, the temperature decreases (Figure 24). The intensification of the blood-flow causes this "bump" in temperature and it is visible only when the time-lagging feedback appears at the end of the period of intensively rising temperature. Note, the break of the linearity could be earlier in preclinical measurements (see Figure 19), where the homeostatic reactions are quicker. The thermal homeostatic function keeps the temperature unchanged $\left(T_{H 2}\right)$ and is the first saturation period, where the vasodilatation/vasoconstriction transition balances approximately constant value in the tumour (see the tumour-curve up to $39^{\circ} \mathrm{C}$ in Figure 6), After this point, the temperature might stabilize at another level for a short time due to the balance $\left(T_{H 1}\right)$, or, if the homeostatic regulation cannot stabilize the equilibrium, it might start to grow continuously. The vasoconstriction could easily develop additional necrotic volumes lacking blood-flow regulation such that the temperature could grow in those regions rapidly. While the forwarded $S A R$ does not chage; its hetereogenic absorption changes, but varies from the temperature development primarily because of the heterogeneity of $B F$. The applied $S A R$ is constant, while the absorbed energy grows but not as rapidly as expected, because the blood-cooling takes energy away in the system. The energy absorption changes at the vasodilatation/vasoconstriction transition.

The homeostatic "bump" modifies the temperature development at all variations of the power, too (Figure 25), but the slope of the quasi-adiabatic linear-fit at the beginning does not change until the very slow temperature increase when the time-lag of the homeostatic control modifies the starting slope as well. We assume that the homeostatic cooling switches on smoothly by a Gaussian distribution and with an amplitude factor $A$ :

$$
\frac{A}{\sigma \sqrt{2 \pi}} \exp \left[-\left(\frac{t-\mu}{\sigma \sqrt{2}}\right)^{2}\right]
$$




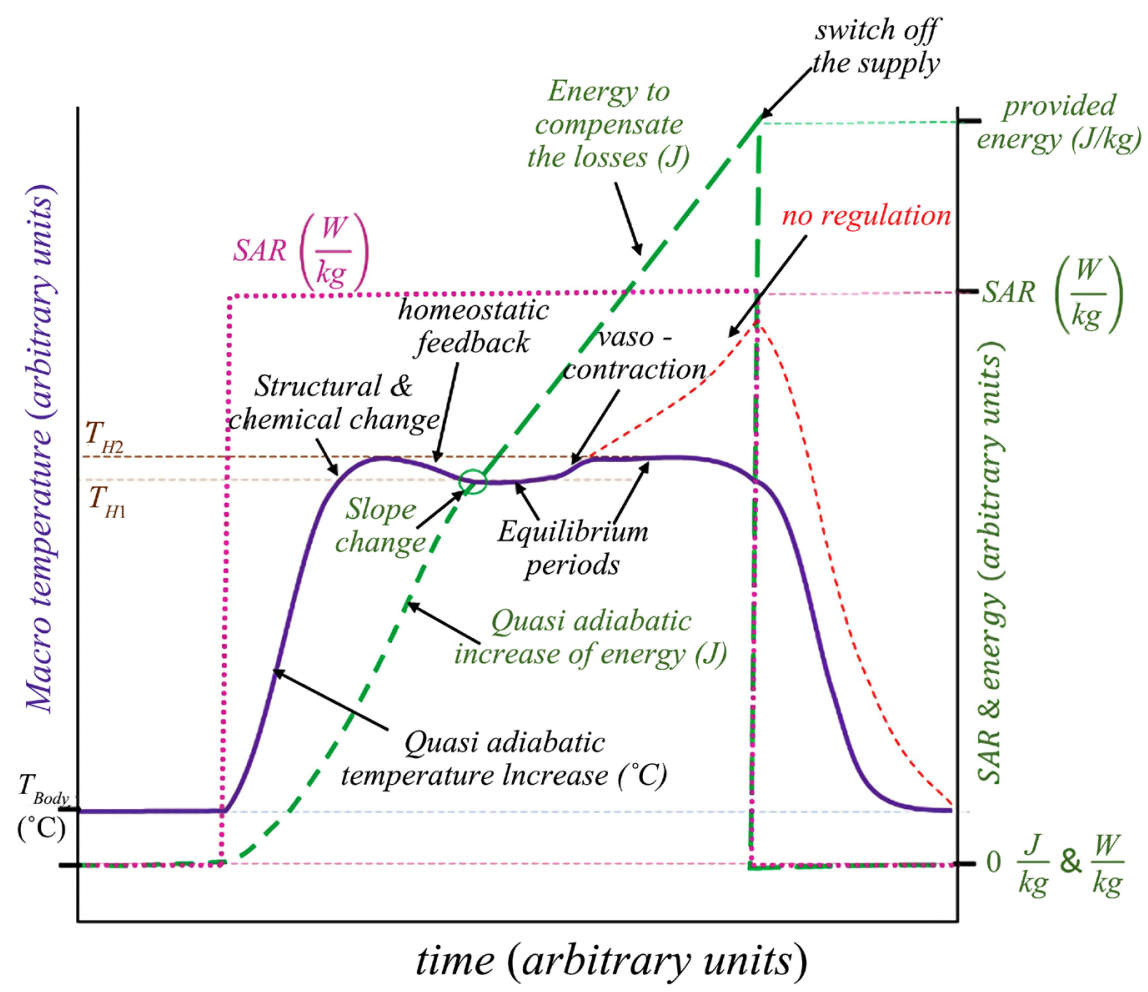

Figure 24. The possible fine structure of the development of temperature in macroscopic steps. The important factor of the figure is the time-lag of the various effects. Here all the possible effects are shown, not all of which will necessarily be active in the actual energy-absorption.

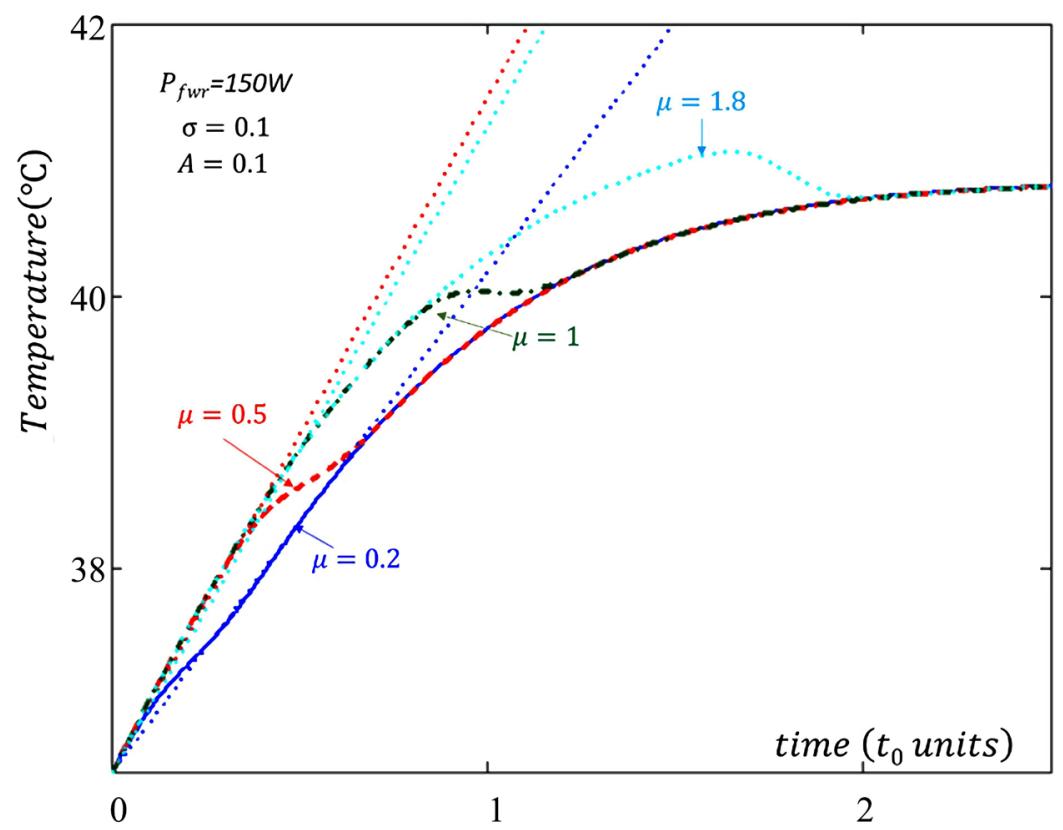

Figure 25. The homeostatic regulation could become active with different time-lags $\mu$.

which is equal with WF when $t_{0}=\sigma \sqrt{2}$ and $n=2$. The time-lag of the start of this feedback is included in the $\mu$, and the "smoothness" is in the $t_{0}$. The shape 
does not change, $n=2$. The time-lag $\mu=0.2$ shows an early homeostatic reaction, which regulation requires a high velocity of $B F$. In animal experiments where the heart-rate is higher than in humans, because of the allometric scaling, a short time-lag is frequent, as we see in preclinical experiments [130]; see Figure 19. Different time-lags have been used under various conditions in calculations [43].

The thermal and electromagnetic heterogeneity allow two different ways of handling the energy-absorption of the living material: make a complete average of the microscopic deviations, regarding this as equal in the target, or use the biophysical differences accepting the micro-variations to select the malignant cells. The first approach considers the entire volume in focus as being like homogeneous matter, and it is heated irrespective of the differences in the micro-environments, while the second one concentrates on malignant cells as the direct aim of the study. The two approaches fundamentally define the performance of the actual treatment. When the target is regarded as homogeneous, its full mass represents the energy-absorber, requesting such energy as is enough for this task. The micro-selection however demands much lower energy consumption, the intended target of the energy absorption being only a fraction of that in the homogeneous approach. The selection of the energy absorption specifies the efficacy of the actual treatment.

The isothermal, homogeneous heating of a local tumour does not reach stable thermal equilibrium, because the non-linear reaction of the feedback mechanisms opposes the heating action, so an instable equilibrium forms a steady-state situation. In this process, the target develops new thermal inhomogeneities, because the cooling action of the blood is not equally distributed in the volume of the focus. As a consequence, clinical practice divides patients into "heatable" or "non-heatable" categories [144]. The selection is based on the possibility of the temperature increase in the actual location by local/regional treatment failing to reach the desired temperature in the target. The "non-heatable" cases could have the same $S A R$ as the "heatable" ones, but their intensive homeostatic control blocks the marked temperature increase. We have to accept the real situation: the technical difficulty of the focussing of temperature is not identical with that of the focussing of $S A R$. The temperature depends on various processes, and naturally changes by elapsed time, spreading over the neighbouring volume.

The final goal of the energy-absorption is not a simple heating; the intention is to destroy the malignancy. Naturally, chemical and structural changes happen in the process of the cell dying. An overall, isothermal heating could complete this task, pumping much more energy into the target than necessary for the elimination of the cancer cells, heating up all the parts, even those which trigger the counter-actions of the thermal control. The isothermal approach requires extra energy to compensate for the forced physio-regulation attempting to restore thermal homeostasis. The homogeneous heating induces intensive BF and so risks the development of life-threatening micro and macrometastases, by the in- 
tensification of the delivery of the circulating tumour cells, worsening the life-prognosis. Multiple isothermal hyperthermia studies have shown effective and significant local control of the treated tumour, but at the same time present a decreased overall survival among others for breast carcinoma [145] [146], for non-small-cell lung cancer [147] [148], for uterine cervix cancer [149] [150], and even for the easily "heatable" surface tumours [151].

However, the thermal and electronic parameters differ between the tumour and the healthy environment, allowing the microscopic selection of biophysical origin. The variation of these parameters modifies the macro and microstructures of the tissue, varying the heterogeneity of the energy absorption. Malignant cells metabolize intensively, supporting their proliferation [152]. Their increased glucose metabolism can be measured by positron emission tomography (PET) [153]. The extra metabolic activity increases the ionic concentration in the vicinity, increasing the conductivity of that region [154], also detectable by imaging [155]. The changing of the networking arrangement microscopically causes the loss of the healthy cooperative connections with neighbouring cells, constructing a largely different fractal structure [156]. The malignant cells break their intercellular bonds [157] and junctions [158], and individually "combat" all other cells for metabolic energy. Measurement of the growing disorder in cancer came with the first imaging of a lesion [159], proving the increase of the dielectric constant in the microenvironment of the cells [160]. This decreases the complex electric impedance of the microenvironment of the tumour cells, channeling the radiofrequency $(R F)$ current to their location [161], allowing their selection by electromagnetic means [162].

The energy of the current primarily heats up the lipid rafts on the membrane of the cancer cells [163]. The membrane rafts are groups of clustered transmembrane proteins fixed by lipid-protein interactions [164]. A dominant part of the transmembrane proteins is clustered in raft domains. The rafts collect dynamic proteins [165], and have high lateral mobility in the membrane [166]. The size of these clusters is in the nano-range; depending on the ratio of protein to lipid content, different ranges of their horizontal diameters have been measured: 10 $100 \mathrm{~nm}$ [167]; 25 - $700 \mathrm{~nm}$ [168]; 100 - $200 \mathrm{~nm}$ [169]. The width of the membrane is $5 \mathrm{~nm}$ [170], but the thickness of rafts, due to their transmembrane proteins, is larger. An interesting result [216] is that the temperature increase of the nanoparticle is proportional to the square of its radius, which gives an easy comparison of the temperature using the sizes of the particles. The size of rafts is $6-50 \mathrm{~nm}$, and the large rafts dominate the protein content of the membrane [171]. The malignant cells lose their intercellular connections, and the formerly connected transmembrane proteins form rafts, which are significantly denser in the membrane of cancer-cells than in their noncancerous counterparts [172].

The extracellular matrix (ECM) and the cellular membrane absorb the main part of the energy in the $\mathrm{MHz}$ region of $R F$ [173]. The water content of the ECM interacts with the membrane [174], having variant bonds [175], and importantly 
alters the membrane effect, showing a low $S A R$ but high voltage drop [176], which can help the signal's excitation of the raft proteins [177]. The electrostatic charge of the membrane attracts the ions from the ECM, the effect of which is sufficient to establish a transmembrane potential [178].

The primary targets to absorb the well-chosen $R F$ on the membrane of the selected malignant cells are the transmembrane proteins located in the rafts. The $\beta / \delta$ frequency dispersion [179] promotes the focusing of the energy on the lipid-protein interactions at the applied $10^{7} \mathrm{~Hz}$ frequency range. Nearly ten times higher conductivity was measured at transmembrane proteins [180]. Models of added protein domains with different concentrations in the lipid layer showed between one and three orders of magnitude higher conductivity in the presence of protein fractions than the lipid membrane alone [181]. These electric impedance differences guide the $R F$ to the rafts [182]. The thermal effect is limited to nanoscopic local "points", the rafts, which are most sensitive to any lethal attack on malignant cells, which is the basis of the mEHT method. The well-chosen $R F$ current [183] uses a $13.56 \mathrm{MHz}$ carrier frequency according to the medical standards. An appropriate time-fractal modulation is applied [184], which is essential to obtaining the proper selection effect. (The technical description can be found elsewhere [185] [186]). In this way, mEHT targets the lipid-protein interactions that can cause specific energy-absorption in the membrane rafts, which carry many signal-receptors and are involved in multiple functional signal pathways [182].

Many observations have been made on various electromagnetic energy-absorptions, aside from those regarding temperature changes. The electric field promotes cellular fusion at low [187], and high [188] frequencies; a field-strength-dependent haemolytic effect has been observed resulting from RF exposure [189], as has the activation of ion-channels at the cellular membrane [190], membrane-mediated $\mathrm{Ca}^{2+}$ signalling effects on the immune system [191], and the induction of transmembrane $\mathrm{Ca}^{2+}$ by alternating current (low-frequency electromagnetic fields [LFEMF]) [192]. The biological effects of LFEMF have raised significant interest and debate in the past. Numerous reviews [193] [194] and articles report the responses of biological matter to LFEMF [195]-[203]. These observations realize the entropy change (structural and chemical alterations), which due to the energy absorption, are clearly thermal, but the temperature is only a condition and does not change during the process [204].

The strength of electric field $\Xi(t)$ determines the energy delivery by the electromagnetic energy supplies, and determines the $S A R$ in the media of $\rho$ density and $\sigma$ conductivity (assuming homogeneous target):

$$
\operatorname{SAR}(t)=\frac{\sigma}{2 \rho} \Xi(t)^{2}\left[\frac{\mathrm{W}}{\mathrm{kg}}\right]
$$

Note, the $\sigma$ thermal conductivity varies non-linearly by temperature [205]. Radiating the homogeneous resistive media with $R$ resistance by $P$ power, and 
the thickness of the target being $d$, we may calculate the $\Xi(t)$ field:

$$
\Xi(t)=\frac{\sqrt{R \cdot P}}{d}\left[\frac{\mathrm{V}}{\mathrm{m}}\right]
$$

If the energy delivery is sinusoidal, the average of the $\langle\Xi\rangle=\frac{\Xi}{\sqrt{2}}$, so the effective electric field is:

$$
\Xi_{\text {eff }}(t)=\frac{\sqrt{R \cdot P}}{d \sqrt{2}}
$$

when the target resistance is $R=50 \Omega$, and the applied power is $P=150 \mathrm{~W}$, and $\sigma=0.75 \mathrm{~S} / \mathrm{m}=1 / \Omega \cdot \mathrm{m}$, the $S A R$ from (61) and (62) is:

$$
S A R(t)=\frac{\sigma}{2 \rho} \frac{R \cdot P}{d} \cong 45\left[\frac{\mathrm{W}}{\mathrm{kg}}\right]
$$

The provided energy inversely depends on the mass of the target and linearly by the duration of the $S A R$. For example, the energy in ablation techniques to gain high temperature needs extremely high $S A R$ (in the range of $10-100$ $\mathrm{kW} / \mathrm{kg}$ [206]), but it targets only a relatively small mass, so the absorbed energy is small. Local hyperthermia with isothermal intent uses a relatively large $S A R$ compared to the selective method, to heat the mass as homogeneously as possible. However, these treatments can create unwanted hot-spots [207] depending on the technical realization and the actual conditions of the patient, causing very frequent complaints during the treatment [208].

In heterogenic matter, when we select the absorption target inside the volume, and the mass ratio of the selected mass $m$ to the total $M$ is $\xi$, the $S A R$ concentrates on the selected part with a value of $\xi=\frac{m}{M}$ higher. So when nanoparticles (NPs) are chosen there, and its concentration is a $50 \mathrm{mg}$ mass in $1 \mathrm{~kg}$, the corresponding SAR in our numerical example (65) is $S A R_{\text {nano }} \cong 1.8 \times 10^{5} \frac{\mathrm{W}}{\mathrm{kg}}=180 \frac{\mathrm{kW}}{\mathrm{kg}}$, and when the energy pump is sinusoidally periodic, according to (63) it becomes halved: $90 \mathrm{~kW} / \mathrm{kg}$.

Usually, the $S A R$ value in nano-heating is even higher, ranging from 100 to $500 \mathrm{~kW} / \mathrm{kg}$ [209]. These values are 1000 times higher than local hyperthermia uses but correspond well with the absorbed power in a nano-selective heating solution of membrane rafts.

The mEHT method could be used to heat injected artificial nanoparticles together with exciting the intrinsic membrane rafts. When injecting gold nanoparticles in the tissue the energy absorption is focused on both nano-centres, and the temperature grows by the diffuse heating from these [210]. However, the apoptotic cell-distortion, which is the hallmark of mEHT action, was decreased, probably because of the sharing of the energy between the membrane rafts and the gold nanoparticles; however, the heating was active in both situations. 
The selective heating of mEHT uses the membrane's peculiarities for the excitation of the transmembrane proteins by energy absorption of the chosen cells. The absorbed energy at the membrane sharply depends on the electric field conditions in the membrane and its immediate vicinity. The double phospholipid membrane structure modifies the applied electric field. The temperature gradient is one of the driving forces of the signal propagation that starts at the outer membrane of the cell as extrinsic excitation. The excitation requires energy absorption and changes the molecular structure, involving the bound water. The effects cause thermal changes, but not in a temperature-dependent manner [128] [211]. The action is like a first-order phase transition with latent energy exchange at constant (transition) temperature.

The absorbed bound water on the membrane has an important role in the $S A R$ and electric field distribution [176]. The modification distinguishes the intra- and extracellular electrolytes and the membrane itself, as well as the outer and inner sides of the membrane water-absorption layer [176]; see Figure 26.

Heating of the transmembrane protein clusters (rafts) shows different patterns than in the phospholipid membrane [182]. The water bound to the protein increases the altogether otherwise high average dielectric constant of the raft [212]. A precise model calculation [182] shows the electric loss density jump on the raft (Figure 27) with a rapid change on the membrane surfaces on both sides. Two calculations were made: in the homogenous approach the two sides of the raft

(a)

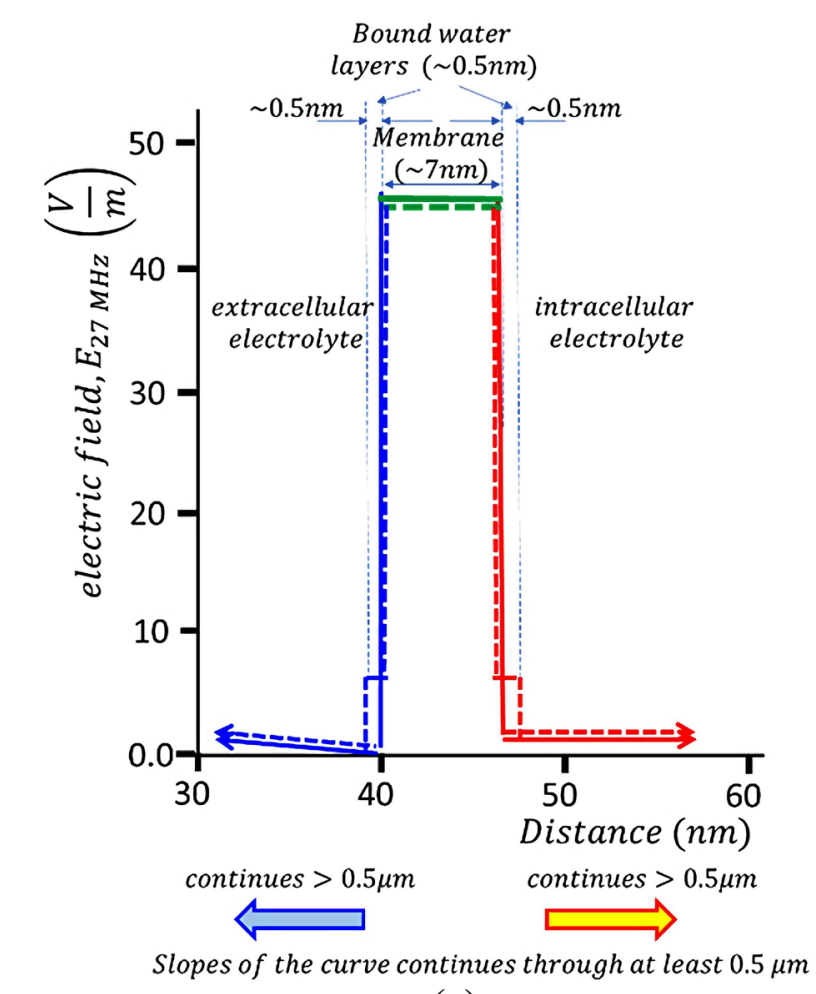

Figure 26. Comparison of the free membrane (solid lines) and membrane-bounded water (dashed line) electric field (a) and the $S A R$ (b) at $27 \mathrm{MHz}$ in spherical cell-model (It is modified to same scales from [176]).

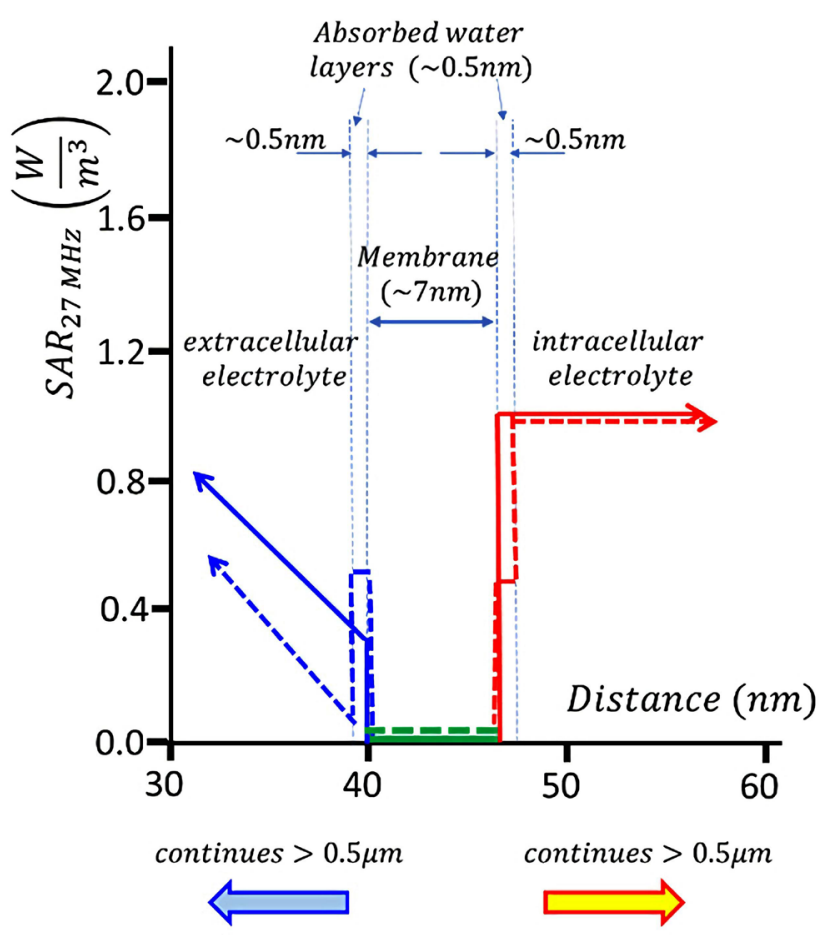

Slopes of the curve continues through at least $0.5 \mu \mathrm{m}$ (b) 


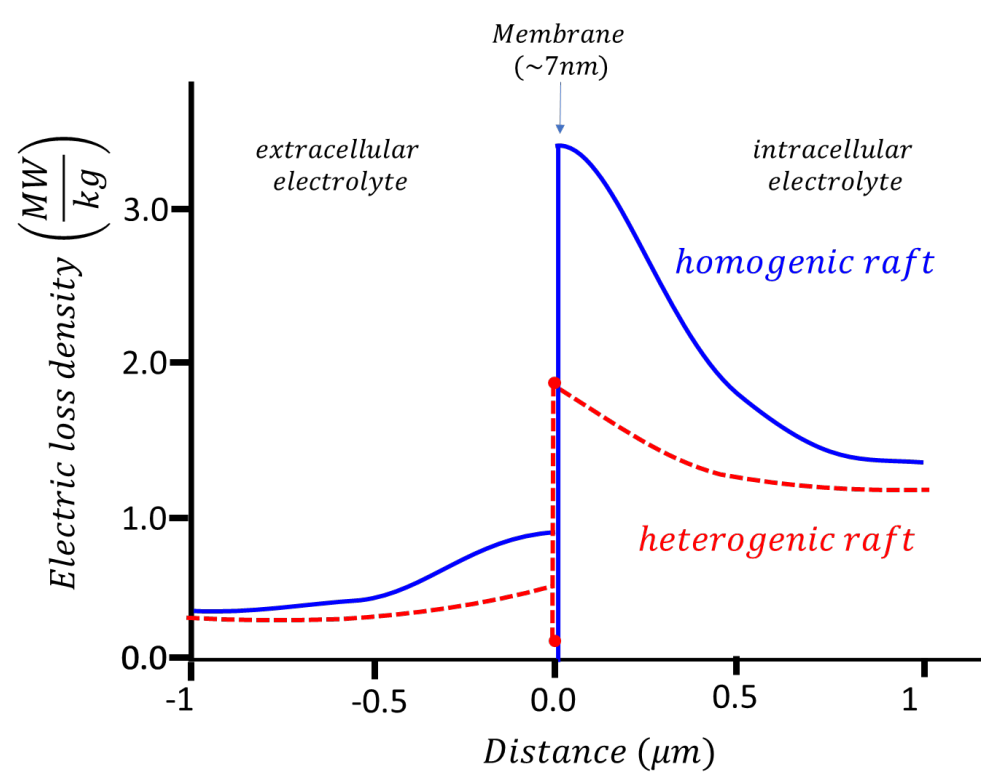

(a)

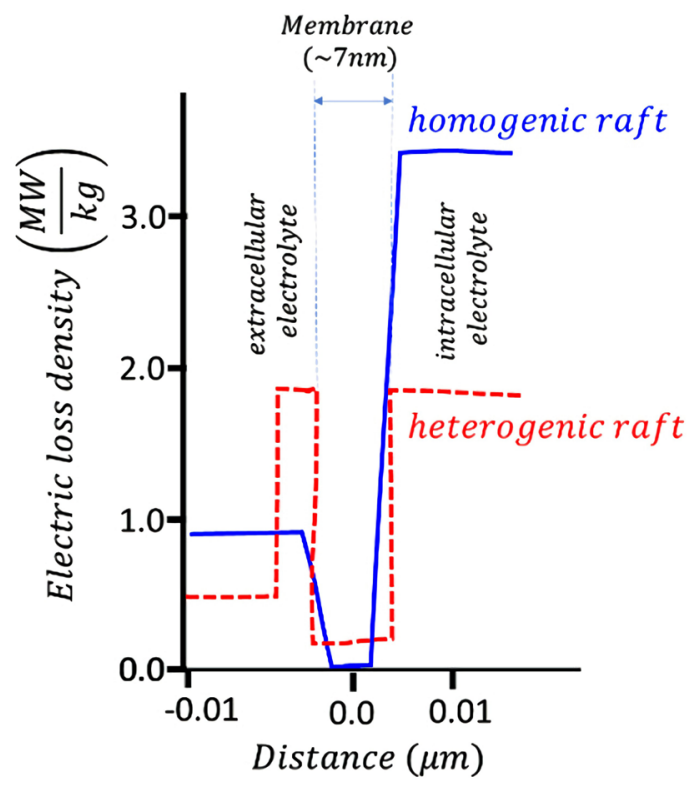

(b)

Figure 27. The electric energy loss density near the membrane of the cell in a spot of the raft under homogenous (solid line) and complex heterogenic (dashed line) assumptions: (a) The environment of the membrane; (b) Enlarged membrane area.

are identical, while in the complex, heterogenic one, the outer side has higher conductivity due to the difference of the electrolyte composition of the cytoplasm and the extracellular matrix (ECM), and the inner part has a lower dielectric constant, due to the complex connections inside the cell. The energy loss density is higher in the ECM.

The calculation used $f=13.56 \mathrm{MHz}$ frequency and assumed $E_{13.56 \mathrm{MHz}}=1.1 \times 10^{7} \frac{\mathrm{V}}{\mathrm{m}}=11 \frac{\mathrm{mV}}{\mathrm{nm}}$, consequently having $55 \mathrm{mV}$ membrane potential in the thickness of $d_{\text {membrane }}=5 \mathrm{~nm}$. This potential is lower than the healthy cell usually has, but the malignancy lowers the membrane potential in most cases [213]. The heterogenic complexity decreases the jump of electric loss density, which is clearly followed by the local $S A R$ (Figure 28).

The temperature development on the surface of the membrane is the same on both sides; but macroscopically (distant from the surface), the temperature is lower in the ECM than in the cytoplasm (Figure 29).

The temperature of the rafts affects the ECM in its immediate vicinity only. A similar size gold nanoparticle with radius $r_{n}=30 \mathrm{~nm}$, absorbing $I_{0}=10^{4} \frac{\mathrm{W}}{\mathrm{m}^{2}}$ energy flux, was heated up by $4^{\circ} \mathrm{C}$ in surrounding water, and at a distance of 70 $\mathrm{nm}$ from its surface, the gain of temperature practically vanished [214]. This rapid disappearance of the temperature in the vicinity of the nanoparticle supports the approximation in which we ignored the diffusion part of the Pennes equation, to simplify its solution. This approach is valid in nanoscopic energy-absorption only, which is realized in the mEHT too.

The excitation of the rafts needs extra energy, and structural changes happen, 


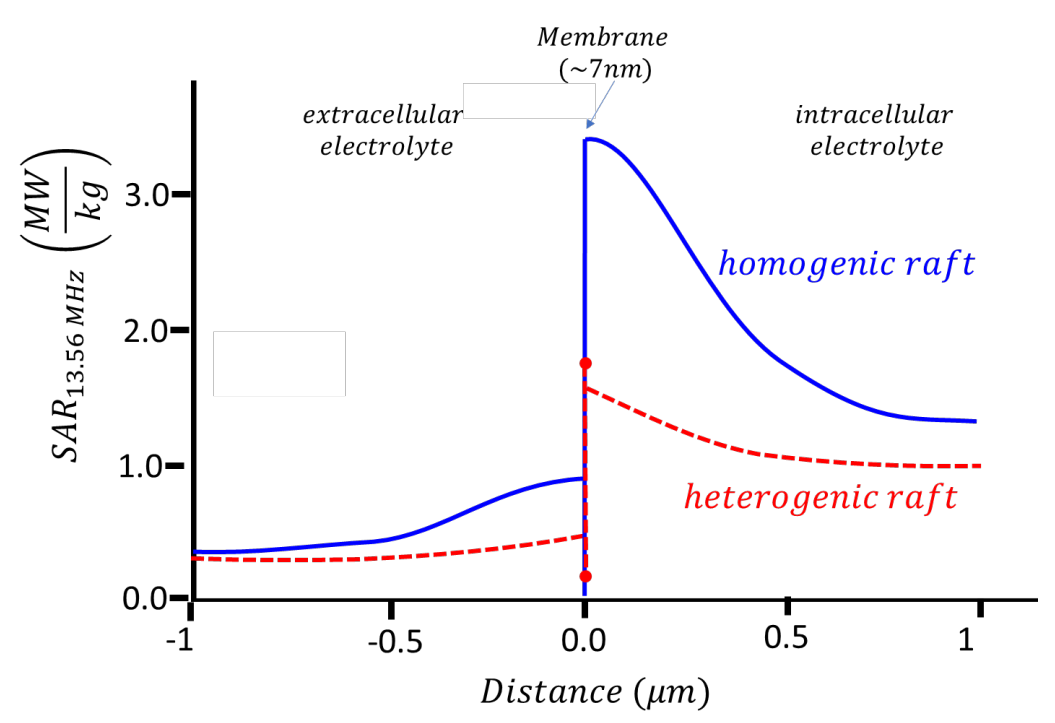

Figure 28. The provided $S A R$ to the membrane area, in a spot of the raft under homogenous (solid line) and complex heterogenic (dashed line) assumptions.

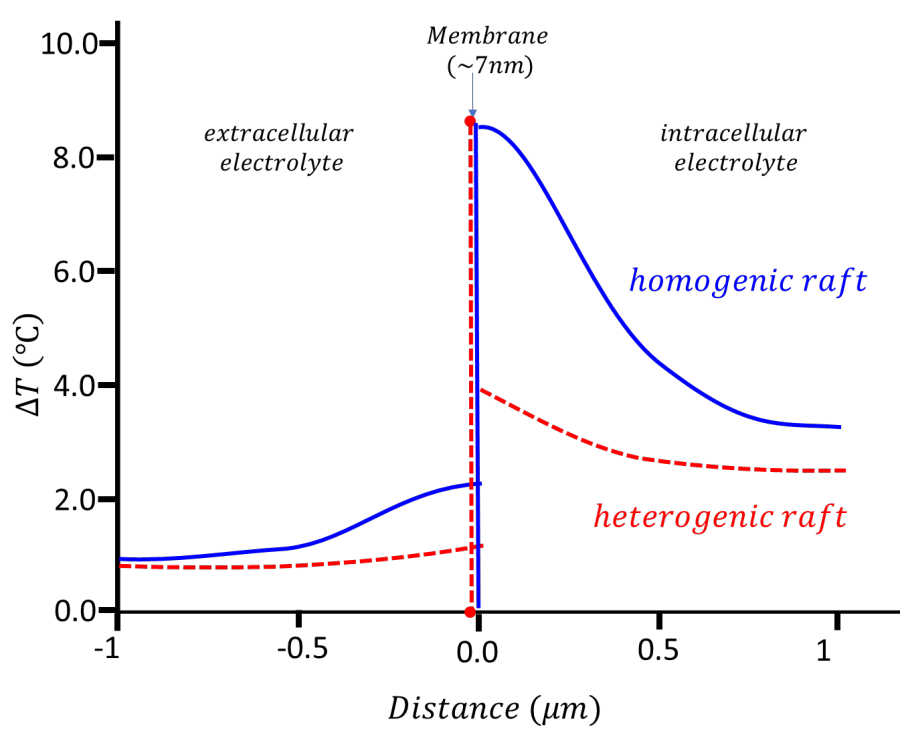

(a)

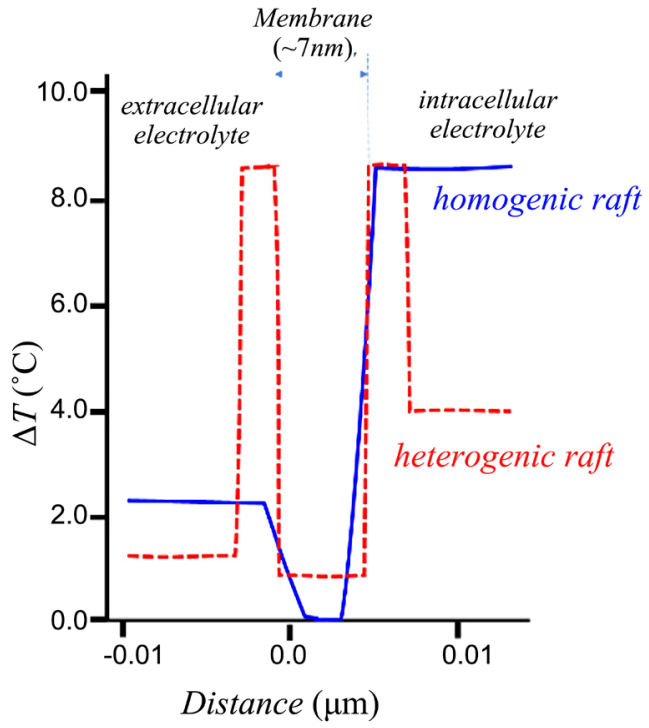

(b)

Figure 29. The developed temperature in a spot of the raft under homogenous (solid line) and complex heterogenic (dashed line) assumptions: (a) The environment of the membrane; (b) Enlarged membrane area.

which rearranges the giant membrane vehicles [215] and could modify the cell membrane [216]. The membrane phase transition can be modelled experimentally too, when the Arrhenius dependence breaks in both the resistivity and capacity parts of the lipid bilayer [217] (Figure 30). This again needs a local, microscopic increase in the absorbed energy, which appears microscopically.

The energy absorption of membrane rafts realizes heterogenic energy absorption, which follows the natural heterogeneities of the living matter. While the homogeneous concept intensifies the quick physiological regulation, the heterogenic selection has less strength to trigger the immediate feedback of regulation 


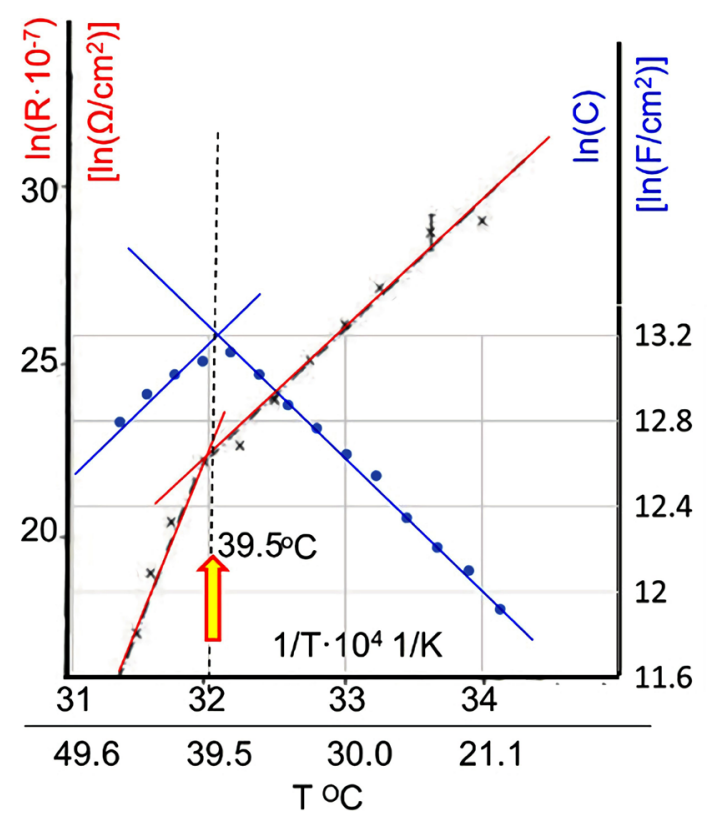

Figure 30. Arrhenius-like plots of the resistance and capacity of the membrane. It shows a phase transition at the temperature of $39.5^{\circ} \mathrm{C}(\bullet$ The capacitive $\mathrm{x}$ the resistive plot).

mechanisms. The physiological reaction appears later when the small heated substances heat up their environment, attracting the reaction of the general control. The temperature development in the microscopic range has many similarities with the macroscopic pattern but has a certain difference in the absorbed $S A R$ (Figure 31). The absorbed $S A R$ transfers one state to the other one, and the change of temperature is a "side effect": the excess part of the constant systemic $S A R$ heats up. The spread of heat energy by time keeps the energy-replacement macroscopic, and gradually less energy will be selectively taken by the rafts, which constitute only a minimal fraction of the total mass of the tumour. There are two possible phase transitions that happen: one is for the chemical changes to produce signals and its structural consequences; the other one is the phase transition of the lipid membrane. Their temperatures are denoted by $T_{c h}$ and $T_{m e m}$, respectively. Both transitions are temperature-dependent, so when the raft does not heat up to the transition temperatures, these will not occur. When the transition happens, the temperature remains constant until it finishes. Afterwards, the temperature increases as usual until the $S A R$ switches off. When the rafts absorb the constant average, which heats the entire mass, its temperature will be equal to its environment. The selection disappears due to the homeostatic equilibrium. However, in this state, the energy-absorption in the target acts only to replace the energy being carried away by heat-exchange with the environment of the target and also the environmental conditions of the human body.

The constant $S A R$ is macroscopic; the active absorption at the microscopic level is different, being deducted from the average $S A R$, and the remaining power heating the lesion, as is shown in a hypothetical situation in Figure 31. The $S A R$ value which is required to maintain a chosen temperature changes. The 


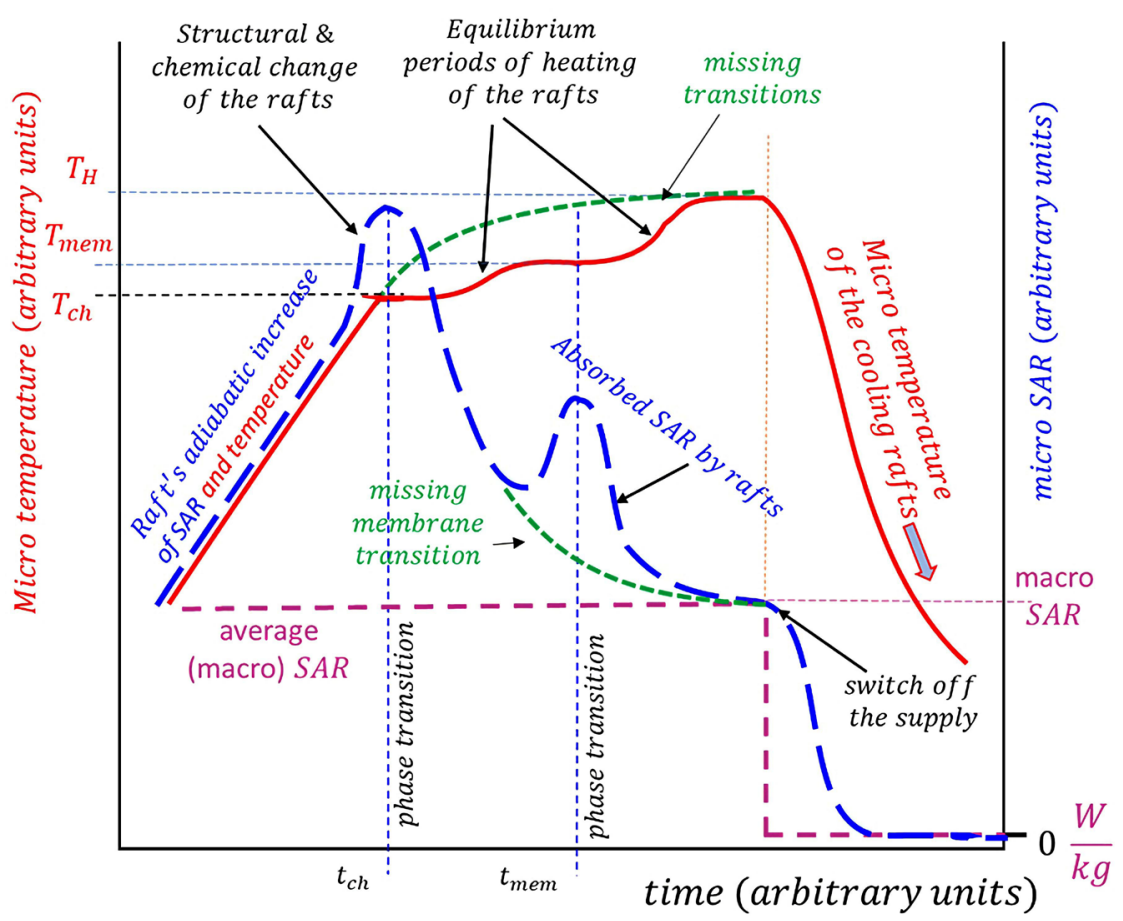

Figure 31. The temperature development and the $S A R$ in the microscopic range (For explanation, see the text).

continuously growing temperature reaches definite values at which the energy requirement is higher than the general adiabatic need, as we showed by time development in Figure 31. The points at which the required micro (mSAR) changes, in order to energize the micro processes, are: the chemical phase transition $T_{c h}$, the membrane phase transition $T_{m e m}$ and the switching off of the supply after reaching the $T_{H}$ homeostatic equilibrium, Figure 31 . The first, chemical phase transitions, modify the microscopic energy consumption through chemical processes (signal excitation, signal transduction, protein structural changes), and usually we do not take the temperature so high as that at which the membrane phase transition happens $\left(>42^{\circ} \mathrm{C}\right)$. The change of $m S A R$ vs temperature development shows a double peak pattern when the temperature goes over $42^{\circ} \mathrm{C}$, and afterward, the temperature grows directly with the constant average $S A R$ in the target (Figure 32; it becomes a homogenous situation, the rafts having the same average $S A R$ as the wider environment, which is in thermal equilibrium. The system temperature grows until reaching the homeostatic point and remains at this temperature until the switching off of the $S A R$. This is the stage at which the system has constant temperature due to the constant $S A R$ replacement of lost energy.

Changes of $m S A R$ by temperature depend on the demand for energy in the studied region. This changes not only with the phase transitions but also due to the homeostatic mechanisms, and in the end, the raft is heated in the same way as its environment.

Understanding these heating processes, the optimal strategy is to keep the growth 


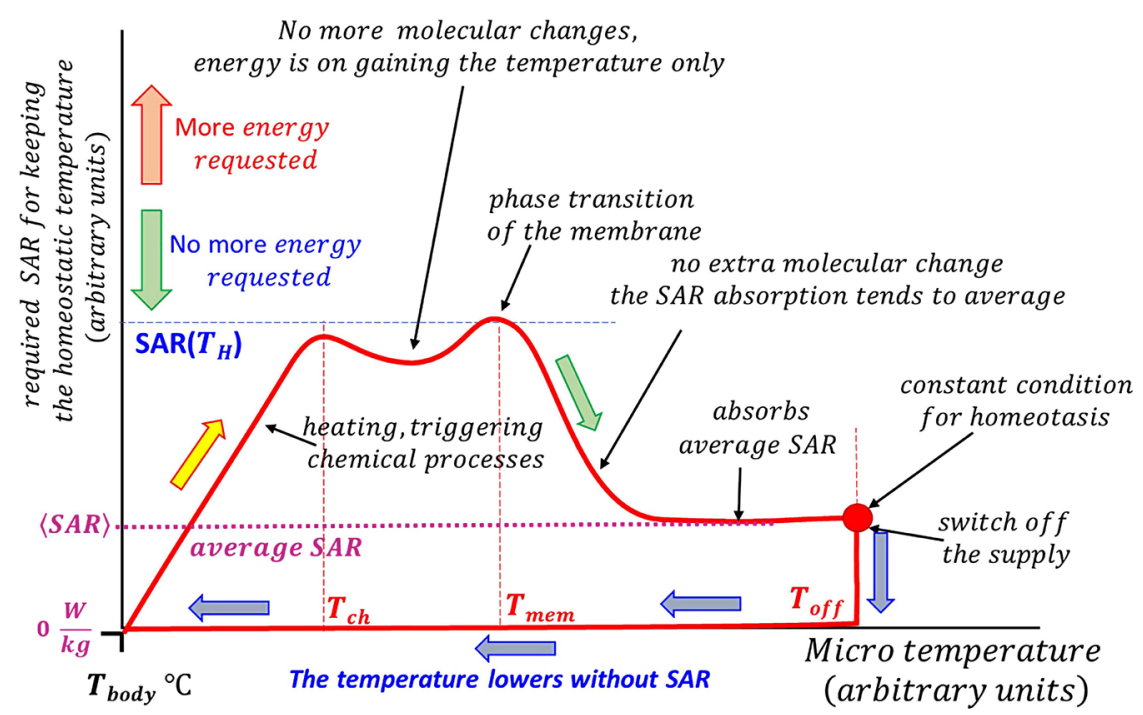

Figure 32. The required $S A R$ values vs temperature in the micro-region of selectively heated rafts. The red dot before the switching off of the $S A R$ represents the equilibrium when both the $S A R$ and the temperature are constant. The provided absorbed energy is only replacing the loss by cooling to the environment.

of temperature continuous, so to maintain the condition where $\frac{\Delta T}{\Delta t}=\frac{1}{C} S A R$. The well-developed treatment protocol makes use of step-up heating when the linear $\frac{\Delta T}{\Delta t}$ slope dominates (Figure 33).

When the temperature development deviates from the slope, going to be stationary another so called constant perfusion rate model could be introduced, when the Pennes' Equation (11) reduced to:

$$
\rho_{h} c_{h} \frac{\partial T}{\partial t}=\rho_{h} S A R-c_{b} \rho_{b} w_{b}(T)(\Delta T)
$$

The solution of (66):

$$
\Delta T=\frac{\rho_{h} S A R}{c_{b} \rho_{b} w_{b}(T)}\left(1-\mathrm{e}^{-\left(\frac{t}{\tau_{c p}}\right)}\right)
$$

where

$$
\tau_{c p}=\frac{c_{h} \rho_{h}}{c_{b} \rho_{b} w_{b}(T)}
$$

Is the time-constant of the constant perfusion model, and $\tau_{c p} \cong t_{0}$ when $t$ is large, corresponding with the stationery solution of (57). Using realistic parameters we get $\tau_{c p} \cong 7 \mathrm{~min}$. So the temperature rise will be different, Figure 34 .

In the case of gradual step-up heating the simplified Pennes equation:

$$
\begin{aligned}
& \rho c \frac{\partial T}{\partial t}+c_{b} \rho_{b} w_{b}\left(T-T_{b}\right)=p(t), \rho c \cong c_{b} \rho_{b}, \\
& p(t)=p_{0}\left(H_{1}(t)+H_{1}(t-\Theta)+H_{1}(t-2 \Theta)+\cdots+H_{1}(t-n \Theta)\right)
\end{aligned}
$$




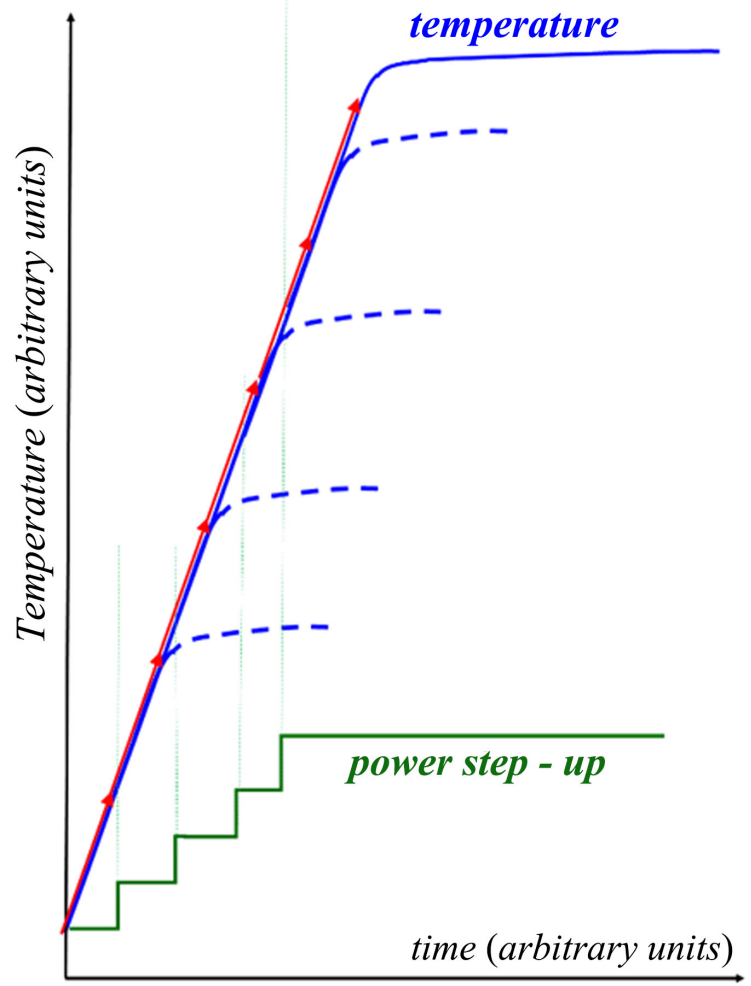

Figure 33. The temperature development by the step-up in the time period, when the curve is in the quasi-adiabatic line.

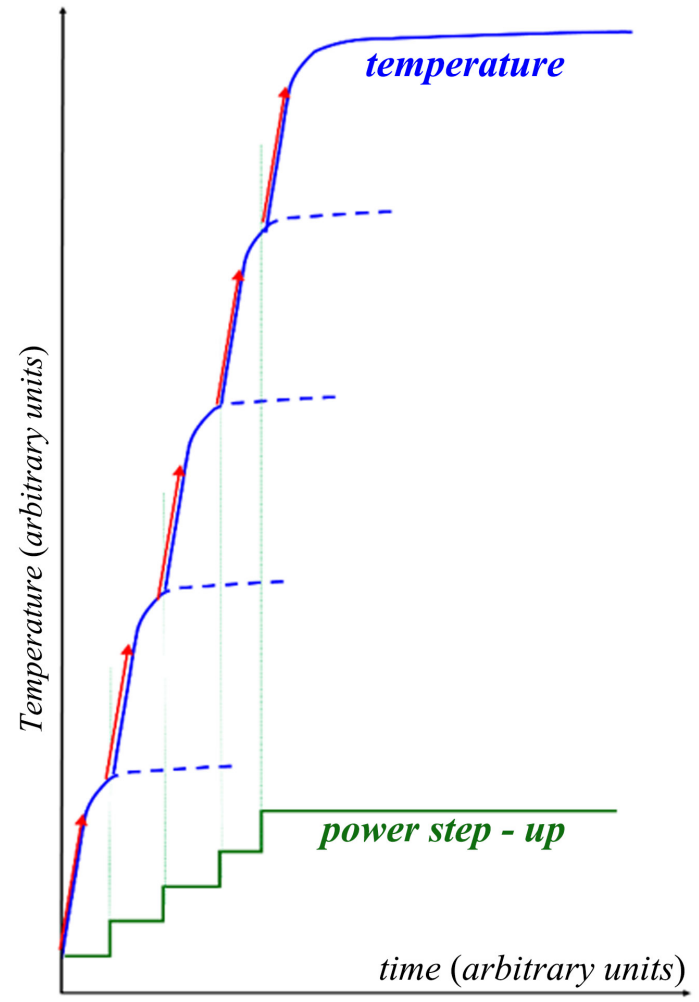

Figure 34. The temperature development by the step-up in the period out of the constant perfusion model, Note, at the end the temperature could grow higher than in Figure 33. 
where $H_{1}(t)$ is the Heaviside unit-jump function, $p_{0}$ is the jump of $S A R$ (assumed equal tranches!) and $\Theta$ is the time between the two jumps on.

So, we get:

$$
\begin{aligned}
& \frac{\partial \Delta T}{\partial t}+\frac{1}{\tau} \Delta T=\frac{p(t)}{\rho c}, \\
& \tau=w_{b}^{-1}
\end{aligned}
$$

Using Laplace transformation:

$$
\begin{aligned}
& \Delta T(s)=\frac{\tau}{\rho c} \frac{1}{1+s \tau} p(s), \\
& p(s)=p_{0} \frac{1}{s}\left(1+\mathrm{e}^{-s \Theta}+\mathrm{e}^{-s 2 \Theta}+\cdots+\mathrm{e}^{-s n \Theta}\right)
\end{aligned}
$$

We get by inverse Laplace transformation the time-function of the temperature rise:

$$
\begin{aligned}
\Delta T(t)= & \frac{\tau}{\rho c} p_{0}\left[\left(1-\mathrm{e}^{-\frac{t}{\tau}}\right) H_{1}(t)+\left(1-\mathrm{e}^{-\frac{t-\Theta}{\tau}}\right) H_{1}(t-\Theta)\right. \\
& \left.+\left(1-\mathrm{e}^{-\frac{t-2 \Theta}{\tau}}\right) H_{1}(t-2 \Theta)+\cdots+\left(1-\mathrm{e}^{-\frac{t-n \Theta}{\tau}}\right) H_{1}(t-n \Theta)\right]
\end{aligned}
$$

Note, $p_{0}=S A R$, in simple one-step heating, like it was used in (54). This is physically simple: in every $\Theta$ time a new exponential function starts and added to the previous time-function Figure 35.

The time-derivative function of (72) is:

$$
\begin{aligned}
\frac{\mathrm{d} \Delta T}{\mathrm{~d} t}= & \frac{p_{0}}{\rho c}\left[\mathrm{e}^{-\frac{t}{\tau}} H_{1}(t)+\mathrm{e}^{-\frac{t-\Theta}{\tau}} H_{1}(t-\Theta)+\mathrm{e}^{-\frac{t-2 \Theta}{\tau}} H_{1}(t-2 \Theta)+\cdots\right. \\
& \left.+\mathrm{e}^{-\frac{t-n \Theta}{\tau}} H_{1}(t-n \Theta)\right]
\end{aligned}
$$

The right-side derivatives of the time-dependent temperature of (72) show the newly started targeting:

$$
\begin{aligned}
& \left.\frac{\mathrm{d} \Delta T}{\mathrm{~d} t}\right|_{t=+0}=\frac{p_{0}}{\rho c},\left.\frac{\mathrm{d} \Delta T}{\mathrm{~d} t}\right|_{t \rightarrow+\Theta}=\frac{p_{0}}{\rho c}\left(1+\mathrm{e}^{-\frac{\Theta}{\tau}}\right), \cdots, \\
& \left.\frac{\mathrm{d} \Delta T}{\mathrm{~d} t}\right|_{t \rightarrow+n \Theta}=\frac{p_{0}}{\rho c}\left(1+\mathrm{e}^{-\frac{\Theta}{\tau}}+\mathrm{e}^{-\frac{2 \Theta}{\tau}}+\cdots+\mathrm{e}^{-\frac{n \Theta}{\tau}}\right)
\end{aligned}
$$

It is simply the identical restart of the SAR process, when the time $\Theta$ is longer than the $\tau$ blood-perfusion time-constant. In this case all the jumps could be described independently. Using the practical units in physiology:

$$
\begin{aligned}
& \left.\frac{\Delta T}{t}\right|_{t=0}=\frac{\tau}{\rho c} p_{0}\left(1-\mathrm{e}^{-\frac{t}{\tau}}\right) \cong \frac{p_{0}}{\rho c} \\
& \text { in practical units }:\left.\frac{\Delta T}{t}\right|_{t=0}\left[C^{0} / \min [] \frac{S A R[\mathrm{~W} / \mathrm{kg}]}{C} \frac{S A R[\mathrm{~W} / \mathrm{kg}]}{67}\right]
\end{aligned}
$$




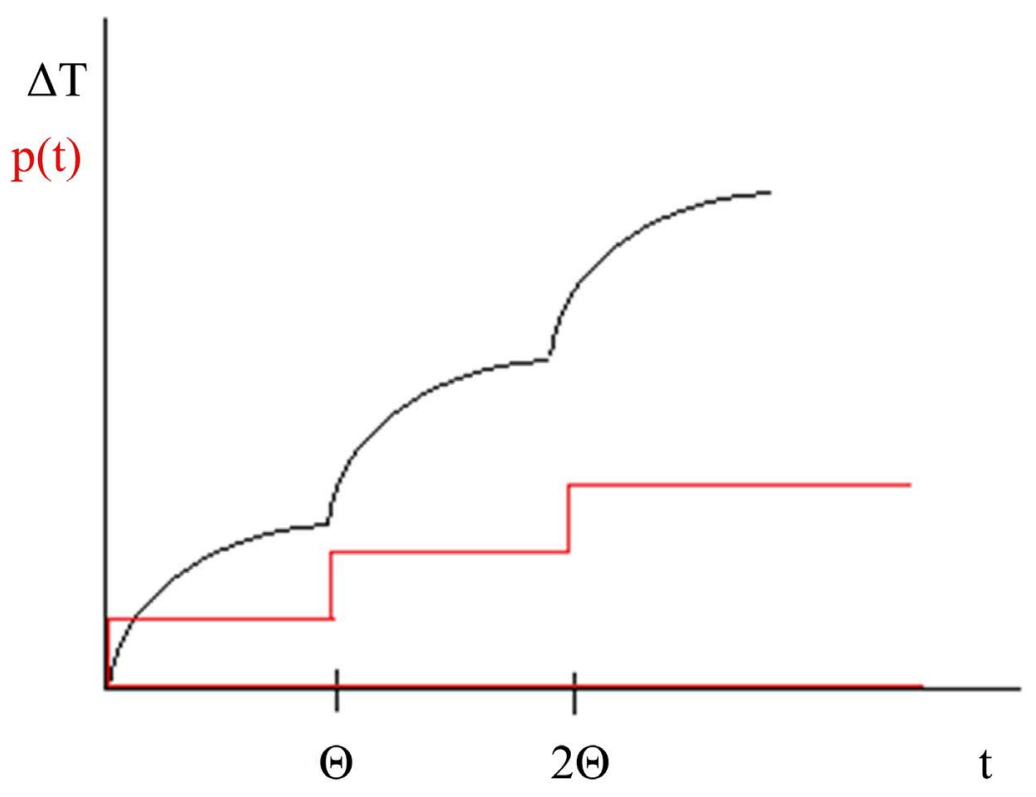

Figure 35. The time-function of temperature in case of step-up jumps of $S A R$.

with the above calculated (75).

When the incident power is terminated, the blood-perfusion starts to cool the target (clearance of temperature). This could be described by the Pennes equation too:

$$
\begin{aligned}
& \frac{\partial\left(T-T_{b}\right)}{\partial t}+\frac{1}{\tau}\left(T-T_{b}\right)=0, \\
& \tau=w_{b}^{-1}
\end{aligned}
$$

Its solution is:

$$
\Delta T(t)=\left(T-T_{b}\right)=\frac{\tau}{\rho c} p_{0} \mathrm{e}^{-\frac{t}{\tau}},
$$

From $\Delta T(t)$ function the $\tau$ blood-perfusion time-constant could be determined, and so we get $w_{b}$ too by (57) and (70). The clearance temperature (the speed of cooling) is:

$$
\left.\frac{\mathrm{d} \Delta T}{\mathrm{~d} t}\right|_{t=0}=-\frac{p_{0}}{\rho c}
$$

which is in its absolute value identical with (54) (after stationary heating, and so the target is in thermal-equilibrium). Using again the physiology units, we get:

$$
\left.\frac{\mathrm{d} \Delta T}{\mathrm{~d} t}\right|_{t=0}\left[C^{0} / \min [] \frac{S A R[\mathrm{~W} / \mathrm{kg}]}{67}\right]
$$

The results have to be generalized, recognizing, that the living target changes during the heating in its multiple parameters, including the thermal and the electrical ones. This changes the blood-perfusion as well as the complete temperature rise, despite the constant power provided, the SAR will change too. Due to this instead of (72) we use 


$$
\begin{aligned}
\Delta T(t)= & \frac{1}{\rho c}\left[\tau_{0} p_{0}\left(1-\mathrm{e}^{-\frac{t}{\tau}}\right) H_{1}(t)+\tau_{1} p_{1}\left(1-\mathrm{e}^{-\frac{t-\Theta}{\tau}}\right) H_{1}(t-\Theta)\right. \\
& +\tau_{2} p_{2}\left(1-\mathrm{e}^{-\frac{t-2 \Theta}{\tau}}\right) H_{1}(t-2 \Theta)+\cdots \\
& \left.+\tau_{n} p_{n}\left(1-\mathrm{e}^{-\frac{t-n \Theta}{\tau}}\right) H_{1}(t-n \Theta)\right]
\end{aligned}
$$

and consequently instead of (73):

$$
\begin{aligned}
\frac{\mathrm{d} \Delta T}{\mathrm{~d} t}= & \frac{1}{\rho c}\left[p_{0} \mathrm{e}^{-\frac{t}{\tau}} H_{1}(t)+p_{1} \mathrm{e}^{-\frac{t-\Theta}{\tau}} H_{1}(t-\Theta)\right. \\
& \left.+p_{2} \mathrm{e}^{-\frac{t-2 \Theta}{\tau}} H_{1}(t-2 \Theta)+\cdots+p_{n} \mathrm{e}^{-\frac{t-n \Theta}{\tau}} H_{1}(t-n \Theta)\right]
\end{aligned}
$$

The right derivatives of the curve in (81):

$$
\begin{aligned}
& \left.\frac{\mathrm{d} \Delta T}{\mathrm{~d} t}\right|_{t=+0}=\frac{p_{0}}{\rho c},\left.\frac{\mathrm{d} \Delta T}{\mathrm{~d} t}\right|_{t \rightarrow+\Theta}=\frac{p_{1}}{\rho c}\left(1+\mathrm{e}^{-\frac{\Theta}{\tau_{0}}}\right), \cdots, \\
& \left.\frac{\mathrm{d} \Delta T}{\mathrm{~d} t}\right|_{t \rightarrow+n \Theta}=\frac{p_{0}}{\rho c}\left(1+\mathrm{e}^{-\frac{\Theta}{\tau_{0}}}+\mathrm{e}^{-\frac{2 \Theta}{\tau_{1}}}+\cdots+\mathrm{e}^{-\frac{n \Theta}{\tau_{n-1}}}\right)
\end{aligned}
$$

And again, when the switching time $\Theta$ is much longer the largest blood-perfusion time-constant, than we may use again the approximation (75):

$$
\begin{aligned}
& \left.\frac{\mathrm{d} \Delta T}{\mathrm{~d} t}\right|_{t=+0, \cdots,+n \Theta}\left[C^{0} / \min [] \frac{S A R_{0}[\mathrm{~W} / \mathrm{kg}]}{67}\right] \\
& \left.\frac{\mathrm{d} \Delta T}{\mathrm{~d} t}\right|_{t=+\Theta}\left[C^{0} / \min [] \frac{S A R_{1}[\mathrm{~W} / \mathrm{kg}]}{67}\right] \\
& \left.\frac{\mathrm{d} \Delta T}{\mathrm{~d} t}\right|_{+n \Theta}\left[C^{0} / \min [] \frac{S A R_{n}[\mathrm{~W} / \mathrm{kg}]}{67}\right]
\end{aligned}
$$

The realization of the strategy of blocking the development of thermal spreading could be more effective when the linear period of $\frac{\Delta T}{\Delta t}$ is carefully managed and the system cooled down before the spread of the heat starts. The concept could be completed by the cutting of the heating curve, which could be done at various points of the temperature development (Figure 36).

The straight-line sided triangle at the early cut looks the most controllable situation, stopping the heating at the end-point when the linear slope fits. Technically the appropriate pulsing of the SAR follows the optimizing rule well (Figure 37). This protocol does not change, or changes by only a little, the overall temperature, so all the energy is concentrated on the selected rafts.

Note, the selective, non-isothermal energy-absorption is similar to the ionizing radiation concept when the selection is directed at the breaking of DNA. The heat and temperature gain which they produce during treatment are adverse effects, and the protocols try to avoid them. The dose in the ionizing radiation is 


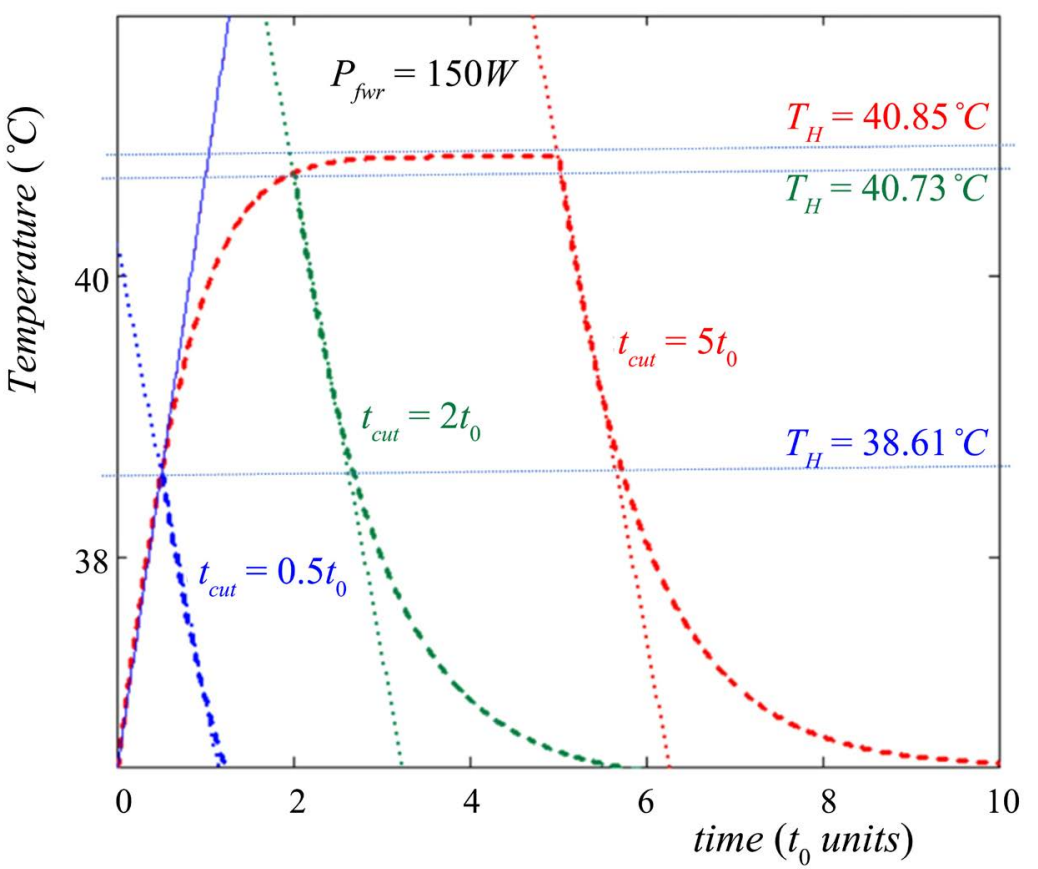

Figure 36. The temperature development terminated in different stages of the process.

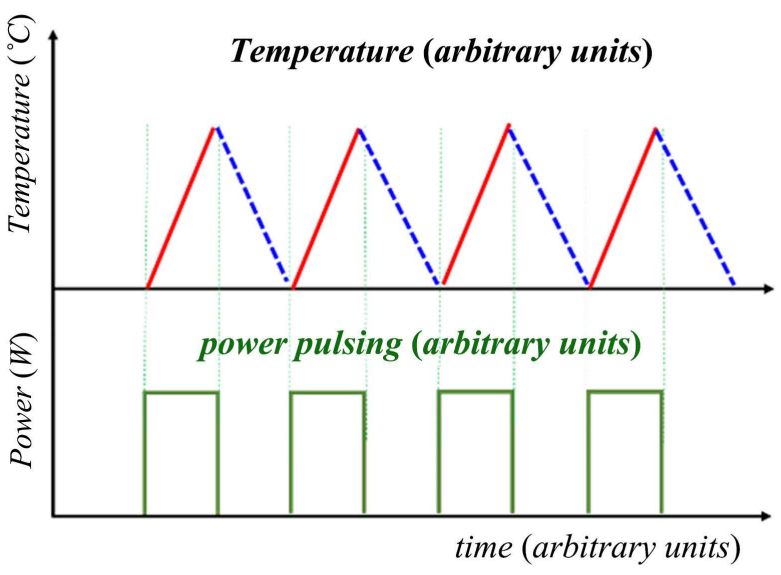

(a)

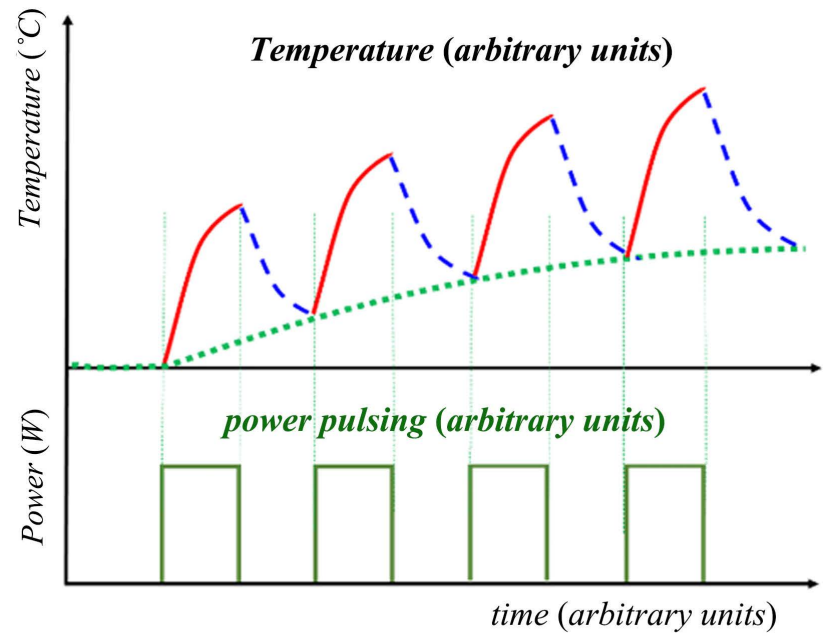

(b)

Figure 37. Temperature development by the appropriately pulsed power, providing step-up: (a) Terminated before the non-linear period starts; (b) Terminated after the non-linear period starts.

the Gray Gy = J/kg, which is the measure of the absorbed energy, by (3), and in time-dependent power by (4). The dose of the radiotherapy treatment-cycle is the sum of the fractional doses in the process. We may introduce the same in hyperthermia with regard to the absorbed energy:

$$
E_{\text {dose }}\left(t_{\Sigma}\right)=\sum_{i=1}^{N} \int_{0}^{t_{i}} S A R(\tau) \mathrm{d} \tau
$$

where $N$ is the number of treatments in the actual cycle, $t_{i}$ is the time of the $i$-th treatment and 


$$
t_{\Sigma}=t_{1}+t_{2}+\cdots+t_{N-1}+t_{N}=\sum_{i=1}^{N} t_{i}
$$

is the entire treatment time in the cycle.

The evaluation of $\operatorname{SAR}(\tau)$ in a selective mode of hyperthermia counts the energy absorbed in the target irrespective of the kind of source, so the specific energy unit Gy could be applied in the non-ionizing radiation too. The energy which is provided by ionizing radiation (IR) triggers biological mechanisms, which are mostly the rupturing of DNA, while the desired effects are different in non-ionizing applications (nIR). We may observe contrary interests in using the absorbed energy in these therapies [3]. In the ionizing strategy, the distortion of the DNA strands is the goal, and the heat-production during this process is an adverse effect. In nIR hyperthermia, it is the other way round, and the heat production becomes the goal of the treatment. While the IR treatment is of short duration, the nIR is significantly longer, and while the physiological control mechanisms have no role in IR, these have an important role in nIR applications. Both treatments are electromagnetic, but IR has a frequency a few billion times higher and also has much shorter duration of treatment than nIR.

\section{Verification}

The preclinical verification of the dose and its temperature dependence shows the practical applicability of the above model-calculation. Phantom experiments [218], and in vitro cell-culture measurements show the apoptotic efficacy [219] [220] of mEHT, and the temperature mapping gives also a hint, that the above considerations are realistic [221]. The pulsed power application is measured [222] and verifies the advantage of the increased efficacy of such heating method [223]. The clinical applications have a well-defined protocol [224] and guideline [225] with the step-up heating requirements, and the clinical results validate the usage of the step-up heating model [226].

The present considerations are valid for solid tumours, where the Pennesequation is effective. The selective activation of the haematological cancers is in progress.

\section{Conclusion}

Considering the homeostatic self-similarity, we have shown a stochastic heuristic solution of the Pennes equation and its applicability in hyperthermia treatments in oncology. Weibull parametric distribution with satisfactory refinement can solve the problem of the description of the heating of the body, without the complications involved in solving the Pennes equation. This solution is stochastic, having a probability distribution which fits much more to the dynamic changes in the living objects, and eliminates the problem of the deterministic behaviour of the Pennes approach. The introduced selective heating allows focusing upon the malignant cells using the thermal and bioelectromagnetic heterogeneity of the tumorous lesions. The solution allows the introduction of a 
protocol that most optimally uses the provided energy for molecular changes, destroying the malignant cells without a noticeable effect on their healthy counterparts. The present considerations are valid for solid tumors, where the Pennes-equation is effective. The selective activation of the haematological cancers is in progress.

\section{Conflicts of Interest}

The authors declare no conflicts of interest regarding the publication of this paper.

\section{References}

[1] Vaupel, P. and Hammersen, F. (1982) Mikrozirkulation in malignen Tumoren. Karger, Basel.

[2] Vaupel, P. (1990) Pathophysiological Mechanism of Hyperthermia in Cancer Therapy. In: Gautherie, M., Ed., Methods of Hyperthermia Control, Biological Basis of Oncologic Thermotherapy. Clinical Thermology (Subseries Thermotherapy), Springer Verlag, Berlin, Heidelberg, 73-134.

https://doi.org/10.1007/978-3-642-74939-1_2

[3] Szasz, A. (2019) Thermal and Nonthermal Effects of Radiofrequency on Living State and Applications as an Adjuvant with Radiation Therapy. Journal of Radiation and Cancer Research, 10, 1-17. https://doi.org/10.4103/jrcr.jrcr_25_18

[4] Vaupel, P., Kallinowski, F. and Okunieff, P. (1989) Blood Flow, Oxygen and Nutrient Supply, and Microenvironment of Human Tumours: A Review. Cancer Research, 49, 6449-6465.

[5] Song, C.W., Choi, I.B., Nah, B.S., Sahu, S.K. and Osborn, J.L. (1995) Microvasculature and Perfusion in Normal Tissues and Tumours. In: Seegenschmiedt, M.H., Fessenden, P. and Vernon, C.C., Eds., Thermoradiometry and Thermochemotherapy, Vol. 1, Springer-Verlag, Berlin Heidelberg, 139-156.

https://doi.org/10.1007/978-3-642-57858-8_7

[6] Takana, Y. (2001) Thermal Responses of Microcirculation and Modification of Tumour BF in Treating the Tumours. In: Kosaka, M., Sugahara, T., Schmidt, K.L. and Simon, E., Eds., Theoretical and Experimental Basis of Hyperthermia. Thermotherapy for Neoplasia, Inflammation, and Pain, Springer Verlag, Tokyo, 408-419. https://doi.org/10.1007/978-4-431-67035-3_45

[7] Song, C.W., Park, H. and Griffin, R.J. (2001) Theoretical and Experimental Basis of Hyperthermia. In: Kosaka, M., Sugahara, T., Schmidt, K.L., et al., Eds., Thermotherapy for Neoplasia, Inflammation, and Pain, Springer Verlag, Tokyo, 394-407. https://doi.org/10.1007/978-4-431-67035-3_44

[8] Wu, M., Frieboes, H.B., McDougall, S.R., et al. (2013) The Effect of Interstitial Pressure on Tumor Growth: Coupling with the Blood and Lymphatic Vascular Systems. Journal of Theoretical Biology, 320, 131-151.

https://doi.org/10.1016/j.jtbi.2012.11.031

[9] Song, C.W., Lokshina, A., Rhee, J.G., et al. (1984) Implication of BF in Hyperthermic Treatment of Tumours. IEEE Transactions on Biomedical Engineering, 31, 9-16. https://doi.org/10.1109/TBME.1984.325364

[10] Jain, R.K. (1988) Determinants of Tumor Blood Flow: A Review. Cancer Research, 48, 2641-2658. 
[11] Song, C.W. (1984) Effect of Local Hyperthermia on Blood Flow and Microenvironment: A Review. Cancer Research (Suppl.), 44, 4721s-4730s.

[12] Dudar, T.E. and Jain, R.K. (1984) Differential Response of Normal and Tumour Microcirculation to Hyperthermia. Cancer Research, 44, 605-612.

[13] Hietanen, T., Kapanaen, M. and Kellokumpu-Legtinen, P.L. (2016) Restoring Natural Killer Cell Cytotoxicity after Hyperthermia Alone or Combined with Radiotherapy. Anticancer Research, 36, 555-564.

[14] Beachy, S.H. and Repasky, E.A. (2011) Toward Establishment of Temperature Thresholds for Immunological Impact of Heat Exposure in Humans. International Journal of Hyperthermia, 27, 344-352. https://doi.org/10.3109/02656736.2011.562873

[15] Jones, E., Thrall, D., Dewhirst, M.W. and Vujaskovic, Z. (2006) Prospective Thermal Dosimetry: The Key to Hyperthermia's Future. International Journal of Hyperthermia, 22, 247-253. https://doi.org/10.1080/02656730600765072

[16] Fatehi, D., van der Zee, J., van der Wal, E., et al. (2006) Temperature Data Analysis for 22 Patients with Advanced Cervical Carcinoma Treated in Rotterdam Using Radiotherapy, Hyperthermia and Chemotherapy: A Reference Point Is Needed. International Journal of Hyperthermia, 22, 353-363. https://doi.org/10.1080/02656730600715796

[17] Separeto, S.A. and Dewey, W.C. (1984) Thermal Dose Determination in Cancer Therapy. International Journal of Radiation Oncology, Biology, Physics, 10, 787-800. https://doi.org/10.1016/0360-3016(84)90379-1

[18] Arrhenius, S. (1915) Quantitative Laws in Biological Chemistry. G. Bell, London. https://doi.org/10.5962/bhl.title.22817

[19] Jackson, M.B. (2006) Molecular and Cellular Biophysics. Cambridge University Press, Cambridge. https://doi.org/10.1017/CBO9780511754869

[20] Nelson, P. (2004) Biological Physics. WH Freeman and Company, New York.

[21] Perez, C.A. and Sapareto, S.A. (1984) Thermal Dose Expression in Clinical Hyperthermia and Correlation with Tumor Response/Control. Cancer Research, 44, $4818 \mathrm{~s}-4825 \mathrm{~s}$.

[22] Feo, F., Canuto, R.A. and Garcea, R. (1976) Lipid Phase Transition and Breaks in the Arrhenius Plots of Membrane-Bound Enzymes in Mitochondria from Normal Rat Liver and Hepatoma AH-130. FEBS Letters, 72, 262-266. https://doi.org/10.1016/0014-5793(76)80982-9

[23] Overath, P., Schairer, H.U. and Stoffel, W. (1970) Correlation of in Vivo and in Vitro Phase Transitions of Membrane Lipids in Escherichia coli. Proceedings of the National Academy of Sciences, 67, 606-312. https://doi.org/10.1073/pnas.67.2.606

[24] Watson, K., Bertoli, E. and Griffiths, D.E. (1975) Phase Transitions in Yeast Mithochondrial Membranes. Biochemical Journal, 146, 401-407. https://doi.org/10.1042/bj1460401

[25] Dewey, W.C., Hopwood, L.E., Sapareto, S.A., et al. (1977) Cellular Response to Combination of Hyperthermia and Radiation. Radiology, 123, 463-474. https://doi.org/10.1148/123.2.463

[26] Lindholm, C.-E. (1992) Hyperthermia and Radiotherapy. PhD Thesis, Lund University, Malmo.

[27] Hafstrom, L., Rudenstam, C.M., Blomquist, E., et al. (1991) Regional Hyperthermic Perfusion with Melphalan after Surgery for Recurrent Malignant Melanoma of the Extremities. Swedish Melanoma Study Group. Journal of Clinical Oncology, 9, 
2091-2094. https://doi.org/10.1200/JCO.1991.9.12.2091

[28] Franckena, M., Fatehi, D., de Bruijne, M., Canters, R.A.M., van Norden, Y., Mens, J.W., van Rhoon, G.C. and van der Zee, J. (2009) Hyperthermia Dose-Effect Relationship in 420 Patients with Cervical Cancer Treated with Combined Radiotherapy and Hyperthermia. European Journal of Cancer, 45, 1969-1978.

https://doi.org/10.1016/j.ejca.2009.03.009

[29] Ballesteros, F.J., Martinez, V.J., Luque, B., et al. (2018) On the Thermodynamic Origin of Metabolic Scaling. Scientific Reports, 8, Article No. 1448. https://doi.org/10.1038/s41598-018-30973-x

[30] Zotin, A.I. (2010) Thermodynamic Bases of Biological Processes. Cambridge Univ. Press, Cambridge.

[31] Matay, G. and Zombory, L. (2000) Physiological Effects of Radiofrequency Radiation and Their Application for Medical Biology. Muegyetemi Kiado, Budapest, 80.

[32] Brown, J.H., West, G.B. and Enquist, B.J. (2005) Yes, West, Brown and Enquist's Model of Allometric Scaling Is Both Mathematically Correct and Biologically Relevant. Functional Ecology, 19, 735-738. https://doi.org/10.1111/j.1365-2435.2005.01022.x

[33] Fristoe, T.S., Burger, J.R., Balk, M.A., et al. (2015) Metabolic Heat Production and Thermal Conductance Are Mass-Independent Adaptations to Thermal Environment in Birds and Mammals. PNAS, 112, 15934-15939. https://doi.org/10.1073/pnas.1521662112

[34] Pennes, H.H. (1948) Analysis of Tissue and Arterial Blood Temperatures in the Resting Human Forearm. Journal of Applied Physics, 1, 93-122.

https://doi.org/10.1152/jappl.1948.1.2.93

[35] Deng, Z.-S. and Liu, J. (2012) Analytical Solutions to 3-D Bioheat Transfer Problems with or without Phase Change. In: Heat Transfer Phenomena and Applications, Intech, Rijeka, Chapter 8, 205-242. https://doi.org/10.5772/52963

[36] Giordano, M.A., Gutierrez, G. and Rinaldi, C. (2010) Fundamental Solutions to the Bioheat Equation and Their Application to Magnetic Fluid Hyperthermia. International Journal of Hyperthermia, 26, 475-484.

[37] Cundin, L.X., Roach, W.P. and Millenbaugh, N. (2009) Empirical Comparison of Pennes' Bio-Heat Equation. Proceedings of SPIE, 7175, 717516-717519. https://doi.org/10.1117/12.805577

[38] Lakhssassi, A., Kengne, E. and Semmaoui, H. (2010) Modified Pennes' Equation Modelling Bio-Heat Transfer in Living Tissues: Analytical and Numerical Analysis. Natural Science, 2, 1375-1385. https://doi.org/10.4236/ns.2010.212168

[39] Gao, B., Langer, S. and Corry, P.M. (1995) Application of the Time-Dependent Green's Function and Fourier Transforms to the Solution of the Bioheat Equation. International Journal of Hypertension, 11, 267-285. https://doi.org/10.3109/02656739509022462

[40] Van der Gaag, M.L., De Bruijne, M., Samaras, T., van der Zee, J. and Van Rhoon, G. (2006) Development of a Guideline for the Water Bolus Temperature in Superficial Hyperthermia. International Journal of Hyperthermia, 22, 637-656. https://doi.org/10.1080/02656730601074409

[41] Liu, K.-C. and Tu, F.-J. (2019) Numerical Solution of a Bioheat Transfer Problem with Transient Blood Temperature. International Journal of Computational Methods, 16, Article ID: 1843001. https://doi.org/10.1142/S0219876218430016

[42] (2006) IEEE C95.1. IEEE Standard for Safety Levels with Respect to Human Expo- 
sure to Radio Frequency Electromagnetic Fields, $3 \mathrm{kHz}$ to $300 \mathrm{GHz}$; IEEE Std C95.1-2005. IEEE, Piscataway.

[43] Ma, J., Yang, X., Sun, Y., et al. (2019) Thermal Damage in Three-Dimensional Vivo Bio-Tissues Induced by Moving Heat Sources in Laser Therapy. Scientific Reports, 9, Article No. 10987. https://doi.org/10.1038/s41598-019-47435-7

[44] Thermal Conditions, CUErgo, Cornell University Ergonomics Web. http://ergo.human.cornell.edu/studentdownloads/DEA3500notes/Thermal/thcondn otes.html

[45] Van Haaren, P.M.A., Hulshof, M.C.C.M., Kok, H.P., et al. (2008) Relation between Body Size and Temperatures during Locoregional Hyperthermia of Oesophageal Cancer Patients. International Journal of Hypertension, 24, 663-674. https://doi.org/10.1080/02656730802210448

[46] Giering, K., Lamprecht, I. and Minet, O. (1996) Specific Heat Capacities of Human and Animal Tissues. Proceedings of SPIE-The International Society for Optical Engineering, Vol. 2624, 178-188. https://doi.org/10.1117/12.229547

[47] de Greef, M. (2012) Loco-Regional Hyperthermia Treatment Planning: Optimisation under Uncertainty. Dutch Cancer Society, Amsterdam.

[48] ESHO Taskgroup Committee (1992) Treatment Planning and Modelling in Hyperthermia, a Task Group Report of the European Society for Hyperthermic Oncology. Tor Vergata, Rome.

[49] Kok, H.P., Van Haaren, P.M.A., Van de Kamer, J.B., et al. (2005) High-Resolution Temperature-Based Optimization for Hyperthermia Treatment Planning. Physics in Medicine and Biology, 50, 3127-3141. https://doi.org/10.1088/0031-9155/50/13/011

[50] Newman, W.H., Lele, P.P. and Bowman, H.P. (1990) Limitations and Significance of Thermal Washout Data Obtained during Microwave and Ultrasound Hyperthermia. International Journal of Hypertension, 6, 771-784.

https://doi.org/10.3109/02656739009140824

[51] Kodera, S. and Hirata, A. (2018) Comparison of Thermal Response for RF Exposure in Human and Rat Models. International Journal of Environmental Research and Public Health, 15, 2320. https://doi.org/10.3390/ijerph15102320

[52] Vincze, Gy. and Szasz, A. (2011) On the Extremum Properties of Thermodynamic Steady State in Non-Linear Systems. In: Piraján, J.C.M., Ed., Thermodynamics-Physical Chemistry of Aqueous Systems, IntechOpen, London, 241-316.

http://www.intechopen.com/books/thermodynamics-physical-chemistry-of-aqueou s-systems/on-the-extremum-properties-of-thermodynamic-steady-state-in-non-line ar-systems https://doi.org/10.5772/21871

[53] Vincze, Gy. and Szasz, A. (2019) New Look at an Old Principle: An Alternative Formulation of the Theorem of Minimum Entropy Production. Journal of Advances in Physics, 16, 508-517. https://doi.org/10.24297/jap.v16i1.8516

[54] Weiss, T.F. (1996) Cellular Biophysics. Transport, Vol 1. MIT Press, Cambridge.

[55] Head, J.F., Wang, F., Lipari, C.A., et al. (2000) The Important Role of Infrared Imaging in Breast Cancer. IEEE Engineering in Medicine and Biology Magazine, 19, 52-57. https://doi.org/10.1109/51.844380

[56] Baronzio, G.F., Gramaglia, A., Baronzio, A., et al. (2006) Influence of Tumor Microenvironment on Thermoresponse: Biologic and Clinical Implications. In: Baronzio, G.F. and Hager, E.D., Eds., Hyperthermia in Cancer Treatment. A Primer, Landes Bioscience, Springer Science, New York, 62-86. 
[57] Kelleher, D.K. and Vaupel, P. (2006) Vascular Effects of Localized Hyperthermia. In: Baronzio, G.F. and Hager, E.D., Eds., Hyperthermia in Cancer Treatment. $A$ Primer, Landes Biosceince, Springer Science, New York, 94-104.

[58] Schwan, H.P. (1957) Electrical Properties of Tissue and Cell Suspensions. Advances in Biological and Medical Physics, 5, 147-209. https://doi.org/10.1016/B978-1-4832-3111-2.50008-0

[59] Pethig, R. and Kell, D.B. (1987) The Passive Electrical Properties of Biological Systems: Their Significance in Physiology, Biophysics and Biotechnology. Physics in Medicine and Biology, 32, 933-977. https://doi.org/10.1088/0031-9155/32/8/001

[60] Kurakin, A. (2011) The Self-Organizing Fractal Theory as a Universal Discovery Method: The Phenomenon of Life. Theoretical Biology and Medical Modelling, 8, 4. https://doi.org/10.1186/1742-4682-8-4

[61] Walleczek, J. (2000) Self-Organized Biological Dynamics \& Nonlinear Control. Cambridge University Press, Cambridge. https://doi.org/10.1017/CBO9780511535338

[62] Haken, H. (1987) Self-Organization and Information. Physica Scripta, 35, 247-254. https://doi.org/10.1088/0031-8949/35/3/006

[63] Sornette, D. (2000) Chaos, Fractals, Self-Organization and Disorder: Concepts and Tools. Springer Verlag, Berlin, Los Angeles.

[64] Deering, W. and West, B.J. (1992) Fractal Physiology. IEEE Engineering in Medicine and Biology, 11, 40-46. https://doi.org/10.1109/51.139035

[65] West, B.J. (1990) Fractal Physiology and Chaos in Medicine. World Scientific, Singapore, London.

[66] Kauffman, S.A. (1993) The Origins of Order: Self-Organization and Selection in Evolution. Oxford University Press, New York, Oxford.

https://doi.org/10.1007/978-94-015-8054-0_8

[67] Brummer, A.B., Savage, van M. and Enquist, B.J. (2017) A General Model for Metabolic Scaling in Self-Similar Asymmetric Networks. PLOS Computational Biology, 13, e1005394. https://doi.org/10.1371/journal.pcbi.1005394

[68] Ochiai, T., Nacher, J.C. and Akutsu, T. (2018) Symmetry and Dynamics in Living Organisms: The Self-Similarity Principle Governs Gene Expression Dynamics.

[69] Bassingthwaighte, J.B., Leibovitch, L.S. and West, B.J. (1994) Fractal Physiology. Oxford Univ. Press, New York, Oxford. https://doi.org/10.1007/978-1-4614-7572-9

[70] Musha, T. and Sawada, Y. (1994) Physics of the Living State. IOS Press, Amsterdam.

[71] Glazier, D.S. (2014) Metabolic Scaling in Complex Living Systems. Systems, 2, 451-540. https://doi.org/10.3390/systems2040451

[72] Scheffer, M. and Nes, V.E.H. (2006) Self-Organized Similarity, the Evolutionary Emergence of Groups of Similar Species. PNAS, 103, 6230-6235.

https://doi.org/10.1073/pnas.0508024103

[73] West, G.B., Woodruf, W.H. and Born, J.H. (2002) Allometric Scaling of Metabolic Rate from Molecules and Mitochondria to Cells and Mammals. Proceedings of the National Academy of Sciences of the United States of America, 99, 2473-2478. https://doi.org/10.1073/pnas.012579799

[74] Li, W. (1989) Spatial 1/f Spectra in Open Dynamical Systems. Europhysics Letters, 10, 395-400. https://doi.org/10.1209/0295-5075/10/5/001

[75] Schlesinger, M.S. (1987) Fractal Time and 1/f Noise in Complex Systems. Annals of the New York Academy of Sciences, 504, 214-228. 
https://doi.org/10.1111/j.1749-6632.1987.tb48734.x

[76] Brown, J.H. and West, G.B. (2000) Scaling in Biology. Oxford University Press, Oxford.

[77] West, G.B. and Brown, J.H. (2005) The Origin of Allometric Scaling Laws in Biology from Genomes to Ecosystems: Towards a Quantitative Unifying Theory of Biological Structure and Organization. Journal of Experimental Biology, 208, 1575-1592. https://doi.org/10.1242/jeb.01589

[78] Aon, M.A., Saks, V. and Schlattner, U. (2014) Systems Biology of Metabolic and Signaling Networks: Energy, Mass and Information Transfer. Springer Series in Biophysics No. 16. Springer, Berlin. https://doi.org/10.1007/978-3-642-38505-6

[79] Song, C., Havlin, S. and Makse, H.A. (2005) Self-Similarity of Complex Networks. Letters to Nature, 433, 392-395. https://doi.org/10.1038/nature03248

[80] Frohlich, H. (1983) Coherence in Biology. In: Frohlich, H. and Kremer, F., Eds., Coherent Excitations in Biological Systems, Springer Verlag, Berlin, Heidelberg, 1-5. https://doi.org/10.1007/978-3-642-69186-7_1

[81] Frohlich, H. (1988) Biological Coherence and Response to External Stimuli. Springer Verlag, Berlin, Heidelberg. https://doi.org/10.1007/978-3-642-73309-3

[82] Camazine, S., Deneubourg, J.L., Franks, N.R., et al. (2003) Self-Organization in Biological Systems. Princeton Studies in Complexity. Princeton Univ. Press, Princeton, Oxford.

[83] Szasz, O., Szigeti, Gy.P. and Szasz, A. (2017) On the Self-Similarity in Biological Processes. Open Journal of Biophysics, 7, 183-196.

https://doi.org/10.4236/ojbiphy.2017.74014

[84] Weibull, W. (1951). A Statistical Distribution Function of Wide Applicability. Journal of Applied Mathematics, 18, 293-297.

[85] Lloyd, D., Aon, M.A. and Cortassa, S. (2001) Why Homeodynamics, Not Homeostasis? The Scientific World, 1, 133-145. https://doi.org/10.1100/tsw.2001.20

[86] Wang, H., Wang, Z., Li, X., et al. (2011) A Robust Approach Based on Weibull Distribution for Clustering Gene Expression Data. Algorithms for Molecular Biology, 6, 14. https://doi.org/10.1186/1748-7188-6-14

[87] Hesse, J. and Gross, T. (2014) Self-Organized Criticality as a Fundamental Property of Neural Systems. Frontiers in Systems Neuroscience, 8, 166.

https://doi.org/10.3389/fnsys.2014.00166

[88] West, G.B., Brown, J.H. and Enquist, B.J. (2001) A General Model for Ontogenetic Growth. Nature, 413, 628-631. https://doi.org/10.1038/35098076

[89] Pugno, N.M. (2005) On the Statistical Law of Life. https://arxiv.org/ftp/q-bio/papers/0503/0503011.pdf

[90] Sharkovsky, S. and Grab, E. (2011) Modelling Self-Similar Traffic in Networks. RTU 52nd International Scientific Conference, Riga, 13-15 October 2011.

[91] Avrami, M.A. (1939) Kinetics of Phase Change. I General Theory. The Journal of Chemical Physics, 7, 1103.

[92] Cope, F.W. (1977) Detection of Phase Transitions and Cooperative Interactions by Avrami Analysis of Sigmoid Biological Time Curves for Muscle, Nerve, Growth, Firefly, and Infrared Phosphorescence, of Green Leaves, Melanin and Cytochrome C. Physiological Chemistry and Physics, 9, 443-459.

[93] Cope, F.W. (1980) Avrami Analysis of Electrical Switching in Hydrated Melanin Suggest Dependence on a Phase Transition. Physiological Chemistry and Physics, 
$12,537-538$.

[94] May, K.A. and Solomon, J.A. (2013) Four Theorems on the Psychometric Function. PLOS ONE, 8, e74815. https://doi.org/10.1371/journal.pone.0074815

[95] Szasz, O., Szigeti, G.P. and Szasz, A. (2019) The Intrinsic Self-Time of Biosystems. Open Journal of Biophysics, 9, 131-145.

[96] Andresen, B., Shiner, J.S. and Uehlinger, D.E. (2002) Allometric Scaling and Maximum Efficiency in Physiological Eigen Time. Proceedings of the National Academy of Sciences of the United States of America, 90, 5822-5824. https://doi.org/10.1073/pnas.082633699

[97] Brown, J.H. and West, G.B. (2000) Scaling in Biology. Oxford University Press, Oxford.

[98] Gunther, B. and Morgado, E. (2005) Allometric Scaling of Biological Rhythms in Mammals. Biological Research, 38, 207-212. https://doi.org/10.4067/S0716-97602005000200010

[99] Benzinger, T.H. (1959) On Physical Heat Regulation and the Sense of Temperature in Man. Proceedings of the National Academy of Sciences of the United States of America, 45, 645-659. https://doi.org/10.1073/pnas.45.4.645

[100] Erdmann, B., Lang, J. and Seebass, M. (1998) Optimization of Temperature Distributions for Regional Hyperthermia Based on a Nonlinear Heat Transfer Model. Annals of the New York Academy of Sciences, 858, 36-46.

https://doi.org/10.1111/j.1749-6632.1998.tb10138.x

[101] Tompkins, D.T., Vanderby, R., Klein, S.A., Beckman, W.A., Steeves, R.A., Frey, D.M. and Palival, B.R. (1994) Temperature-Dependent versus Constant-Rate Blood Perfusion Modelling in Ferromagnetic Thermoseed Hyperthermia: Results with a Model of the Human Prostate. International Journal of Hyperthermia, 10, 517-536. https://doi.org/10.3109/02656739409009355

[102] Guy, A.W. and Chou, C.K. (1983) Physical Aspects of Localized Heating by Radio-Waves and Microwaves. In: Storm, K.F., Ed., Hyperthermia in Cancer Therapy, GK Hall Medical Publishers, Boston, 279-304.

[103] Gottstein, U. (1969) Störungen des Hirnkreislaufes und zerebralen Stoffwechsels durch Hypoglykämie. In: Quandt, J., Ed., Die zerebralen Durchblutungsstörungen des Erwachsenenalters, Volk und Gesundheit, Berlin, 857-867.

[104] Hahn, G.M. (1987) Blood-Flow. In: Field, S.B. and Franconi, C., Eds., Physics and Technology of Hyperthermia, NATO ASI Series, Series E: Applied Sciences, Martinus Nijhoff Publishers, Dordrecht, Boston, Lanchester, No. 127, 441-446. https://doi.org/10.1007/978-94-009-3597-6_19

[105] Pence, D.M. and Song, C.W. (1986) Effect of Heat on Blood-Flow. In: Anghileri, L.J. and Robert, J., Eds., Hyperthermia in Cancer Treatment, Vol. II, CRC Press Inc., Boca Raton, 1-17. https://doi.org/10.1201/9780429266546-1

[106] Szasz, A., Szasz, O. and Szasz, N. (2010) Oncothermia-Principles and Practices. Springer Verlag, Dordrecht, Heidelberg. https://doi.org/10.1007/978-90-481-9498-8

[107] Silbernagl, S. and Despopoulos, A. (2015) Color Atlas of Physiology. 7th Edition, Georg Thieme Verlag, Stuttgart/New York. https://doi.org/10.1055/b-005-148942

[108] Wildeboer, R., Southern, P. and Pankhurst, Q.A. (2014) On the Reliable Measurement of Specific Absorption Rates and Intrinsic Loss Parameters in Magnetic Hyperthermia Materials. Journal of Physics D: Applied Physics, 47, Article ID: 495003. https://doi.org/10.1088/0022-3727/47/49/495003

[109] Wust, P. (2005) Thermoregulation in Humans-Experiences from Thermotherapy. 
Conference in Stuttgart, Nov. 21, 2005.

[110] Bassingthwaighte, J.B. (1977) Physiology and Theory of Tracer Washout Techniques for the Estimation of Myocardial Blood Flow: Flow Estimation from Tracer Washout. Progress in Cardiovascular Diseases, 20, 165-189. https://doi.org/10.1016/0033-0620(77)90019-6

[111] Bassingthwaighte, J.B. (1974) Organ Blood Flow, Wash-In, Washout, and Clearance of Nutrients and Metabolites. Mayo Clinic Proceedings, 49, 248-255.

[112] Feldmann, H.J., Molls, M., Hoederath, A., et al. (1992) Blood Flow and Steady State Temperatures in Deep-Seated Tumors and Normal Tissues. International Journal of Radiation Oncology, Biology, Physics, 23, 1003-1008. https://doi.org/10.1016/0360-3016(92)90906-X

[113] Samulski, T.V., Fessenden, P., Valdagni, R., et al. (1987) Correlations of Thermal Washout Rate, Steady State Temperatures, and Tissue Type in Deep Seated Recurrent or Metastatic Tumors. International Journal of Radiation Oncology, Biology, Physics, 13, 907-916. https://doi.org/10.1016/0360-3016(87)90106-4

[114] Mandl, F. (2008) Statistical Physics. 2nd Edition, Manchester Physics, John Wiley \& Sons, Hoboken.

[115] Liu, J. (2000) Temperature Monitoring and Heating Optimization in Cancer Hyperthermia. Progress in Natural Science, 10, 787-793.

[116] Deng, Z.-S. and Liu, J. (2002) Analytical Study on Bioheat Transfer Problems with Spatial or Transient Heating on Skin Surface or inside Biological Bodies. Journal of Biomechanical Engineering, 124, 638-649. https://doi.org/10.1115/1.1516810

[117] Wren, J., Karlsson, M. and Loyd, D. (2001) A Hybrid Equation for Simulation of Perfused Tissue during Thermal Treatment. International Journal of Hypertension, 17, 483-498. https://doi.org/10.1080/02656730110081794

[118] Davalos, R.D., Rubinsky, B. and Mir, L.M. (2003) Theoretical Analysis of the Thermal Effects during in Vivo Tissue Electroporation. Bioelectrochemistry, 61, 99-107. https://doi.org/10.1016/j.bioelechem.2003.07.001

[119] Bagaria, H.G. and Johnson, D.T. (2005) Transient Solution to the Bioheat Equation and Optimization for Magnetic Fluid Hyperthermia Treatment. International Journal of Hyperthermia, 21, 57-75. https://doi.org/10.1080/02656730410001726956

[120] Izquierdo-Kulich, E. and Nieto-Villar, J.M. (2013) Morphogenesis and Complexity of the Tumor Patterns. In: Rubio, R.G., Ryazantsev, Y.S., Starov, V.M., Huang, G.-X., Chetverikov, A.P., Arena, P., Nepomnyashchy, A.A., Ferrus, A. and Morozov, E.G., Eds., Without Bounds. A Scientific Canvas of Nonlinearity and Complex Dynamics. Understanding Complex Systems, Springer-Verlag Berlin Heidelberg, 657-691. https://doi.org/10.1007/978-3-642-34070-3_48

[121] Davies, P.C.W., Demetrius, L. and Tuszynski, J.A. (2011) Cancer as a Dynamical Phase Transition. Theoretical Biology and Medical Modelling, 8, 30. https://doi.org/10.1186/1742-4682-8-30

[122] Bru, A., Albertos, S., Subiza, J.L., García-Asenjo, J.L. and Bru, I. (2003) The Universal Dynamics of Tumor Growth. Biophysical Journal, 85, 2948-2961. https://doi.org/10.1016/S0006-3495(03)74715-8

[123] Guiot, C., Degiorgis, P.G., Delsanto, P.P., Gabriele, P. and Deisboeck, T.S. (2003) Does Tumor Growth Follow a "Universal Law"? Journal of Theoretical Biology, 225, 147-151. https://doi.org/10.1016/S0022-5193(03)00221-2

[124] Wissler, E.H. (1998) Pennes' 1948 Paper Revisited. Journal of Applied Physiology, 85, 35-41. https://doi.org/10.1152/jappl.1998.85.1.35 
[125] Nelson, D.A. (1998) Invited Editorial on "Pennes' 1948 Paper Revisited". Journal of Applied Physiology, 85, 2-3. https://doi.org/10.1152/jappl.1998.85.1.2

[126] Charny, C.K., Weinbaum, S. and Levin, R.L. (1990) An Evaluation of the Weinbaum-Jiji Equation for Normal and Hyperthermic Conditions. Journal of Biomechanical Engineering, 112, 80-87. https://doi.org/10.1115/1.2891130

[127] Najarian, S. and Pashaee, A. (2001) Inprovement of the Pennes Equation in the Analysis of Heat Transfer Phenomenon in Blood Perfused Tissues. Biomedical Sciences Instrumentation, 37, 185-190.

[128] Szasz, A. and Vincze, Gy. (2006) Dose Concept of Oncological Hyperthermia: Heat-Equation Considering the Cell Destruction. Journal of Cancer Research and Therapeutics, 2, 171-181. https://doi.org/10.4103/0973-1482.29827

[129] Szasz, A. and Vincze, Gy. (2007) Hyperthermia, a Modality in the Wings. Journal of Cancer Research and Therapeutics, 3, 56-66.

https://doi.org/10.4103/0973-1482.31976

[130] Kim, J.-K., Prasad, B. and Kim, S. (2017) Temperature Mapping and Thermal Dose Calculation in Combined Radiation Therapy and $13.56 \mathrm{MHz}$ Radiofrequency Hyperthermia for Tumor Treatment. Proceedings SPIE 10047, Optical Methods for Tumor Treatment and Detection: Mechanisms and Techniques in Photodynamic Therapy XXVI, Vol. 10047, Article ID: 1004718. https://doi.org/10.1117/12.2253163 http://spie.org/Publications/Proceedings/Paper/10.1117/12.2253163?origin_id=x431 $\underline{8}$

[131] Boldrini, J.L., Viana, M.P., dos Reis, S.F., et al. (2018) A Mathematical Model for Thermoregulation in Endotherms Including Heat Transport by Blood Flow and Thermal Feedback Control Mechanisms: Changes in Coat, Metabolic Rate, Blood Fluxes, Ventilation and Sweating Rates. Letters in Biomathematics, 5, 129-173. https://doi.org/10.1080/23737867.2018.1497458

[132] Vincze, Gy., Szigeti, Gy.P. and Szasz, O. (2016) Non-Newtonian Analysis of Blood Flow. Journal of Advances in Physics, 11, 3470-3481. https://doi.org/10.24297/jap.v11i5.6834

[133] Vincze, Gy., Szigeti, Gy.P. and Szasz, O. (2016) Negative Impedance Interval of Blood Flow in Capillary Bed. Journal of Advances in Physics, 11, 3482-3487. https://doi.org/10.24297/jap.v11i5.365

[134] Szasz, O., Vincze, Gy., Szigeti, Gy.P., et al. (2018) An Allometric Approach of Tumor-Angiogenesis. Medical Hypotheses, 116, 74-78. https://doi.org/10.1016/j.mehy.2018.03.015

[135] Szasz, O., Szigeti, Gy.P. and Szasz, A. (2016) Connections between the Specific Absorption Rate and the Local Temperature. Open Journal of Biophysics, 6, 53-74. https://doi.org/10.4236/ojbiphy.2016.63007

[136] Rao, N.N. (1994) Elements of Engineering Electromagnetics. Prentice Hall International, London.

[137] Jackson, J.D. (1999) Classical Electrodynamics. John Wiley \& Sons Inc., New York.

[138] Polk, C. and Postow, E. (1996) Handbook of Biological Effects of Electromagnetic Fields. CRC Press, New York, London, Tokyo, 15.

[139] Dissado, L.A. (1990) A Fractal Interpretation of the Dielectric Response of Animal Tissues. Physics in Medicine and Biology, 35, 1487-1503. https://doi.org/10.1088/0031-9155/35/11/005

[140] Goldberger, A.L., Amaral, L.A., Hausdorff, J.M., et al. (2002) Fractal Dynamics in Physiology: Alterations with Disease and Aging. PNAS Colloquium, 99, 2466-2472. 
https://doi.org/10.1073/pnas.012579499

[141] Szendro, P., Vincze, G. and Szasz, A. (2001) Pink Noise Behaviour of the Bio-Systems. European Biophysics Journal, 30, 227-231.

https://doi.org/10.1007/s002490100143

[142] Szendro, P., Vincze, G. and Szasz, A. (2001) Bio-Response on White-Noise Excitation. Electromagnetic Biology and Medicine, 20, 215-229. https://doi.org/10.1081/JBC-100104145

[143] Bak, P., Tang, C. and Wieserfeld, K. (1988) Self-Organized Criticality. Physical Review A, 38, 364-373. https://doi.org/10.1103/PhysRevA.38.364

[144] Jones, E., Dewhirst, M. and Vujaskovic, Z. (2003) Hyperthermia Improves the Complete Response Rate for Superficial Tumours Treated with Radiation: Results of a Prospective Randomized Trial Testing the Thermal Dose Parameter CEM $43^{\circ} \mathrm{T} 90$. International Journal of Radiation Oncology, Biology, Physics, 57, S253-S254. https://doi.org/10.1016/S0360-3016(03)01088-5

[145] Vernon, C.C., Hand, J.W., Field, S.B., Machin, D., Whaley, J.B., van der Zee, J., van Putten, W.L.J., van Rhoon, G.C., van Dijk, J.D.P., Gonzalez Gonzalez, D., Liu, F.-F., Goodman, P. and Sherar, M. (1996) Radiotherapy with or without Hyperthermia in the Treatment of Superficial Localized Breast Cancer: Results from Five Randomized Controlled Trials. International Journal of Radiation Oncology, Biology, Physics, 35, 731-744. https://doi.org/10.1016/0360-3016(96)00154-X

[146] Sherar, M., Liu, F.-F., Pintilie, M., et al. (1997) Relationship between Thermal Dose and Outcome in Thermoradiotherapy Treatments for Superficial Recurrences of Breast Cancer: Data from a Phase III Trial. International Journal of Radiation Oncology, Biology, Physics, 39, 371-380.

https://doi.org/10.1016/S0360-3016(97)00333-7

[147] Mitsumori, M., Zeng, Z.F., Oliynychenko, P., et al. (2007) Regional Hyperthermia Combined with Radiotherapy for Locally Advanced Non-Small Cell Lung Cancers. International Journal of Clinical Oncology, 12, 192-198. https://doi.org/10.1007/s10147-006-0647-5

[148] Shinn, K.S., Choi, I.B., Kay, C.S., et al. (1996) Thermoradiotherapy in the Treatment of Locally Advanced Nonsmall Cell Lung Cancer. Journal of the Korean Society for Therapeutic Radiology and Oncology, 14, 115-122.

https://doi.org/10.1016/0169-5002(96)85955-1

[149] Vasanthan, A., Mitsumori, M., Park, J.H., et al. (2005) Regional Hyperthermia Combined with Radiotherapy for Uterine Cervical Cancers: A Multi-Institutional Prospective Randomized Trial of the International Atomic Energy Agency. International Journal of Radiation Oncology, Biology, Physics, 61, 145-153.

https://doi.org/10.1016/j.ijrobp.2004.04.057

[150] Zolciak-Siwinska, A., Piotrkowicz, N., Jonska-Gmyrek, J., et al. (2013) HDR Brachytherapy Combined with Interstitial Hyperthermia in Locally Advanced Cervical Cancer Patients Initially Treated with Concomitant Radiochemotherapy-A Phase III Study. Radiotherapy and Oncology, 109, 194-199.

https://doi.org/10.1016/j.radonc.2013.04.011

[151] Jones, E.L., Oleson, J.R., Prosnitz, L.R., et al. (2005) Randomized Trial of Hyperthermia and Radiation for Superficial Tumors. Journal of Clinical Oncology, 23, 3079-3085. https://doi.org/10.1200/JCO.2005.05.520

[152] Vaupel, P.W. and Kelleher, D.K. (1996) Metabolic Status and Reaction to Heat of Normal and Tumour Tissue. In: Seegenschmiedt, M.H., Fessenden, P. and Vernon, C.C., Eds., Thermo-Radiotherapy and Thermo-Chemotherapy. Biology, Physiology 
and Physics, Vol. 1, Springer Verlag, Berlin Heidelberg, 157-176.

https://doi.org/10.1007/978-3-642-57858-8_8

[153] Oehr, P., Biersack, H.J. and Coleman, R.E. (2004) PET and PET-CT in Oncology. Springer Verlag, Berlin-Heidelberg. https://doi.org/10.1007/978-3-642-18803-9

[154] Foster, K.R. and Schepps, J.L. (1981) Dielectric Properties of Tumor and Normal Tissues at Radio through Microwave Frequencies. Journal of Microwave Power, 16, 107-119. https://doi.org/10.1080/16070658.1981.11689230

[155] Seersa, I., Beravs, K., Dodd, N.J.F., et al. (1997) Electric Current Imaging of Mice Tumors. MRM, 37, 404-409. https://doi.org/10.1002/mrm.1910370318

[156] Landini, G. and Rippin, J.W. (1993) Fractal Dimensions of the Epithelial-Connective Tissue Interfaces in Premalignant and Malignant Epithelial Lesions of the Floor of the Mouth. Analytical and Quantitative Cytology and Histology, 15, 144-149.

[157] Wong, S.H.M, Fang, C.M., Chuah, L.-H., et al. (2018) E-Cadherin: Its Dysregulation in Carcinogenesis and Clinical Implications. Critical Reviews in Oncology/Hematology, 121, 11-22. https://doi.org/10.1016/j.critrevonc.2017.11.010

[158] Knights, A.J., Funnel, A.P., Crossley, M. and Pearson, R.C.M. (2012) Holding Tight: Cell Junctions and Cancer Spread. Trends in Cancer Research, 8, 61-69.

[159] Damadian, R. (1971) Tumor Detection by Nuclear Magnetic Resonance. Science, 171, 1151-1153. https://doi.org/10.1126/science.171.3976.1151

[160] Szentgyorgyi, A. (1968) Bioelectronics. A Study on Cellular Regulations, Defense and Cancer. Academy Press, New York, London.

[161] Szasz, A., Vincze, Gy., Szasz, O. and Szasz, N. (2003) An Energy Analysis of Extracellular Hyperthermia. Magneto- and Electro-Biology, 22, 103-115.

https://doi.org/10.1081/JBC-120024620

[162] Blad, B. and Baldetorp, B. (1996) Impedance Spectra of Tumour Tissue in Comparison with Normal Tissue; a Possible Clinical Application for Electric Impedance Tomography. Physiological Measurement, 17, A105-A115. https://doi.org/10.1088/0967-3334/17/4A/015

[163] Vincze, Gy., Szigeti, Gy., Andocs, G. and Szasz, A. (2015) Nanoheating without Artificial Nanoparticles. Biology and Medicine, 7, 249.

[164] Thomas, S., Preda-Pais, A., Casares, S. and Brumeanu, T.D. (2004) Analysis of Lipid Rafts in T Cells. Molecular Immunology, 41, 399-409.

https://doi.org/10.1016/j.molimm.2004.03.022

[165] Nicolau, D.V., Burrage, K., Parton, R.G. and Hancock, J.F. (2006) Identifying Optimal Lipid Raft Characteristics Required to Promote Nanoscale Protein-Protein Interactions on the Plasma Membrane. Journal of Molecular Cell Biology, 26, 313-323. https://doi.org/10.1128/MCB.26.1.313-323.2006

[166] Nicolson, G.L. (2014) The Fluid-Mosaic Model of Membrane Structure: Still Relevant to Understanding the Structure, Function and Dynamics of Biological Membranes after More than 40 Years. Biochimica et Biophysica Acta, 1838, 1451-1466. https://doi.org/10.1016/j.bbamem.2013.10.019

[167] Gramse, G., Dols-Perez, A., Edwards, M.A., Fumagalli, L. and Gomila, G. (2013) Nanoscale Measurement of the Dielectric Constant of Supported Lipid Bilayers in Aqueous Solutions with Electrostatic Force Microscopy. Journal of Biophysics, 104, 1257-1262. https://doi.org/10.1016/j.bpj.2013.02.011

[168] Dharia, S. (2011) Spatially and Temporally Resolving Radio-Frequency Changes in Effective Cell Membrane Capacitance. PhD Theses, University of Utah, Salt Lake City. 
[169] Pike, L.J. (2003) Lipid Rafts: Bringing Order to Chaos. The Journal of Lipid Research, 44, 655-667. https://doi.org/10.1194/jlr.R200021-JLR200

[170] Andersen, O.S., Koeppe, I.I. and Roger, E. (2007) Bilayer Thickness and Membrane Protein Function: An Energetic Perspective. Annual Review of Biophysics and Biomolecular Structure, 36, 107-130. https://doi.org/10.1146/annurev.biophys.36.040306.132643

[171] Nicolau Dan, V., Burrage, K, Parton, R.G. and Hancock, J.F. (2006) Identifying Optimal Lipid Raft Characteristics Required to Promote Nanoscale Protein-Protein Interactions in the Plasma Membrane. Molecular and Cellular Biology, 26, 313-323

[172] Staunton, J.R., Wirtz, D., Tlsty, T.D., et al. (2013) A Physical Sciences Network Characterization of Non-Tumorigenic and Metastatic Cells. Scientific Reports, 3, Article No. 1449. https://doi.org/10.1038/srep01449

[173] Kotnik, T. and Miklavcic, D. (2000) Theoretical Evaluation of the Distributed Power Dissipation in Biological Cells Exposed to Electric Fields. Bioelectromagnetics, 21, 385-394. https://doi.org/10.1002/1521-186X(200007)21:5<385::AID-BEM7>3.0.CO;2-F

[174] Pething, R. (1979) Dielectric and Electronic Properties of Biological Materials. John Wiley and Sons, New York.

[175] Volkov, V.V., Palmer, D.J. and Righini, R. (2007) Distinct Water Species Confined at the Interface of a Phospholipid Membrane. Physical Review Letters, 99, Article ID: 078302. https://doi.org/10.1103/PhysRevLett.99.078302

[176] Liu, L.M. and Cleary, S.F. (1995) Absorbed Energy Distribution from Radiofrequency Electromagnetic Radiation in a Mammalian Cell Model: Effect of Membrane-Bound Water. Bioelectromagnetics, 16, 160-171. https://doi.org/10.1002/bem.2250160304

[177] Hendry, B. (1981) Membrane Physiology and Membrane Excitation. Croom Helm, London. https://doi.org/10.1007/978-1-4615-9766-7

[178] Ma, Y., Poole, K., Goyette, J., et al. (2017) Introducing Membrane Charge and Membrane Potential to T Cell Signaling. Frontiers in Immunology, 8, 1513. https://doi.org/10.3389/fimmu.2017.01513

[179] Martinsen, O.G., Grimnes, S. and Schwan, H.P. (2002) Interface Phenomena and Dielectric Properties of Biological Tissue. Corpus ID: 41679856. https://www.semanticscholar.org/paper/INTERFACE-PHENOMENA-AND-DIELE CTRIC-PROPERTIES-OF-Martinsen-Grimnes/96e2f6c14dbba2ae5537a8a637b52d4 $\underline{\text { 86b3925ef }}$

[180] Banerjee, S., Vandenbranden, M. and Ruysschaert, J. (1981) Interaction of Tobacco Mosaic Virus Protein with Lipid Membrane Systems. FEBS Letters, 133, 221-224. https://doi.org/10.1016/0014-5793(81)80510-8

[181] Schubert, D., Bleuel, H., Domninc, B. and Wiedner, G. (1977) Protein-Induced Conductivity Changes in Black Lipid Membranes and Protein Aggregation. FEBS Letters, 74, 47-49. https://doi.org/10.1016/0014-5793(77)80749-7

[182] Papp, E., Vancsik, T., Kiss, E. and Szasz, O. (2017) Energy Absorption by the Membrane Rafts in the Modulated Electro-Hyperthermia (mEHT). Open Journal of Biophysics, 7, 216-229. https://doi.org/10.4236/ojbiphy.2017.74016

[183] Szasz, A., Szasz, O. and Szasz, N. (2001) Electro-Hyperthermia: A New Paradigm in Cancer Therapy. Deutsche Zeitschrift fur Onkologie, 33, 91-99. https://doi.org/10.1055/s-2001-19447

[184] Szasz, O. and Szasz, A. (2013) Burden of Oncothermia: Why Is It Special? Confe- 
rence Papers in Medicine, 2013, Article ID: 938689.

https://doi.org/10.1155/2013/938689

[185] Szasz, A. (2015) Bioelectromagnetic Paradigm of Cancer Treatment Oncothermia. In: Rosch, P.J., Ed., Bioelectromagnetic and Subtle Energy Medicine, CRC Press, Taylor \& Francis Group, London, 323-336.

[186] Szasz, A. (2014) Oncothermia: Complex Therapy by EM and Fractal Physiology. IEEE General Assembly and Scientific Symposium (URSI GASS), 201421 th URSI, Beijing, 16-23 August 2014, 1-4. https://doi.org/10.1109/URSIGASS.2014.6930100

[187] Sowers, A.E. (1984) Characterisation of Electric Field-Induced Fusion in Erythrocyte Ghost Membranes. The Journal of Cell Biology, 99, 1989-1996.

https://doi.org/10.1083/jcb.99.6.1989

[188] Marszalek, P. and Tsong, T.Y. (1995) Cell Fission and Formation of Mini Cell Bodies by High Frequency Alternating Electric Field. Biophysical Journal, 68, 1218-1221. https://doi.org/10.1016/S0006-3495(95)80338-3

[189] Cleary, S.F., Liu, L.-M. and Garber, F. (1985) Erythrocyte Haemolysis by Radiofrequency Fields. Bioelectromagnetics, 6, 313-322.

https://doi.org/10.1002/bem.2250060311

[190] Liu, D.-S., Astumian, R.D. and Tsong, T.Y. (1990) Activation of Na+ and K+ Pumping Modes of $(\mathrm{Na}, \mathrm{K})$-ATPase by an Oscillating Electric Field. The Journal of Biological Chemistry, 265, 7260-7267. https://doi.org/10.1016/S0021-9258(19)39108-2

[191] Walleczek, J. (1992) Electromagnetic Field Effects on Cells of the Immune System: The Role of Calcium Signalling. FASEB Journal, 6, 3177-3185.

https://doi.org/10.1096/fasebj.6.13.1397839

[192] Cho, M.R., Thatte, H.S., Silvia, M.T., et al. (1999) Transmembrane Calcium Influx Induced by AC Electric Fields. FASEB Journal, 13, 677-683.

https://doi.org/10.1096/fasebj.13.6.677

[193] Ho, M.-W., Popp, F.-A. and Warnke, U. (1994) Bioelectrodynamics and Biocommunication. World Scientific, Singapore, London. https://doi.org/10.1142/2267

[194] Bernardi, P. and D’Inzeo, G. (1989) Physical Mechanisms for Electromagnetic Interaction with Biological Systems. In: Lin, J.C., Ed., Electromagnetic Interaction with Biological Systems, Plenum Press, New York, London, 179-214.

https://doi.org/10.1007/978-1-4684-8059-7_9

[195] Markov, M.S. (1994) Biological Effects of Extremely Low Frequency Magnetic Fields. In: Ueno, S., Ed., Biomagnetic Stimulation, Plenum Press, New York, London, 91-104. https://doi.org/10.1007/978-1-4757-9507-3_7

[196] Bauerus, K.C.L., Sommarin, M., Persson, B.R., et al. (2003) Interaction between Weak Low Frequency Magnetic Fields and Cell Membranes. Bioelectromagnetics, 24, 395-402. https://doi.org/10.1002/bem.10136

[197] Benett, W.R. (1994) Cancer and Power Lines. Physics Today, 23-29. https://doi.org/10.1063/1.881417

[198] Portier, C.J. and Wolfe, M.S. (1998) Assessment of Health Effects from Exposure to Power-Line Frequency Electric and Magnetic Fields. National Institute of Environmental Health Sciences, Research Triangle Park, NIH Publication No. 98-3981.

[199] Harland, J.D. and Liburdy, R.P. (1997) Environmental Magnetic Fields Inhibit the Anti-Proliferation Action of Tamoxifen and Melatonin in a Human Breast Cancer Cell Line. Bioelectromagnetics, 18, 555-562. https://doi.org/10.1002/(SICI)1521-186X(1997)18:8<555::AID-BEM4>3.0.CO;2-1

[200] Ahlbom, A., Day, N., Feychting, M., et al. (2000) A Pooled Analysis of Magnetic 
Fields and Childhood Leukaemia. British Journal of Cancer, 83, 692-698. https://doi.org/10.1054/bjoc.2000.1376

[201] Greenland, S., Sheppard, A.R., Kaune, W.T., et al. (2000) A Pooled Analysis of Magnetic Fields, Wire Codes, and Childhood Leukaemia. Epidemiology, 11, 624-634. https://doi.org/10.1097/00001648-200011000-00003

[202] Blackman, C.F., Benane, S.G. and House, D.E. (2001) The Influence of $1.2 \mu \mathrm{T}, 60 \mathrm{~Hz}$ Magnetic Fields on Melatonin- and Tamoxifen-Induced Inhibition of MCF-7 Cell Growth. Bioelectromagnetics, 22, 122-128. https://doi.org/10.1002/1521-186X(200102)22:2<122::AID-BEM1015>3.0.CO;2-V

[203] Glaser, R. (2005) Are Thermoreceptors Responsible for "Non-Thermal” Effects of RF Fields? Edition Wissenschaft Forschungsgemeinschaft Funk e. V. G 14515. Issue No. 21. December 2005.

[204] Zotin, A.A. and Zotin, A.I. (1996) Thermodynamic Bases of Developmental Processes. Journal of Non-Equilibrium Thermodynamics, 21, 307-320. https://doi.org/10.1515/jnet.1996.21.4.307

[205] Lakhssassi, A., Kengne, E. and Semmaoui, H. (2010) Investigation of Nonlinear Temperature Distribution in Biological Tissues by Using Bioheat Transfer Equation of Pennes' Type. Natural Science, 2, 131-138. https://doi.org/10.4236/ns.2010.23022

[206] Chang, I. (2003) Finite Element Analysis of Hepatic Radiofrequency Ablation Probes Using Temperature-Dependent Electrical Conductivity. BioMedical Engineering OnLine, 2, Article No. 12. https://doi.org/10.1186/1475-925X-2-12

[207] Kok, H.P., Navarro, F., Strigari, L., et al. (2018) Locoregional Hyperthermia of Deep-Seated Tumours Applied with Capacitive and Radiative Systems: A Simulation Study. International Journal of Hypertension, 34, 714-730. https://doi.org/10.1080/02656736.2018.1448119

[208] Canters, R.A.M., Franckena, M., van der Zee, J. and van Rhoon, G.C. (2011) Optimizing Deep Hyperthermia Treatments: Are Locations of Patient Pain Complaints Correlated with Modelled SAR Peak Locations? Physics in Medicine and Biology, 56, 439-451. https://doi.org/10.1088/0031-9155/56/2/010

[209] Dutz, S. and Hergt, R. (2013) Magnetic Nanoparticle Heating and Heat Transfer on a Microscale: Basic Principles, Realities and Physical Limitations of Hyperthermia for Tumour Therapy. International Journal of Hypertension, 29, 790-800. https://doi.org/10.3109/02656736.2013.822993

[210] Chen, C.-C., Chen, C.-L., Li, J.-J., et al. (2019) The Presence of Gold Nanoparticles in Cells Associated with the Cell-Killing Effect of Modulated Electro-Hyperthermia. ACS Applied Bio Materials, 2, 3573-3581. https://doi.org/10.1021/acsabm.9b00453

[211] Szasz, A. (2007) Hyperthermia, a Modality in the Wings. Journal of Cancer Research and Therapeutics, 3, 56-66. https://doi.org/10.4103/0973-1482.31976

[212] Guest, W.C., Cashman, N.R. and Plotkin, S.S. (2011) A Theory for the Anisotropic and Inhomogeneous Dielectric Properties of Proteins. Physical Chemistry Chemical Physics, 13, 6286-6295. https://doi.org/10.1039/c0cp02061c

[213] Yang, M. and Brackenbury, W.J. (2013) Membrane Potential and Cancer Progression. Frontiers in Physiology, 4, 185. https://doi.org/10.3389/fphys.2013.00185

[214] Govorov, A.O. and Richardson, H.H. (2007) Generating Heat with Metal Nanoparticles. Nanotoday, 2, 30-39. https://doi.org/10.1016/S1748-0132(07)70017-8

[215] Johnson, S.A., Stinson, B.M., Go, M.S., et al. (2010) Temperature-Dependent Phase Behavior and Protein Partitioning in Giant Plasma Vehicles. Biochimica et Biophysica Acta, 1798, 1427-1435. https://doi.org/10.1016/j.bbamem.2010.03.009 
[216] Veatch, S.L., Cicuta, P., Sengupta, P., Honerkamp-Smith, A., Holowka, D. and Baird, B. (2008) Critical Fluctuations in Plasma Membrane Vesicles. ACS Chemical Biology, 3, 287-295. https://doi.org/10.1021/cb800012x

[217] Langner, M., Komorowska, M., Koter, M. and Gomulkiewicz, J. (1984) Phase Transitions in Spherical Bilayer Membranes Prepared of Bulk Erythrocyte Membrane Lipids. General Physiology and Biophysics, 3, 521-526.

[218] Hossain, M.T., Prasad, B., Park, K.S., et al. (2016) Simulation and Experimental Evaluation of Selective Heating Characteristics of $13,56 \mathrm{MHz}$ Radiofrequency Hyperthermia in Phantom Models. International Journal of Precision Engineering and Manufacturing, 17, 253-256. https://doi.org/10.1007/s12541-016-0033-9

[219] Andocs, G., Rehman, M.U., Zhao, Q.L., Papp, E., Kondo, T. and Szasz, A. (2015) Nanoheating without Artificial Nanoparticles Part II. Experimental Support of the Nanoheating Concept of the Modulated Electro-Hyperthermia Method, Using U937 Cell Suspension Model. Biology and Medicine, 7, 1-9. https://doi.org/10.4172/0974-8369.1000247

[220] Andocs, G., Rehman, M.U., Zhao, Q.-L., Tabuchi, Y., Kanamori, M. and Kondo, T. (2016) Comparison of Biological Effects of Modulated Electro-Hyperthermia and Conventional Heat Treatment in Human Lymphoma U937 Cell. Cell Death Discovery, 2, Article No. 16039. https://doi.org/10.1038/cddiscovery.2016.39

[221] Prasad, B., Kim, S., Cho, W., et al. (2018) Effect of Tumor Properties on Energy Absorption, Temperature Mapping, and Thermal Dose in 13,56-MHz Radiofrequency Hyperthermia. Journal of Thermal Biology, 74, 281-289. https://doi.org/10.1016/j.jtherbio.2018.04.007

[222] Portoro, I., Danics, L. and Veres, D. (2018) Increased Efficacy in Treatment of Glioma by a New Modulated Electro-Hyperthermia (mEHT) Protocol. Oncothermia Journal, 24, 344-356.

[223] Kao, P.H.-J., Chen, C.-H., Chang, Y.-W., et al. (2020) Relationship between Energy Dosage and Apoptotic Cell Death by Modulated Electro-Hyperthermia. Scientific Reports, 10, Article No. 8936. https://doi.org/10.1038/s41598-020-65823-2

[224] Fiorentini, G., Sarti, D. and Casadei, V. (2019) Modulated Electro-Hyperthermia (mEHT) [oncothermia ${ }^{\circledR}$. Protocols as Complementary Treatment. Oncothermia Journal, 25, 85-115.

[225] Szasz, A.M., Arkosy, P., Arrojo, E.E., et al. (2020) Guidelines for Local Hyperthermia Treatment in Oncology. In: Szasz, A., Ed., Challenges and Solutions of Oncological Hyperthermia, Ch. 2, Cambridge Scholars, Cambridge, 32-71.

[226] Szasz, A.M., Minnaar, C.A., Szentmartoni, Gy., et al. (2019) Review of the Clinical Evidences of Modulated Electro-Hyperthermia (mEHT) Method: An Update for the Practicing Oncologist. Frontiers in Oncology, 9, Article No. 1012.

https://doi.org/10.3389/fonc.2019.01012 